TECENVES

NOV $0 \& 2000$

OS $\mathrm{r}$

\title{
Summary and Evaluation of NRC-Sponsored Stellite 6 Aging and Friction Tests
}

\author{
J. C. Watkins \\ K. G. DeWall \\ D. Bramwell
}

Published April 1999

Idaho National Engineering and Environmental Laboratory

Nuclear Engineering Technologies Department

Lockheed Martin Idaho Technologies Company Idaho Falls, Idaho 83415

\author{
Prepared for the \\ Division of Engineering Technology \\ Office of Nuclear Regulatory Research \\ U.S. Nuclear Regulatory Commission \\ Washington, D. C. 20555 \\ Under DOE Idaho Operations Office \\ Contract DE-AC07-94ID13223 \\ NRC Job Code W6593
}


(.

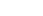




\section{DISCLAIMER}

This report was prepared as an account of work sponsored by an agency of the United States Government. Neither the United States Government nor any agency thereof, nor any of their employees, make any warranty, express or implied, or assumes any legal liability or responsibility for the accuracy, completeness, or usefulness of any information, apparatus, product, or process disclosed, or represents that its use would not infringe privately owned rights. Reference herein to any specific commercial product, process, or service by trade name, trademark, manufacturer, or otherwise does not necessarily constitute or imply its endorsement, recommendation, or favoring by the United States Government or any agency thereof. The views and opinions of authors expressed herein do not necessarily state or reflect those of the United States Government or any agency thereof. 


\section{DISCLAIMER}

\section{Portions of this document may be illegible in electronic image products. Images are produced from the best available original document.}




\begin{abstract}
This report describes four sets of tests sponsored by the U.S. Nuclear Regulatory Commission and conducted by the Idaho National Engineering and Environmental Laboratory. The tests support research addressing the need to provide assurance that motor-operated valves are able to perform their intended safety function, usually to open or close against specified (design basis) flow and pressure loads. One of the parameters that affects a gate valve's operability is the friction between the disc seats and the valve body seats. In most gate valves, these surfaces are hardfaced with Stellite 6, a cobalt-based alloy.
\end{abstract}

The tests described in this report investigate the changes that occur in the friction as the Stellite 6 surfaces develop an oxide film as they age. Stellite 6 specimens were aged in a corrosion autoclave, the oxide films were examined and characterized, and the specimens were subjected to friction testing in a friction autoclave. A very thin oxide film formed after only a few days of natural aging. Even a very thin oxide film caused an increase in friction. The surface structure of the oxide film was dominated by a hard crystalline structure, such that the friction response was analogous to rubbing two pieces of sandpaper together. In the limited data provided by naturally aged specimens ( 78 days maximum exposure, very thin oxide films), the friction increased with greater aging time, approaching an as-yet-undetermined plateau. Although the thickness of the oxide film increased with greater aging time, the mechanical properties of the oxide film (larger granules with greater aging time) appeared to play a greater role in the friction response.

Friction testing of specimens subjected to simulated in-service testing strokes at intervals during the aging process showed only a slight decrease in friction, compared to other specimens. Results from specimens subjected to accelerated aging were inconclusive, because of differences in the structure and composition of the oxide films, compared to naturally aged specimens.

For the naturally aged specimens, the highest friction occurred on the first stroke. The first stroke smeared the oxide film and dislodged some of the granules, so that subsequent strokes saw lower friction values and less variation in the friction. This result underscores the importance of planning in-plant tests so that data are collected from the first stroke following a period of inactivity.

Job Code W6593 - Effects of Aging and Emerging Issues on MOV Performance 


\section{ACKNOWLEDGMENTS}

Dr. Steve Shaffer and Dr. Jeff Colwell of Battelle National Laboratories at Columbus, Ohio performed the aging and friction tests at Batelle's laboratory as part of a contractual arrangement with the Idaho National Engineering and Environmental Laboratory. Their contribution to the research and to the content of this report is significant. Dr. Susan Smialowska of the Fontana Corrosion Center at Columbus, Ohio served as a consultant on issues related to the natural and accelerated aging methods. Dr. Steven Hsu of the National Institute of Standards and Technology reviewed the research and conducted parametric friction tests on a few specimens, as part of an inter-agency agreement with the U.S. Nuclear Regulatory Commission. Christine White, graphic artist at the INEEL, helped prepare the figures and illustrations. Linda Theisen, publications specialist at INEEL, prepared the format of the report for publication. 


\section{CONTENTS}

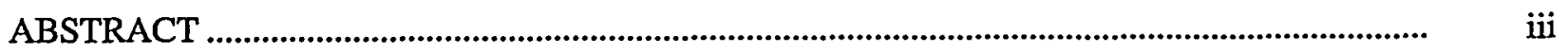

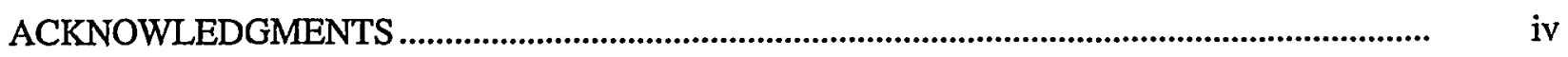

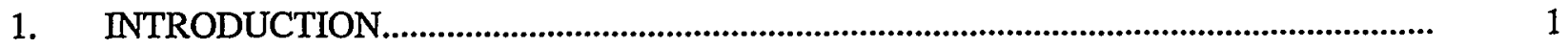

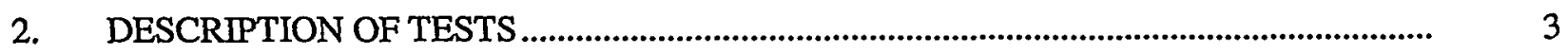

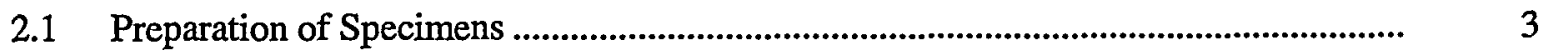

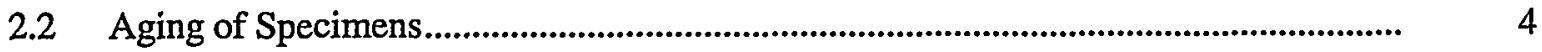

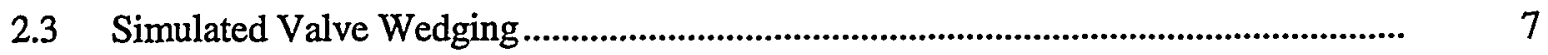

2.4 Friction Testing of Specimens at Battelle Columbus .............................................. 10

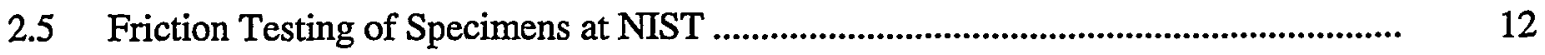

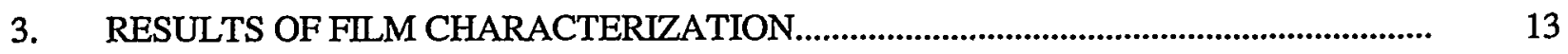

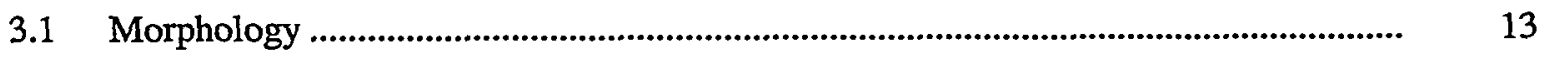

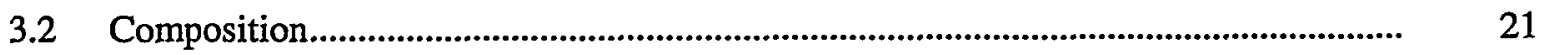

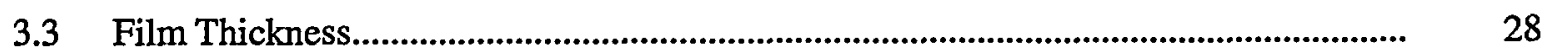

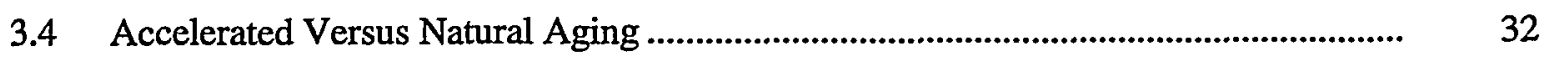

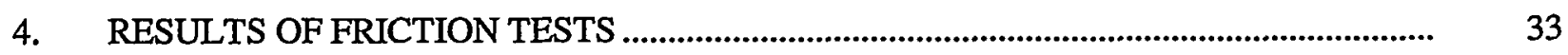

4.1 Differences Due to Aging of the Surface............................................................. 35

4.2 Differences Due to Chemical Composition and Surface Structure............................... 40

4.3 Effect of Friction Testing Versus Valve Operation ...................................................

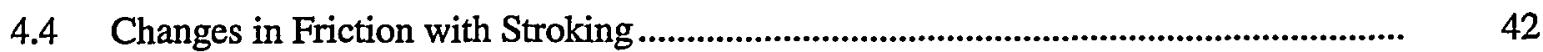

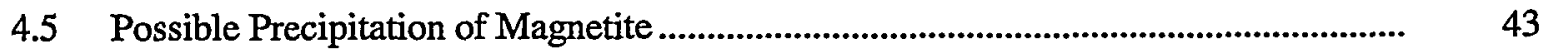

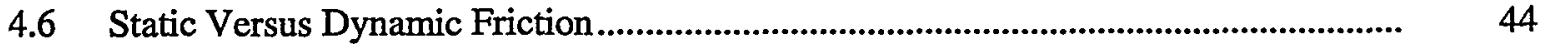

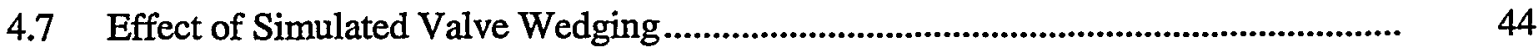

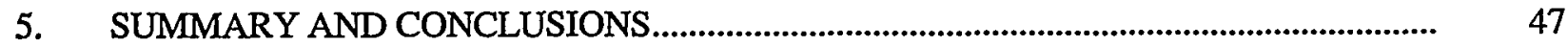

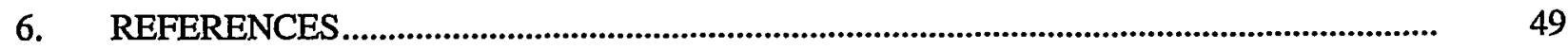




\section{FIGURES}

1. Diagram of a typical motor-operated gate valve, showing the main components

2. Photograph of Stellite 6 specimens before aging (top to bottom: inner, outer, and dummy specimens); the sketch at the top shows dimensions

3. Diagram of the first corrosion autoclave

4. Diagram of the in-service testing simulation rig

5. Details of the simulated valve wedging fixture and loading configuration (top), and a photo of the test fixture with dummy large specimens shown with stripes (bottom).

6. Diagram of the friction autoclave

7. Electron micrographs of the surface of an as-ground Stellite 6 specimen, before exposure to aging; magnification at $\mathrm{X} 300$ and $\mathrm{X} 2,000$.

8. Electron micrographs of the surface of a Stellite 6 specimen after 78 days exposure to natural aging conditions.

9. Electron micrographs of the surface of a Stellite 6 specimen after 78 days exposure to natural aging conditions, with simulated in-service testing at 25 days and again at 50 days

10. Electron micrographs of the surface of a Stellite 6 specimen after 11 days exposure to an anodic current density of $0.15 \mathrm{~mA} / \mathrm{cm}^{2}$

11. Electron micrographs of the surface and cross section of a Stellite 6 specimen after 14 days exposure to an anodic current density of $0.35 \mathrm{~mA} / \mathrm{cm}^{2}$

12. Electron micrograph of the surface of a Stellite 6 specimen after 19 days exposure to high-pH conditions; the large, zirconium-rich crystals are conspicuous

13. Electron micrographs of the surface of a Stellite 6 specimen after 19 days exposure to high-pH conditions; the zirconium-rich crystals have been removed, but iron-rich crystals remain

14. AES depth profile for Stellite 6 after 20 days exposure to natural aging conditions

15. XPS depth profile for Stellite 6 after 10 days exposure to natural aging conditions

16. XPS depth profile for Stellite 6 after 20 days exposure to natural aging conditions

17. XPS depth profile for Stellite 6 after 25 days exposure to natural aging conditions

18. XPS depth profile for Stellite 6 after 40 days exposure to natural aging conditions

19. XPS depth profile for Stellite 6 after 78 days exposure to natural aging conditions 
20. XPS depth profile of the cobalt in Stellite 6 specimens exposed to natural aging conditions

21. XPS depth profile of the cobalt oxide in Stellite 6 specimens exposed to natural aging conditions

22. XPS depth profile of the chromium in Stellite 6 specimens exposed to natural aging conditions

23. XPS depth profile of the chromium oxide in Stellite 6 specimens exposed to natural aging conditions

24. XPS depth profile of the oxygen in Stellite 6 specimens exposed to natural aging conditions

25. AES depth profile for Stellite 6 after 11 days exposure to an anodic current density of $0.15 \mathrm{~mA} / \mathrm{cm}^{2}$

26. XPS depth profile for Stellite 6 after 19 days exposure to high-pH aging conditions

27. Oxide film thickness versus time for Stellite 6, showing the data from the natural aging tests and the parabolic data fit

28. Oxide film thickness versus time for Stellite 6, Type 304 Stainless Steel, and a carbon steel

29. Oxide film thickness versus time for Stellite 6, showing the data from the simulated valve wedging tests and the parabolic data fit of the naturally aged tests

30. Typical friction traces from the friction testing of Stellite 6

31. Photograph of 78-day natural aging Stellite 6 specimens before and after friction testing

32. Coefficient of friction versus stroke for Stellite 6 specimens exposed to natural aging conditions; maximum values (top) and nominal values (bottom)

33. Coefficient of friction versus stroke for Stellite 6 specimens exposed to accelerated aging conditions; maximum values (top) and nominal values (bottom)

34. Coefficient of friction versus stroke for unaged and aged Stellite 6 specimens; maximum values (top) and nominal values (bottom)

35. Coefficient of friction versus time for naturally aged Stellite 6 specimens; maximum values (top) and nominal values (bottom)

36. Coefficient of friction (maximum) versus approximate film thickness for naturally aged and accelerated aging (anodic current) Stellite 6 specimens

37. Coefficient of friction versus stroke for 20- and 40-day naturally aged and high-pH accelerated aging Stellite 6 specimens 
38. Coefficient of friction versus stroke for naturally aged Stellite 6 specimens and specimens subject to in-service testing; maximum values (top) and nominal values (bottom).

\section{TABLES}

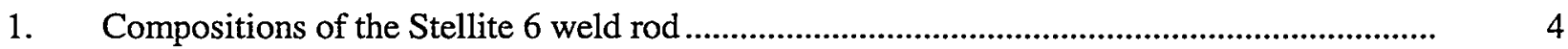

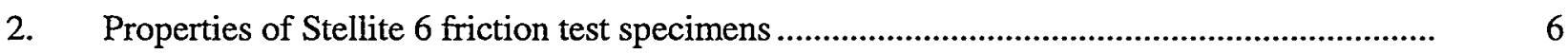

3. Oxide film thickness on Stellite 6 exposed to natural aging; thicknesses are determined from XPS results

4. Oxide film thickness on Stellite 6 exposed to natural aging and simulated valve wedging loads; thicknesses are determined from XPS results.

5. Oxide film thickness on Stellite 6 exposed to accelerated aging via an anodic current; the thicknesses are determined from an electron micrograph of the surface cross section........... 


\section{Summary and Evaluation of NRC-Sponsored Stellite 6 Aging and Friction Tests}

\section{INTRODUCTION}

Under the sponsorship of the U.S. Nuclear Regulatory Commission (NRC), the Idaho National Engineering and Environmental Laboratory (INEEL) has been conducting research investigating the ability of motor-operated valves (MOVs) to function when subjected to design basis loads. That research included several recent tests addressing the friction characteristics of aged Stellite 6 disc and seat surfaces in gate valves. This report describes those aging and friction tests and compares and evaluates the results.

Methods exist to analytically predict the thrust needed to close (or open) motor-operated gate valves at specific flow and pressure conditions; however, the analyst must have a reasonably accurate, though conservative, estimate of the coefficient of friction at the disc-to-seat interface (see Figure 1). In most gate valves, these surfaces are hardfaced with Stellite 6, a cobalt-based alloy. Some of the questions addressed by the recent INEEL aging and friction tests are:

- Does the accumulation of an oxide film on the disc and seat surfaces over time increase the coefficient of friction?

- Does periodic valve cycling typical of in-service testing decrease the coefficient of friction?

- Does increasing the time between periodic valve cycling (in-service testing) increase the coefficient of friction?

- Does valve cycling immediately before a diagnostic test decrease the coefficient of friction?

This report presents the results from an INEEL research project designed to address these concerns. The project consisted of two sets of tests subjecting Stellite 6 specimens to an environment simulating boiling water reactor (BWR) coolant conditions, representing the conditions a typical reactor water cleanup (RWCU) isolation valve would experience, and inducing the accumulation of an oxide film. The tests included analysis of the resulting oxide film and testing to determine the coefficient of friction for specimens subjected to aging only and for specimens subjected to aging with periodic valve cycling.

The Battelle Memorial Institute in Columbus, Ohio performed the testing under a contract with the INEEL. Following the completion of the testing at Battelle, the Stellite 6 aging and friction research results underwent a peer review by internal NRC material experts. In addition, INEEL contracted with the National Institute of Standards and Technology (NIST) for an independent critical review by a corrosion and friction expert. That review evaluated the test methods, processes, and results and included the performance of additional tests on some of the Stellite 6 specimens. The results of those tests are included in this report.

Two earlier, closely related INEEL test programs likewise produced an oxide film on Stellite 6 specimens and subjected the specimens to friction testing. The results of those tests are informative but somewhat inconclusive, for reasons explained later in this report. For completeness, this report includes a discussion of those tests. 

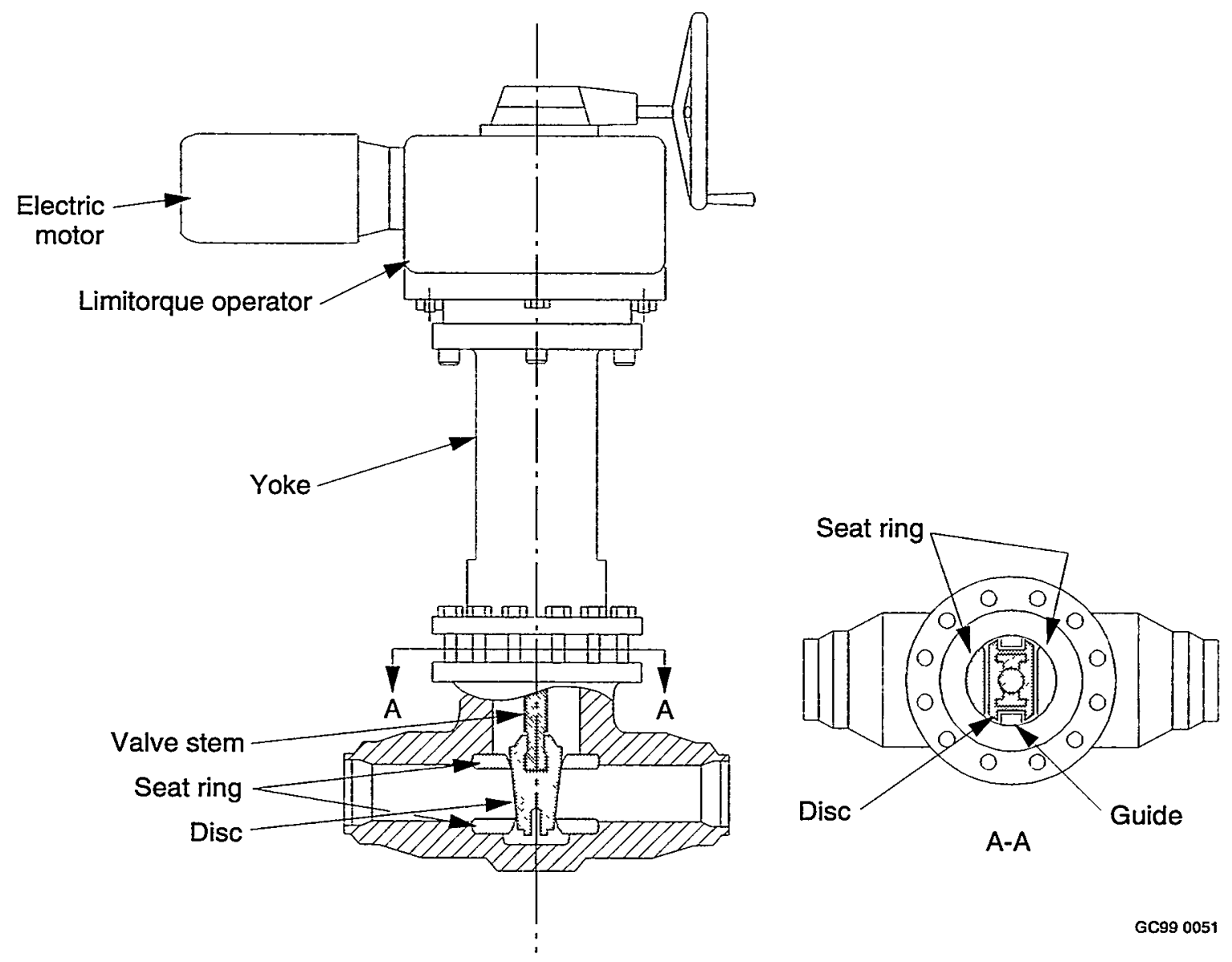

A-A

GC99 0051

Figure 1. Diagram of a typical motor-operated gate valve, showing the main components. 


\section{DESCRIPTION OF TESTS}

In all, this report describes four sets of tests that investigated aging and friction characteristics of Stellite 6. The two earlier tests focused on accelerating the accumulation of the oxide film on the Stellite 6 specimens. The reason for trying to accelerate the aging process was to produce in a few days or weeks an oxide film characteristic of what would be expected in a BWR coolant system after many months or years. One of these tests was very successful in accelerating the growth of an oxide film, while the other was less successful; however the resulting oxide films were not representative of the oxide film developed during natural aging. The third set of specimens underwent natural aging at simulated BWR conditions, and both the oxide film growth and the resulting friction response of the specimens were characterized as the specimens aged. The fourth set of tests included efforts to extend the time the specimens underwent natural aging and to quantify the effect periodic cycling of the valve would have on the growth of the oxide film and on the friction characteristics of the specimens. The four sets of tests were:

- Accelerated aging of specimens for 11 to 14 days using a small anodic electric current

- Accelerated aging of specimens for 19 days using high-pH fluid conditions

- Natural aging of specimens under normal BWR conditions for up to 40 days

- Natural aging of specimens under normal BWR conditions for 78 days, and subjecting some of the specimens to simulated valve wedging cycles (representing typical in-service testing) after 25 days and again after 50 days.

In all four sets of tests, the morphology (physical structure) of the oxide film was evaluated, the chemical composition of the oxide film was analyzed, and the thickness of the oxide film was determined. The specimens were also subjected to friction testing and the results tabulated for comparison. Unaged specimens were also subjected to friction testing, and the results were included for comparison.

\subsection{Preparation of Specimens}

Each of the four sets of tests used several "friction sets" of Stellite 6 specimens. Each friction set consisted of four specimens-two large inner specimens, and two small outer specimens-to accommodate the configuration of the friction testing autoclave described below. The specimens were prepared using methods typically used by valve manufacturers. The Stellite 6 hardfacing was welddeposited onto ANSI 1020 carbon steel blanks using the gas tungsten arc welding (GTAW) process. Uncoated weld rod of 0.125 inch and 0.094 inch diameter was used for the large inner and small outer friction specimens, respectively. The carbon steel blanks for the large inner specimens were 1.0 in. wide by $3.0 \mathrm{in}$. long, onto which a 0.5 -in. wide strip of hardfacing was deposited along the length. The carbon steel blanks for the small outer specimens were $0.5 \mathrm{in}$. wide by $1.1 \mathrm{in}$. long, with the Stellite 6 footprint machined to either $0.25 \mathrm{in}$. wide by $1.1 \mathrm{in}$. long for the 10-ksi tests or $0.15 \mathrm{in}$. wide by $0.4 \mathrm{in}$. long for the 40-ksi tests. Almost all of the testing was performed with the 10-ksi specimens. The composition of the weld rod, as specified by the manufacturer and by the American Welding Society (AWS), is shown in Table 1, along with a check of the major elements by energy dispersive spectroscopy (EDS).

The hardfacing was deposited in three passes (minimum) to achieve a proper thickness of at least $0.20 \mathrm{in}$. and to minimize iron dilution from the carbon steel substrate. The specimens were rough machined by electric discharge machining (EDM), with the final surface finish achieved through fine grinding to a finish of $16 \mu \mathrm{in}$. (arithmetic average) or better. For all specimens, the leading and trailing edges were chamfered to reduce the likelihood that any sharp edges would affect the friction testing. 
Table 1. Compositions of the Stellite 6 weld rod.

\begin{tabular}{lcccc}
\hline Element & $\begin{array}{c}\text { Manufacturer } \\
\text { specified average } \\
\text { value }\end{array}$ & AWS requirement & $\begin{array}{c}\text { Composition of the } \\
\text { small weld rod by } \\
\text { EDS }\end{array}$ & $\begin{array}{c}\text { Composition of the } \\
\text { large weld rod by } \\
\text { EDS }\end{array}$ \\
\hline $\mathrm{C}$ & 1.2 & $0.9-1.4$ & - & - \\
$\mathrm{Mn}$ & 0.05 & $1.00 \mathrm{max}$ & - & - \\
$\mathrm{Si}$ & 1.4 & $2.0 \mathrm{max}$ & 1.1 & 1.4 \\
$\mathrm{Mo}$ & 0.1 & $1.0 \mathrm{max}$ & - & - \\
$\mathrm{Ni}$ & 2.0 & $3.0 \mathrm{max}$ & 1.8 & 2.5 \\
$\mathrm{Fe}$ & 2.1 & $3.0 \mathrm{max}$ & 1.8 & 2.4 \\
$\mathrm{~W}$ & 4.7 & $3.0-6.0$ & 5.4 & 4.8 \\
$\mathrm{Cr}$ & 29.0 & $26.0-32.0$ & 28.1 & 27.4 \\
$\mathrm{Co}$ & Balance (60) & Balance $(49-70)$ & 61.9 & 60.6 \\
\hline
\end{tabular}

All machining and cleaning operations were performed in a manner to avoid contamination. All machining was performed using water-based coolants. Cleaning consisted of scrubbing the specimens with a nylon bristle brush and ultrasonic cleaning using a $2 \%$ solution of a nonionic detergent with demineralized water, followed by ultrasonic cleaning in acetone and then ethyl alcohol. Typical specimens, after final cleaning and before aging, are shown in Figure 2. The sketch at the top of the figure shows the dimensions of the various Stellite 6 specimens. In addition to the large inner and small outer specimens described above, dummy specimens were included. These specimens were obtained by sectioning several of the large inner specimens. The Stellite 6 surface on these specimens was approximately 0.5 in. wide by 0.45 in. long and was used for oxide film characterization only. Following fabrication, the composition of two of the large inner friction specimens and two of the small outer friction specimens was characterized. The composition and hardness of these specimens were within the range of properties typically found in Stellite 6 valve trim hardfacings; Table 2 provides specific data.

\subsection{Aging of Specimens}

The specimens were aged at simulated BWR coolant conditions in a corrosion autoclave. The autoclave was attached to a reservoir of water in which the oxygen was controlled in the range of 100 to $200 \mathrm{ppb}$. Water from the reservoir was continuously supplied to the autoclave, with the temperature in the autoclave maintained at $550^{\circ} \mathrm{F}$, and the pressure at $1050 \mathrm{psi}$, slightly above the saturated steam pressure, such that the water was about $10^{\circ} \mathrm{F}$ subcooled.

The corrosion autoclave used in the first three tests was a five-gallon, flow-through, stainless steel "stirring" autoclave (Figure 3). The setup for the first test included a galvanostat and other provisions for supplying an anodic current to the specimens to accelerate the aging process. These provisions were excluded in the second and third tests. A different autoclave was used in the fourth test. A replacement autoclave was necessary because the original autoclave failed during the initial heatup of the fourth test. A number of cracks were discovered in the autoclave that could not be repaired. The replacement autoclave was made of Hastelloy and was smaller, approximately 1 gallon in size, but still large enough to accommodate all the specimens. The replacement autoclave retained all the functional capabilities of the original autoclave. 

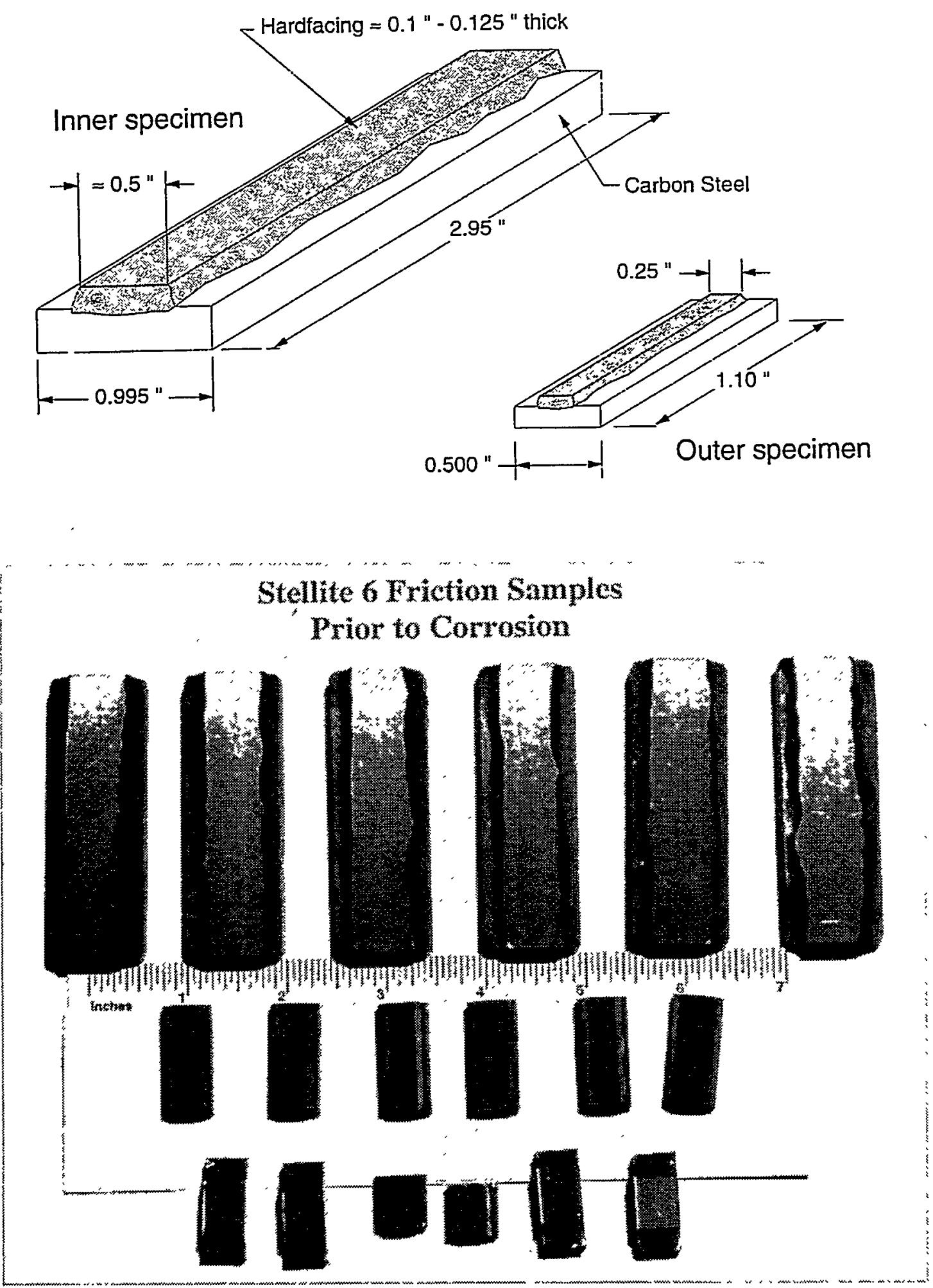

Figure 2. Photograph of Stellite 6 specimens before aging (top to bottom: inner, outer, and dummy specimens); the sketch at the top shows dimensions. 
Table 2. Properties of Stellite 6 friction test specimens.

\begin{tabular}{lcccc}
\hline Element & $\begin{array}{c}\text { Large Friction } \\
\text { Specimen \# }\end{array}$ & $\begin{array}{c}\text { Large Friction } \\
\text { Specimen \#2 }\end{array}$ & $\begin{array}{c}\text { Small Friction } \\
\text { Specimen \#28 }\end{array}$ & $\begin{array}{c}\text { Small Friction } \\
\text { Specimen \#29 }\end{array}$ \\
\hline $\mathrm{Si}$ & 1.2 & 1.2 & 1.2 & 1.1 \\
$\mathrm{~W}$ & 5.5 & 5.5 & 4.3 & 4.6 \\
$\mathrm{Ni}$ & 2.2 & 2.2 & 1.7 & 1.8 \\
$\mathrm{Fe}$ & 2.5 & 2.5 & 8.9 & 10.3 \\
$\mathrm{Cr}$ & 28.3 & 28.4 & 25.7 & 25.2 \\
$\mathrm{Co}$ & 60.3 & 60.4 & 58.4 & 57.1 \\
Hardness (HRC) & 44.0 & 44.7 & 41.8 & 41.0 \\
\hline
\end{tabular}

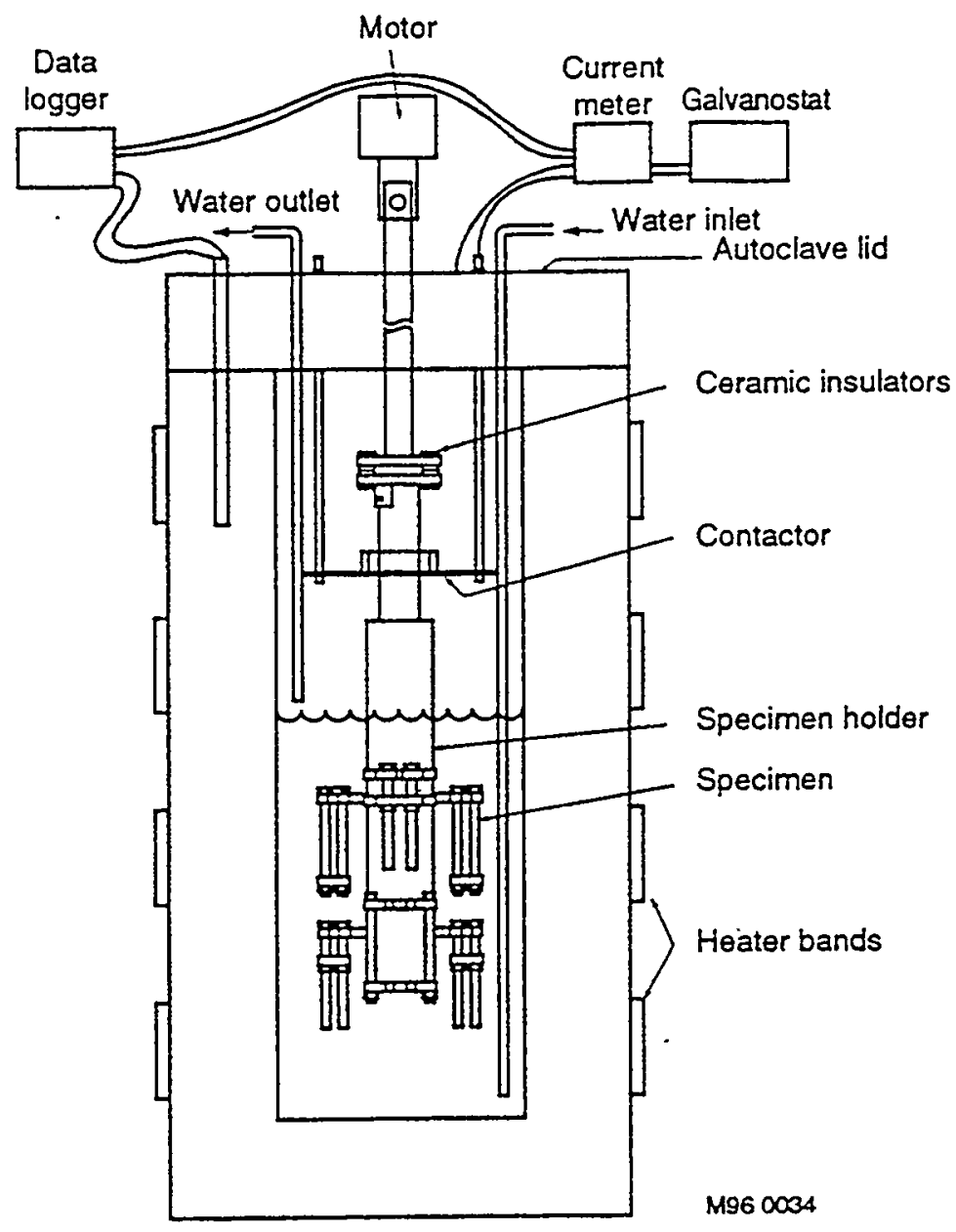

Figure 3. Diagram of the first corrosion autoclave. 
In the original autoclave, the specimens were attached to a rack fabricated from zirconium and heat-treated to provide a non-conductive zirconium dioxide $\left(\mathrm{ZrO}_{2}\right)$ film. A stirring unit was used to ensure adequate mixing during the aging process and to simulate typical flow past a valve in a RWCU system. Except for the accelerated aging tests using high $\mathrm{pH}$ fluid conditions, the $\mathrm{pH}$ was maintained at 6.5 to 7.0. The autoclave pressure and temperature were continuously recorded and the solution conductivity and dissolved oxygen concentration were recorded twice each day. The smaller autoclave used for the fourth test contained a rack made from Type 316 Stainless Steel, with Teflon sheeting to avoid direct contact between the rack and the specimens.

For the first test, specimens were exposed to simulated BWR conditions and a small anodic electric current applied to accelerate the aging. The following anodic currents were applied: (a) $0.15 \mathrm{~mA} / \mathrm{cm}^{2}$ for 11 days; (b) $0.15 \mathrm{~mA} / \mathrm{cm}^{2}$ for 11 days followed by $0.19 \mathrm{~mA} / \mathrm{cm}^{2}$ for 2.5 days; and (c) $0.35 \mathrm{~mA} / \mathrm{cm}^{2}$ for 14 days. The electrically insulating $\mathrm{ZrO}_{2}$ film was removed from the corrosion autoclave rack at points where the specimens were attached, and the voltage was applied so that the anodic current flowed through the specimens to the autoclave wall (counter electrode). Following each exposure to an anodic electric current, the oxide films were characterized and friction testing was performed.

For the second test (accelerated aging with high $\mathrm{pH}$ fluid conditions), specimens were exposed to simulated BWR conditions for 19 days with the $\mathrm{pH}$ of the fluid adjusted to 9.0 (instead of 6.5 to 7.0 ) using carbonate-free sodium hydroxide $(\mathrm{NaOH})$. The rationale for the $\mathrm{pH}$ adjustment was based on solubility versus $\mathrm{pH}$ curves that indicate that increasing the $\mathrm{pH}$ of the fluid will increase the solubility of the oxide. Consequently, it was expected that this technique would lead to thicker oxide films. Following the exposure to high $\mathrm{pH}$ fluid conditions, the oxide film was characterized and friction testing was performed.

For the third test (natural aging), the oxide film was characterized following 2-, 10-, 20-, 25-, 40-, 50-, and 78-day exposure to simulated BWR conditions in the corrosion autoclave. Friction testing was performed following $2,10,20,40$, and 78 days in the corrosion autoclave.

For the fourth test (natural aging plus simulated valve wedging), specimens were removed from the corrosion autoclave and subjected to simulated valve wedging cycles at 25 days and again at 50 days. The oxide film was characterized both before and after the simulated valve wedging cycles so that the effect the wedging had on the oxide film could be determined. Friction testing was performed following 78 days in the corrosion autoclave using specimens that had undergone a simulated valve wedging at 25 days and again at 50 days.

A discussion of the results is presented later in this report.

\subsection{Simulated Valve Wedging}

Selected 10-ksi friction specimens and oxide film characterization specimens underwent simulated valve wedging cycles representing typical in-service testing (IST) in the IST simulation rig (Figures 4 and 5). To subject the entire surface of each specimen to a simulated valve wedging, like-sized specimens were placed with their Stellite 6 surfaces face to face, a normal load of $20 \mathrm{ksi}$ applied, and then the specimens moved 0.040 in. $(1 \mathrm{~mm}$ ) relative to each other. Unlike the corrosion autoclave (described in the previous subsection) and the friction autoclave (described in the next subsection), the IST simulation rig treated the specimens to a water bath at room temperature and atmospheric pressure rather than simulated BWR coolant conditions. (The high-temperature friction autoclave could not be used for the IST simulation, because it was not capable of generating high enough normal loads on the like-sized 


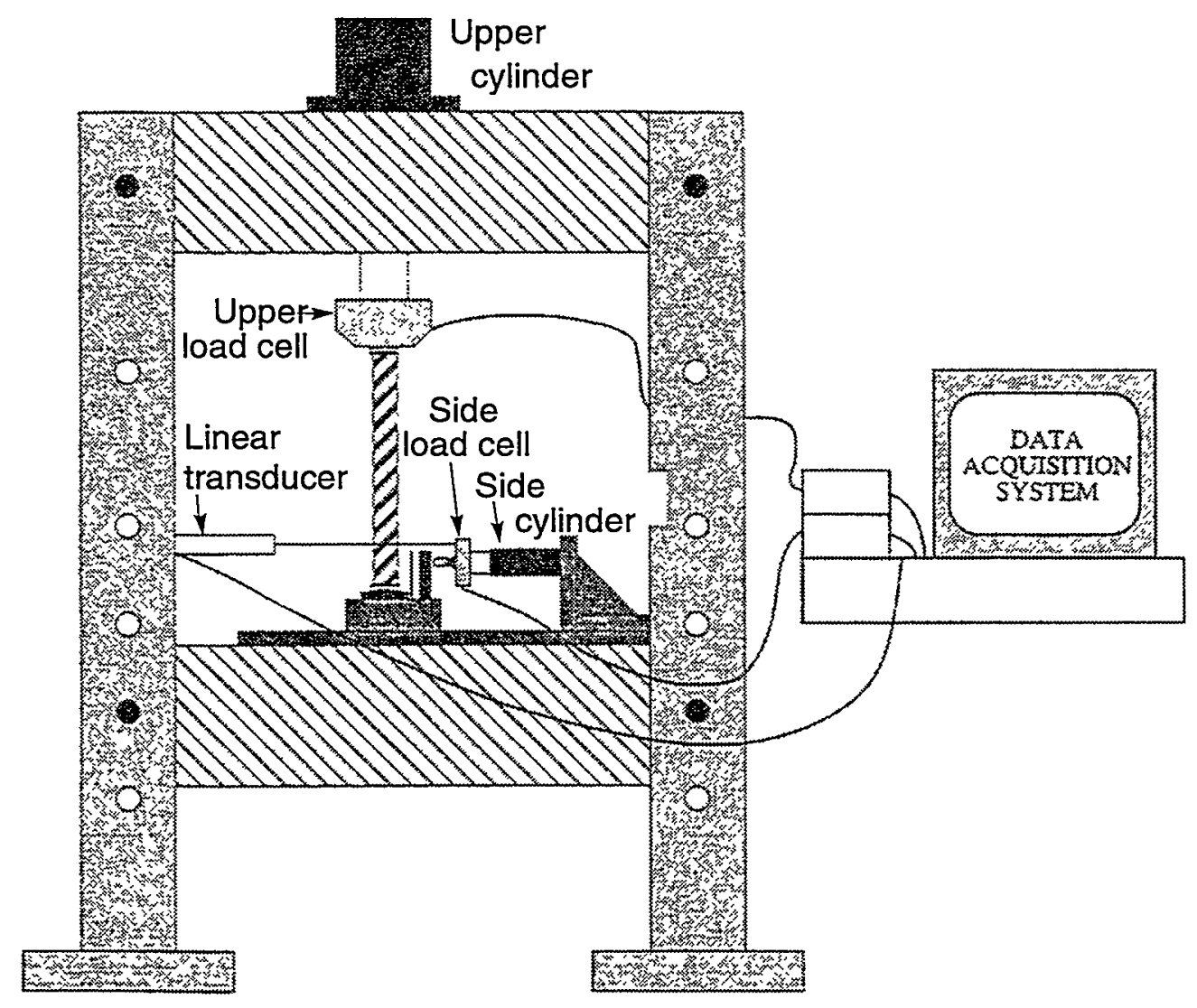

Figure 4. Diagram of the in-service testing simulation rig.

specimens.) The like-sized face-to-face specimen pairs, the dimensions of the contact surface, and the force required to produce a contact stress of $20 \mathrm{ksi}$ are:

- $\quad$ Large, inner friction specimens:

$0.5 \mathrm{in}$. wide by $3.0 \mathrm{in}$. long, $30,000-\mathrm{lb}$ normal force

- Small, outer $10 \mathrm{ksi}$ friction specimens:

0.25 in. wide by $1.1 \mathrm{in.} \mathrm{long,} \mathrm{5,500-lb} \mathrm{normal} \mathrm{force}$

- Dummy specimens for oxide film characterization:

$0.5 \mathrm{in}$. wide by $0.45 \mathrm{in}$. long, $4,500-1 \mathrm{~b}$ normal force.

A stress level of $20 \mathrm{ksi}$ was selected to approximate the stresses occurring during a valve wedging cycle of a typical RWCU system valve. Selected specimens were subjected to the simulated valve wedging after 25 days and again after 50 days of natural aging. 


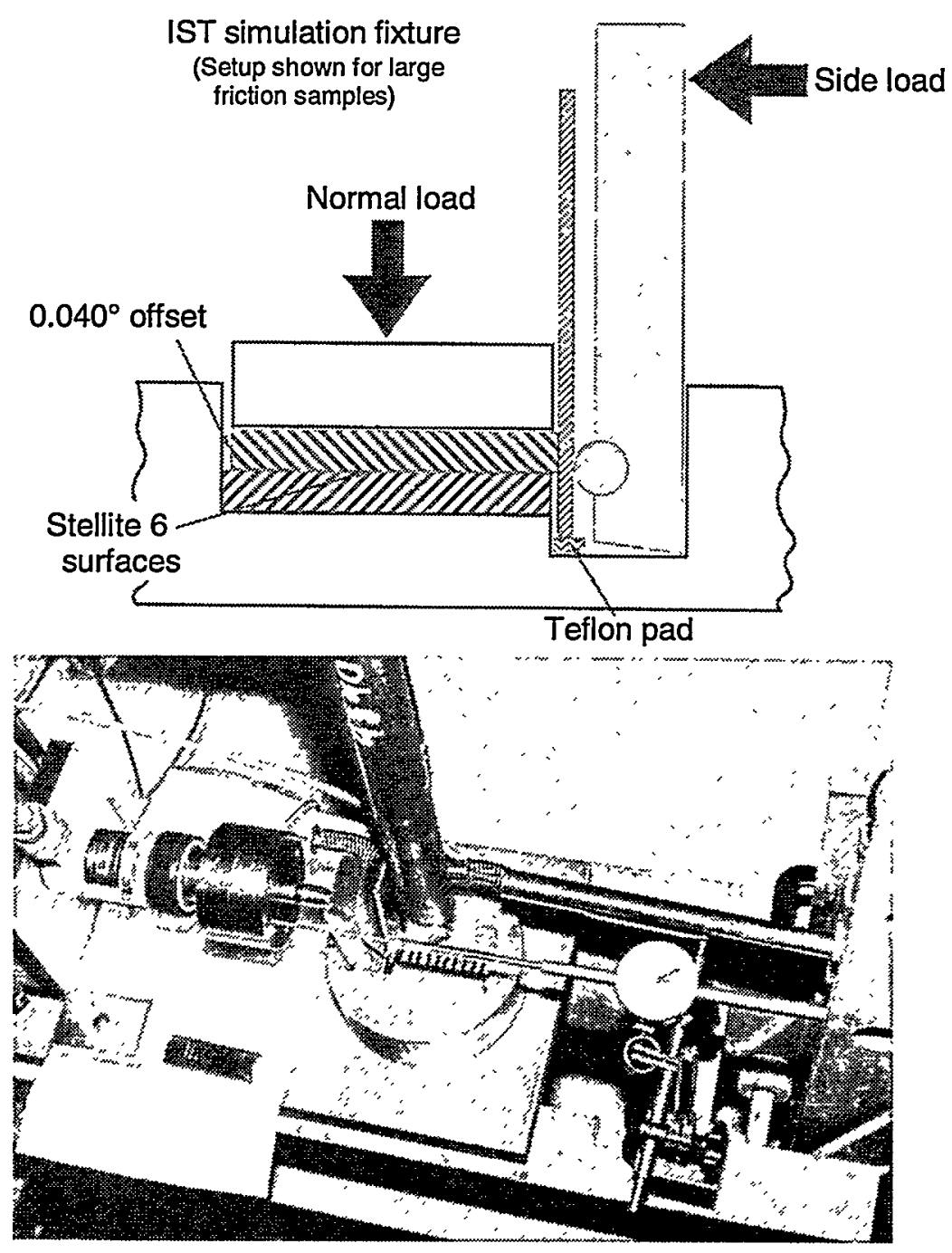

Figure 5. Details of the simulated valve wedging fixture and loading configuration (top), and a photo of the test fixture with dummy large specimens shown with stripes (bottom). 


\subsection{Friction Testing of Specimens at Battelle Columbus}

Friction testing at Battelle used the same friction autoclave in all four sets of tests. The friction autoclave (Figure 6), like the corrosion autoclave, was attached to a reservoir of water in which the oxygen was controlled in the range of 100 to $200 \mathrm{ppb}$. Testing was performed with the autoclave heated to $550^{\circ} \mathrm{F}$ and pressurized to about $1050 \mathrm{psi}$. During each test, a specimen assembly (friction set) consisting of two small outer specimens and two large inner specimens was tested. The small outer specimens were held in a stationary fixture, and the large inner specimens were attached to a carrier bar connected to a movable pull rod. Actuation of the pull rod caused the large inner specimens to slide between the small outer specimens at a relative velocity of $16 \mathrm{in} . / \mathrm{min}$, a rate within the range expected for typical gate valves.

The friction-testing device is equipped with a bellows that can exert a force on one side of the specimen assembly. Pressurizing the bellows imposes a normal force on the specimens to produce the specified nominal contact stress of either $10 \mathrm{ksi}$ or $40 \mathrm{ksi}$. The normal force required to achieve a $10-\mathrm{ksi}$ nominal contract stress on the 0.25 -in.-wide by 1.10 -in.-long specimens is $2,750 \mathrm{lb}$. This contact stress was selected to approximate the stress level occurring during operation of typical RWCU system valves. (Assuming a uniform load distribution, the estimated contact stresses at the seats for typical 4-in. and 6-in. valves subjected to a differential pressure of $1,050 \mathrm{psi}$ are $7.8 \mathrm{ksi}$ and $12.6 \mathrm{ksi}$, respectively.) For the small 0.15 -in.-wide by 0.40 -in.-long specimens, a normal force of $2,400 \mathrm{lb}$ is required to achieve a nominal contact stress of $40 \mathrm{ksi}$.

With the friction coefficient $(\mu)$ defined in the usual manner, as the ratio of the sliding force to the normal force (i.e., $\mu=F_{s} / F_{n}$ ), the friction was determined by measuring the force applied by the bellows and the force required to move the inner specimens. Specifically, the friction coefficient was calculated using the following formula:

i $\mu=\frac{F s / 2}{F_{n}}$

where

$$
\begin{aligned}
& \mu \quad=\text { coefficient of friction } \\
& F_{s} \quad=\text { sliding force }\left(f_{\text {total }}-f_{\text {tare }}\right) \\
& F_{n} \quad=\text { normal force (applied by the bellows) } \\
& f_{\text {total }} \quad=\text { total force measured while the specimens are moving } \\
& f_{\text {tare }} \quad=\text { force measured before the pull rod moves the specimens }\left(f_{\text {seal }}-f_{\text {expulsion }}\right) \\
& f_{\text {seal }} \quad=\text { force due to friction at the seal } \\
& f_{\text {expulsion }}=\text { force due to the fluid pressure in the autoclave trying to expel the pull rod. }
\end{aligned}
$$

The normal force $\left(F_{n}\right)$ was determined using a known calibration between the effective bellows pressure and the resulting force exerted by the bellows. (The effective bellows pressure is the difference between the pressure inside the bellows and the pressure in the autoclave.) 


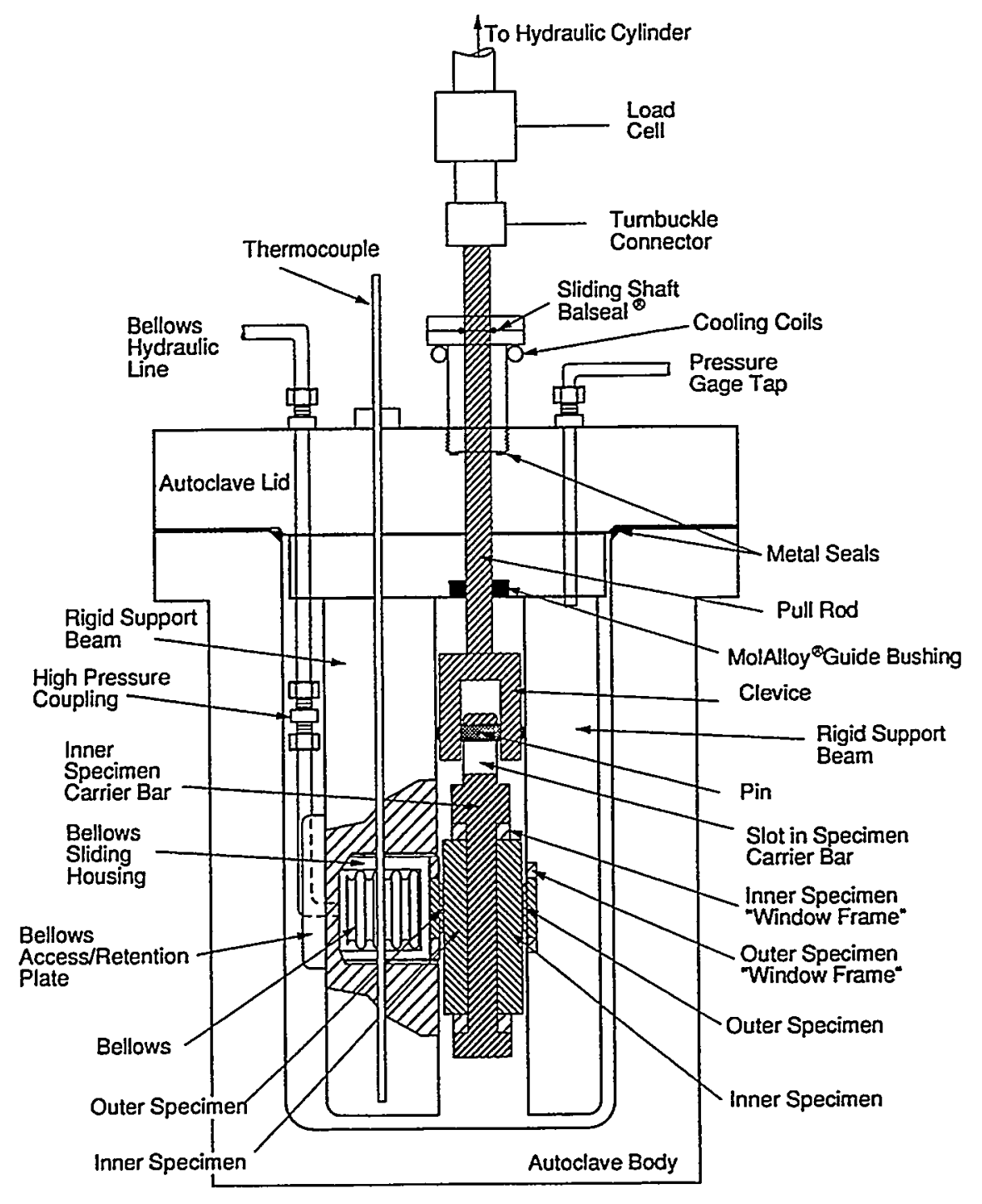

Figure 6. Diagram of the friction autoclave.

The sliding force was determined from a load cell attached between the pull rod and the hydraulic cylinder that actuated it. A high pressure, low-friction seal on the top of the autoclave lid allowed the pull rod to be moved through the lid with minimal friction. As the pull rod was withdrawn during a friction test cycle, the first inch of stroke took up the slack in the pin-to-clevis assembly, thus allowing a measurement of the "tare" force $\left(f_{\text {tare }}\right)$ resulting from the seal friction force $\left(f_{\text {seal }}\right)$ less the expulsion force $\left(f_{\text {expulsion }}\right)$ on the pull rod. In terms of forces on a valve, this represents the packing drag less the stem rejection load. After the pin reached the top of the clevis, the pull rod began pulling the large inner specimens between the small outer (stationary) specimens for a distance of approximately 1.5 to 2.0 inches. During this portion of the stroke, the load cell measurement less the previously determined "tare" force derived the force required to move the specimens. Dividing the sliding force $\left(F_{s}\right)$ by two is necessary because the siding force is the result of friction at two interfaces, not just one. Thus, this formula gives the average friction value for the two sliding interfaces. Continuous measurements were taken during each friction test. The results are presented later in this report. 


\subsection{Friction Testing of Specimens at NIST}

Following the completion of the testing at Battelle, the results underwent a peer review by an independent corrosion and friction expert at NIST. In addition to an evaluation of the test methods, processes, and results, the NIST review included examination and testing of selected Stellite 6 specimens from the testing at Battelle. In particular, 10-day and 50-day specimens (from the third set of tests) were subjected to additional friction testing at NIST. Unlike the friction testing performed in the hightemperature, high-pressure autoclave at Battelle Columbus, the testing at NIST was performed at ambient temperature and pressure. The purpose of this testing was to investigate whether the configuration of the specimens in the friction autoclave at Battelle Columbus was representative of the way the Stellite 6 surfaces in a valve interact, or whether the resulting friction values contained any biases. Unlike the friction testing performed at Battelle Columbus, the friction testing performed at NIST used a single Stellite 6 specimen and either a 0.5 -in. steel ball or a 0.125 -in. steel ball fixed on the end of a push rod. The ball and push rod assembly was loaded with a preset force, and then the assembly was moved across the Stellite 6 surface. During this testing, the force on the ball and the force required to slide the ball over the specimen were continuously recorded. Dividing the sliding force by the normal force results in the friction coefficient. The testing was then repeated using a small flat surface with a contact area of $1.8 \mathrm{~mm}^{2}$ instead of a ball. Since the testing was not performed in an autoclave, correcting for pressure and seal loads (tare) was not necessary. 


\section{RESULTS OF FILM CHARACTERIZATION}

The morphology, or physical structure, of the oxide films was evaluated by examining the electron micrographs of the oxide films. In addition, the surface topography of a few selected specimens was examined at NIST using an Atomic Force Microscope (AFM) and X-ray diffraction. The chemical composition of the oxide films was analyzed by Auger electron spectroscopy (AES) for some specimens and by X-ray photoelectron spectroscopy (XPS) for others (and both methods for a few specimens). The chemical composition analysis for the first two test programs was performed at Evans East Laboratories, located in New Jersey. The chemical composition analysis for the last two test programs was performed at Ohio State University. With AES and XPS, the film is incrementally sputtered away, and the elemental composition of planes in the oxide film determined. The results of these analyses are then plotted versus time (or depth, assuming an oxide film removal rate due to the sputtering) to provide a depth profile so that the relative elemental concentrations can be evaluated. The film thickness was determined from metallographic cross sections for specimens exposed to the anodic current. For the natural aging specimens and the high-pH specimens, the film thickness was determined from the XPS results; this technique uses the change in chemical constituents versus depth (or sputter time) as an indication of film thickness. The following sections discuss each of these topics in more detail.

\subsection{Morphology}

The aging morphologies generated under natural aging conditions would be expected to mirror those found in service. However, it is likely that these films are not as thick as those found in service, because of the relatively short duration of the natural aging times in the tests.

Figure 7 is an electron micrograph showing the surface of a Stellite 6 specimen from one of the natural aging tests before exposure to aging conditions. Note that the machining marks are visible on the surface, which is relatively smooth. Typical results of exposure of the Stellite 6 specimens to natural aging in the corrosion autoclave are shown in Figure 8 for a 78-day specimen. Note that the original machining marks are still visible on the surface. The growth of the oxide film was not sufficient to hide these surface imperfections.

Figure 9 is an electron micrograph showing the surface of a Stellite 6 specimen that was subjected to an in-service test simulation. This specimen has undergone 78 days of natural aging, with simulated valve wedging cycles at 25 days and again at 50 days. Note that the surface shows evidence of deformation due to the simulated valve wedging loads, but only at local regions of contact. That is, the deformation occurs at the high spots that are the result of ordinary irregularities in the original machining of the surface during manufacture. The regions between the high spots were left relatively undisturbed. This is consistent with the visual observation made after the simulated in-service test, in which only a very small fraction of the surface (the high spots) appeared shiny and silver colored.

The surfaces of specimens subjected to accelerate aging (anodic current) are shown in Figures 10 and 11. Figure 10 provides a view of the surface after exposure for 11 days at an applied current density of $0.15 \mathrm{~mA} / \mathrm{cm}^{2}$. Note that there are more and larger nodules present, compared to the natural aging. Nodule sizes were in the range of 0.1 to $1.0 \mu \mathrm{m}$. The remnants of the machining marks are visible to a small extent, but the film appears thicker than with the natural aging.

Figure 11 presents images of the surface and the cross section of Stellite 6 after 14 days aging with an applied current density of $0.35 \mathrm{~mA} / \mathrm{cm}^{2}$. Here, too, the surface shows a large number of nodules; these nodules might be characteristic of surfaces grown under applied currents. The cross section shows the base metal on the left; the right side is a section of the plastic coating applied to the specimen during 


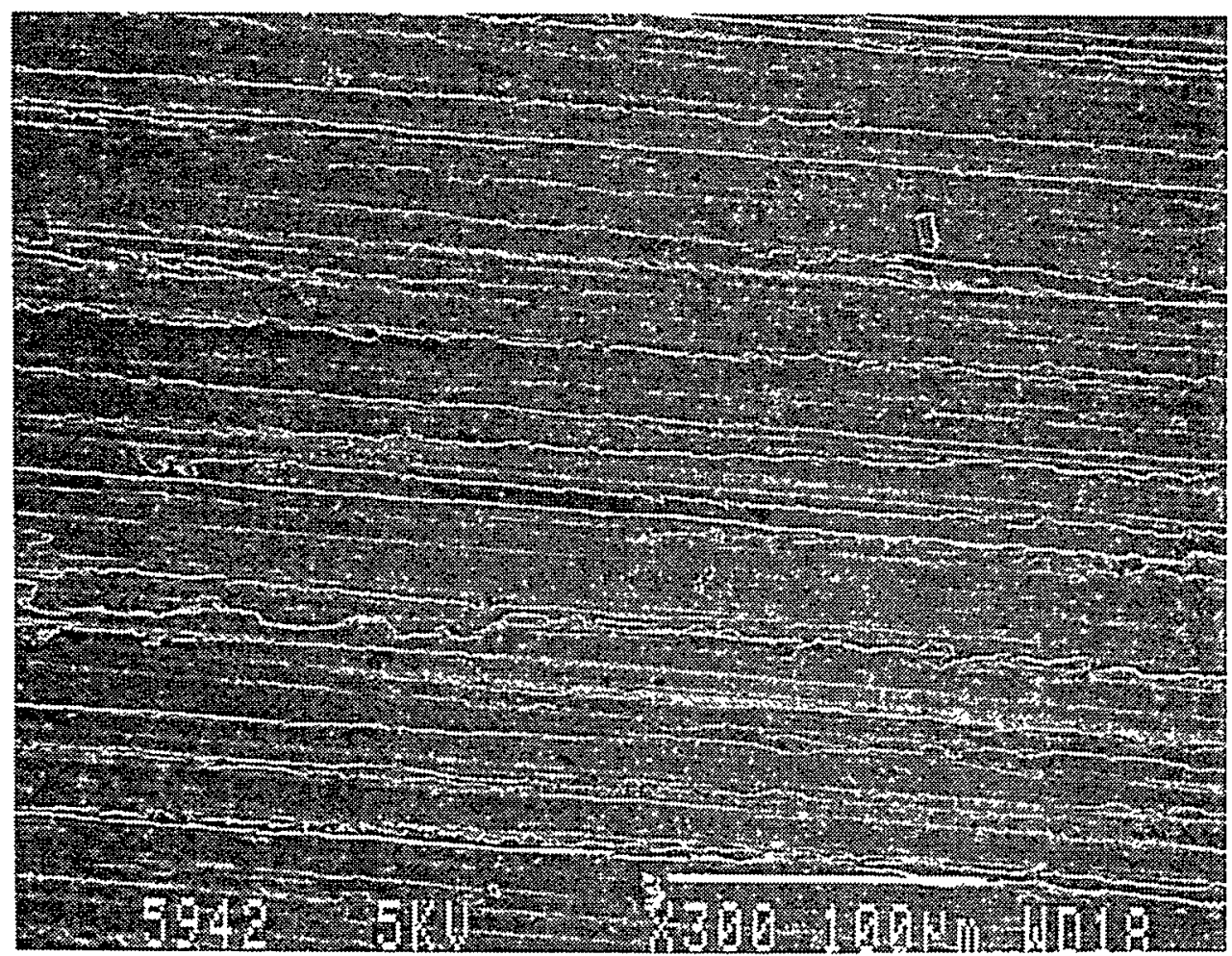

$\times 300$

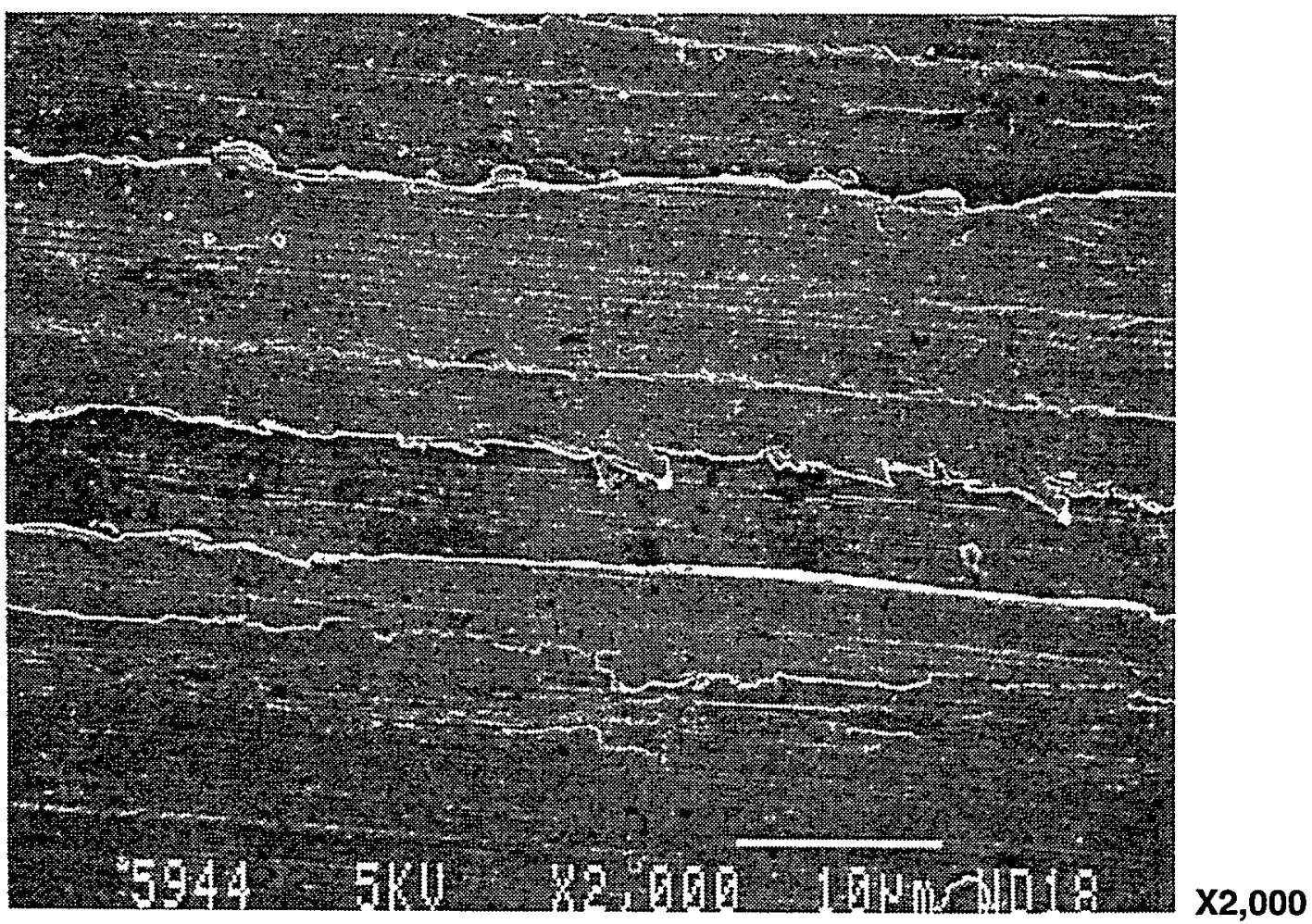

Figure 7. Electron micrographs of the surface of an as-ground Stellite 6 specimen, before exposure to aging; magnification at $\mathrm{X} 300$ and $\mathrm{X} 2,000$. 


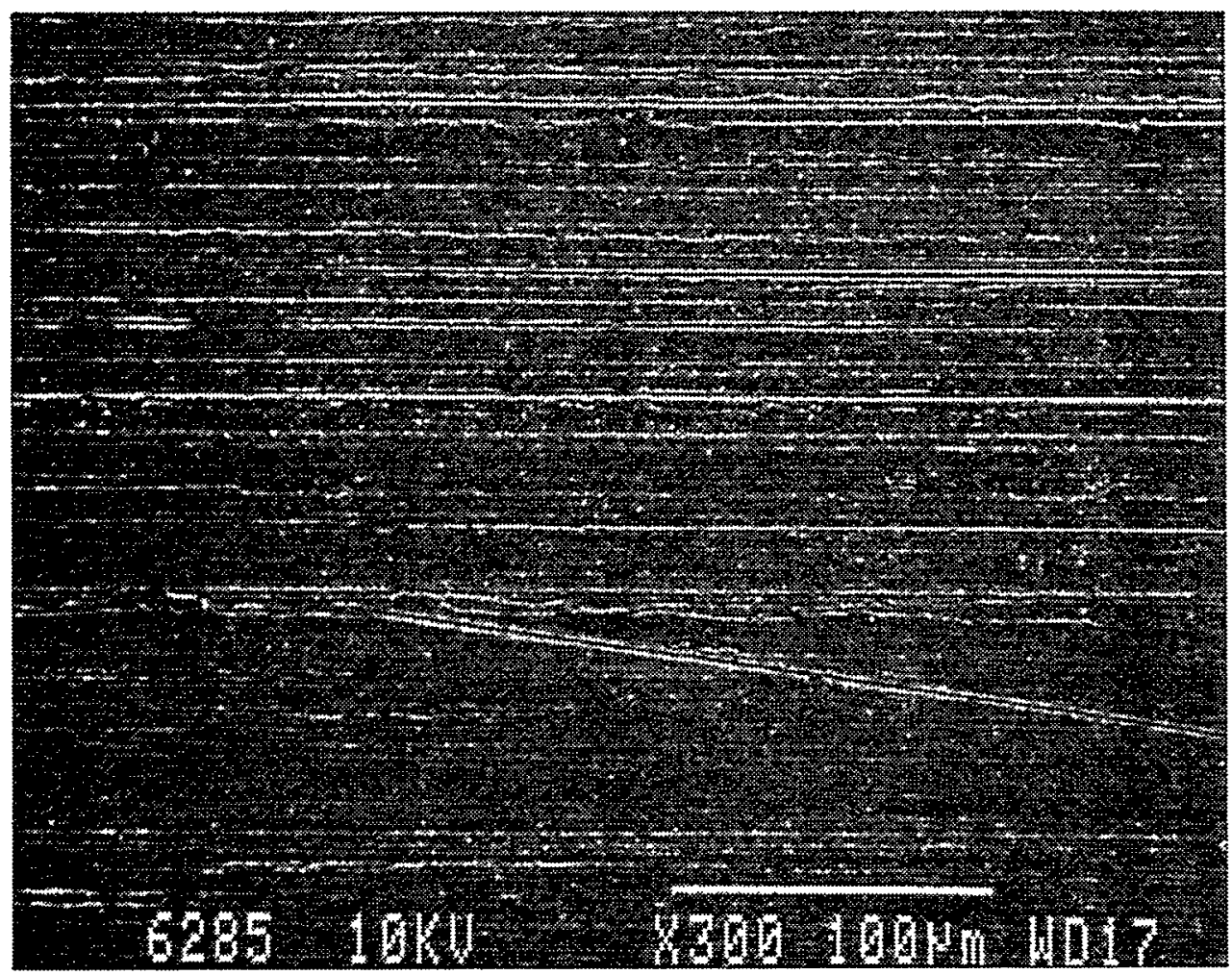

$\mathbf{X} 300$

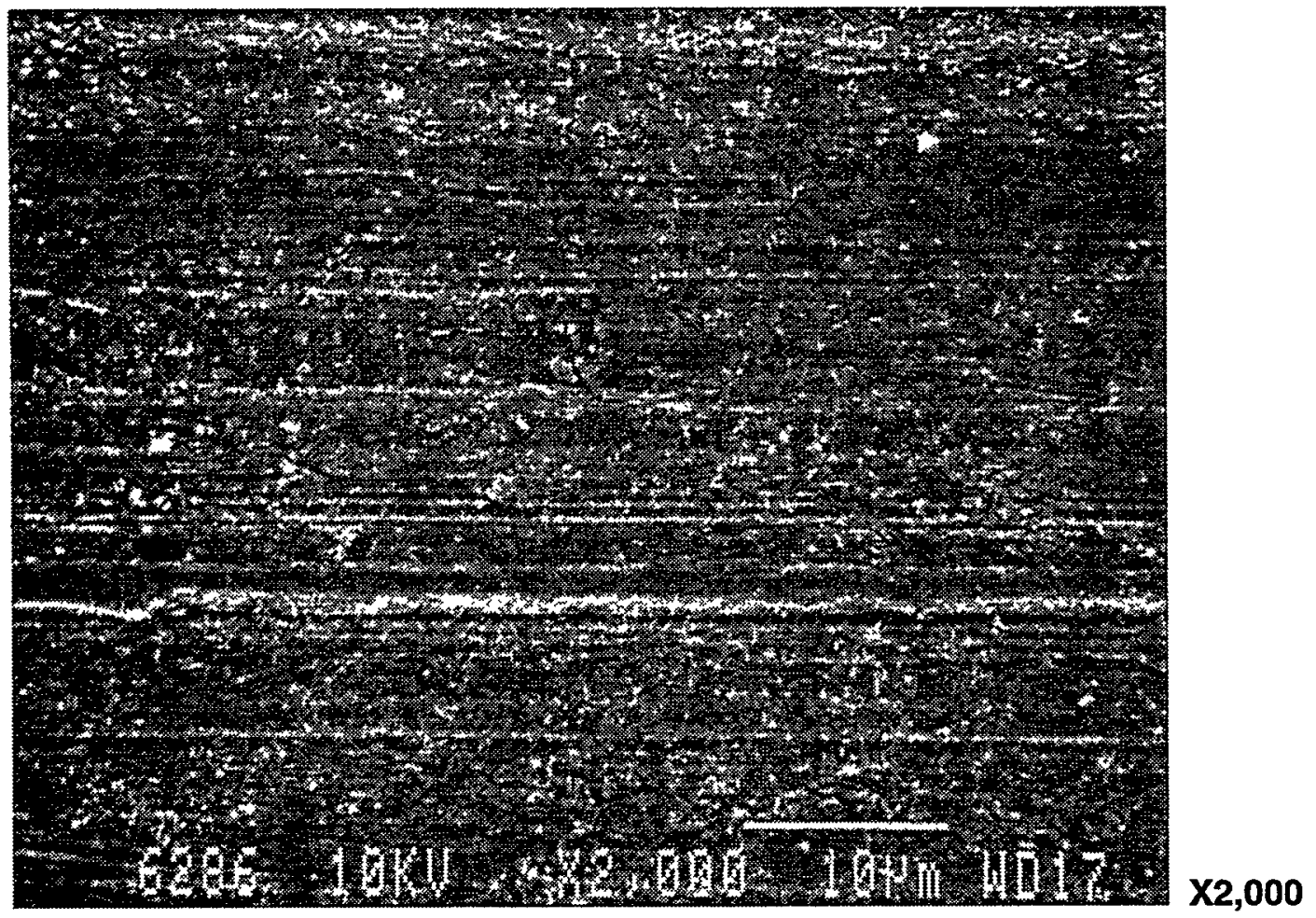

Figure 8. Electron micrographs of the surface of a Stellite 6 specimen after 78 days exposure to natural aging conditions. 

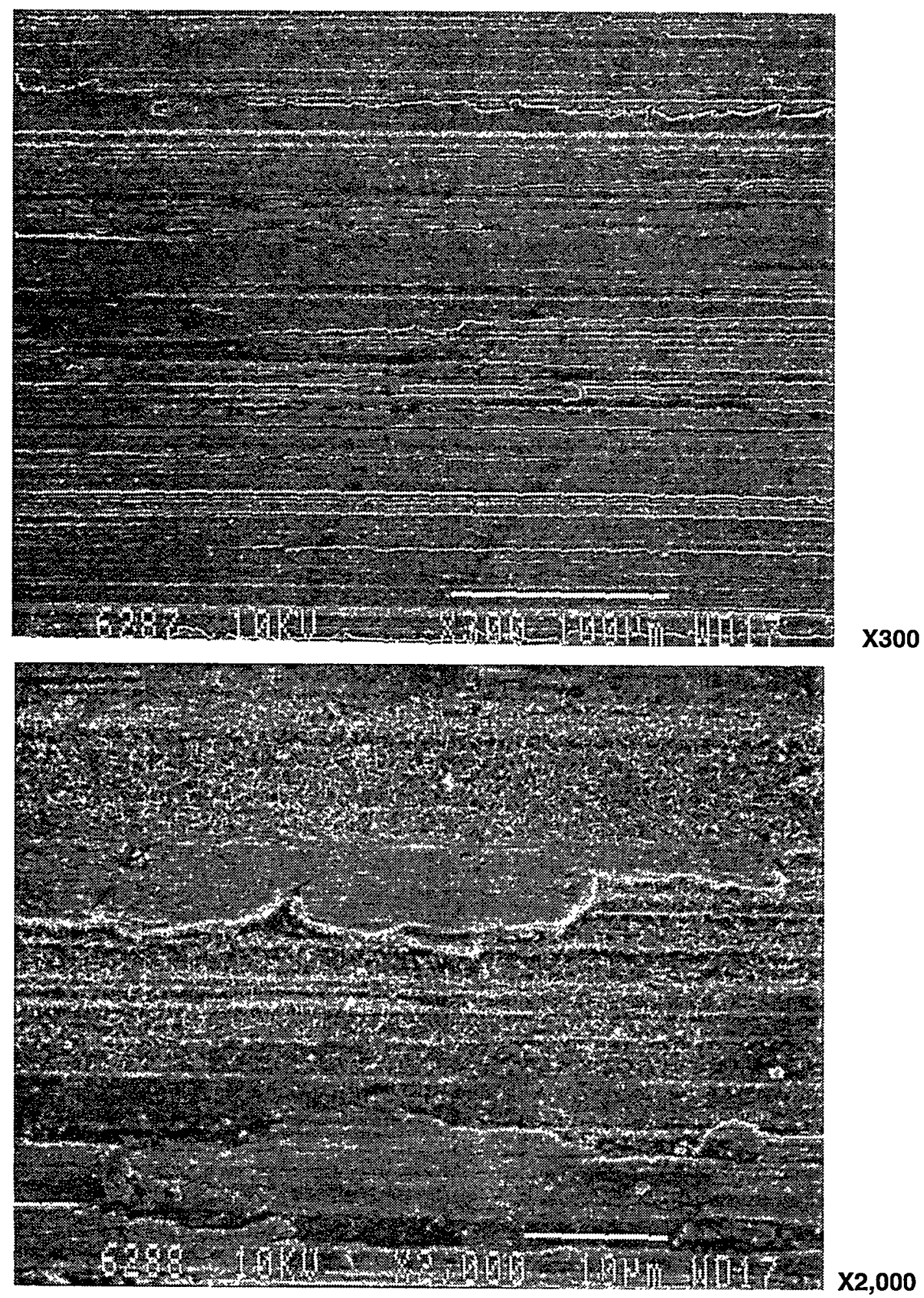

Figure 9. Electron micrographs of the surface of a Stellite 6 specimen after 78 days exposure to natural aging conditions, with simulated in-service testing at 25 days and again at 50 days. 


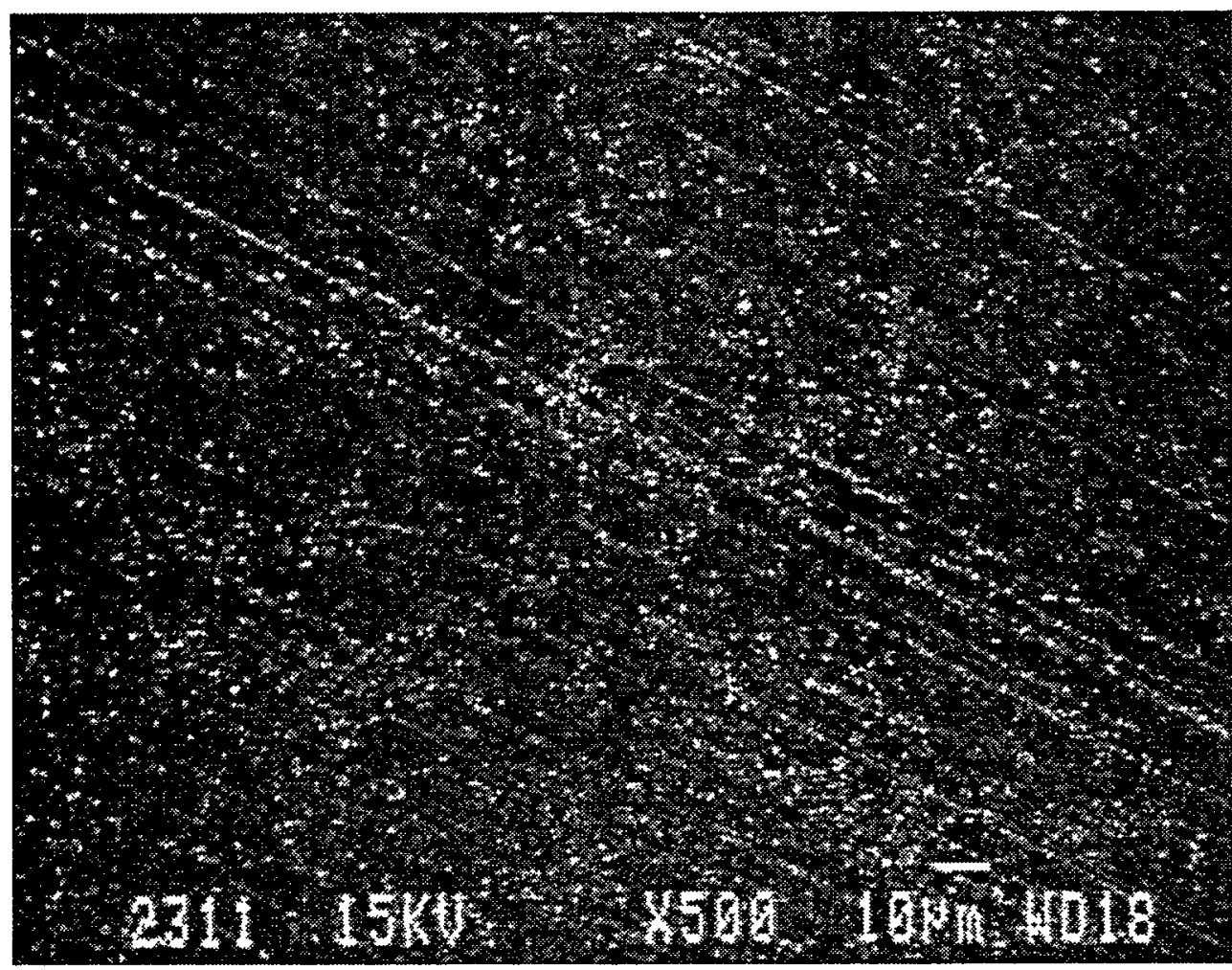

X500

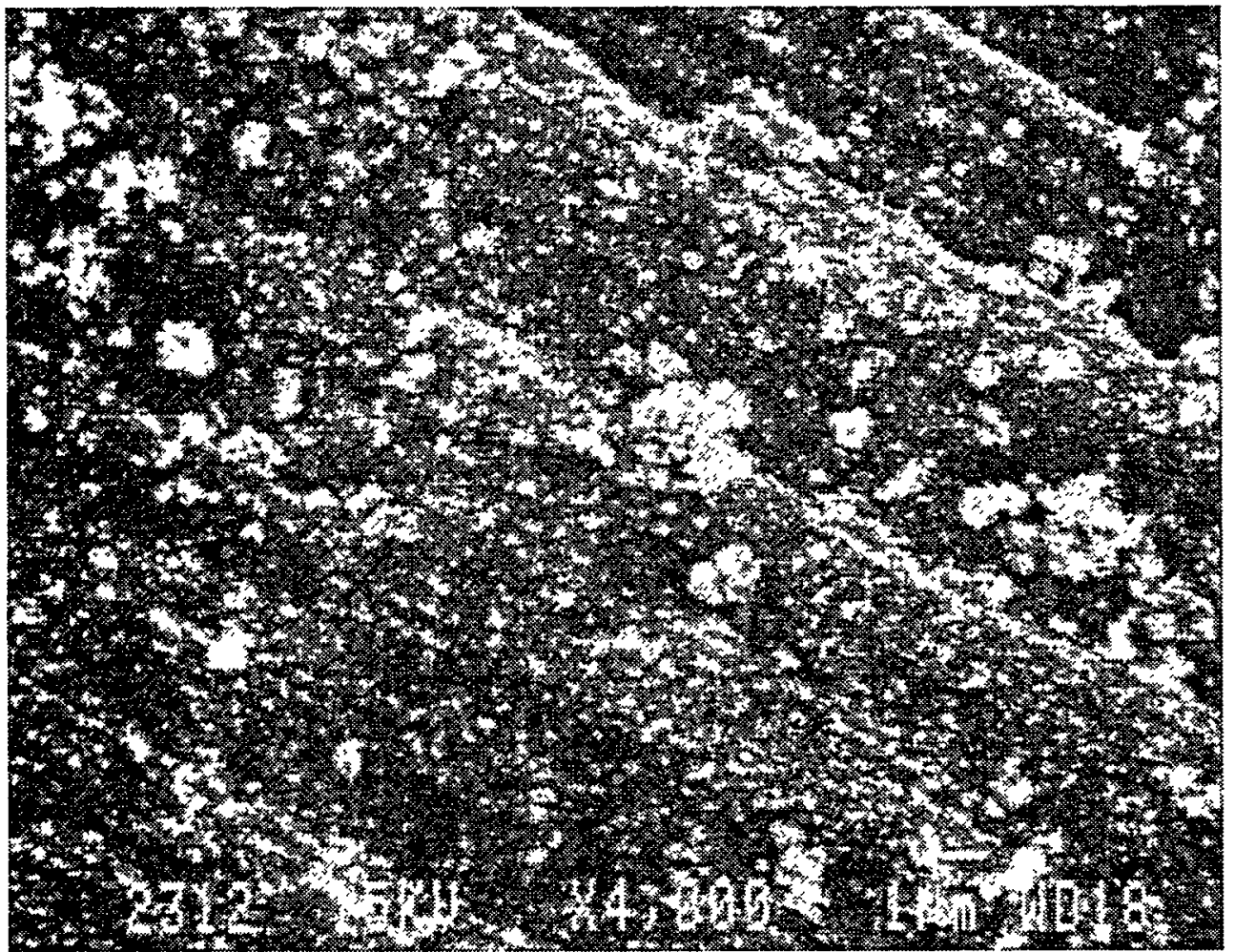

Figure 10. Electron micrographs of the surface of a Stellite 6 specimen after 11 days exposure to an anodic current density of $0.15 \mathrm{~mA} / \mathrm{cm}^{2}$. 


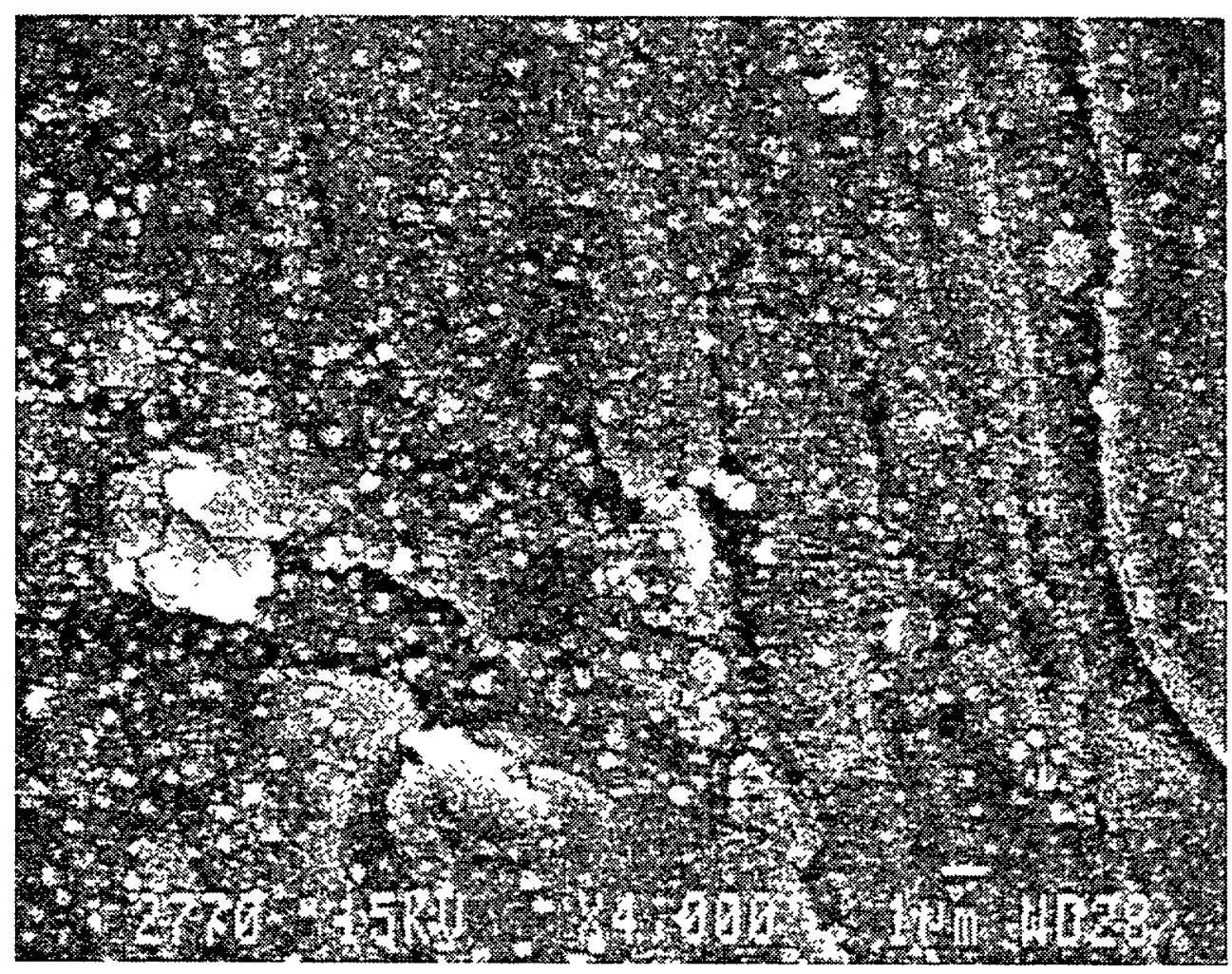

$\mathbf{X} 4,000$

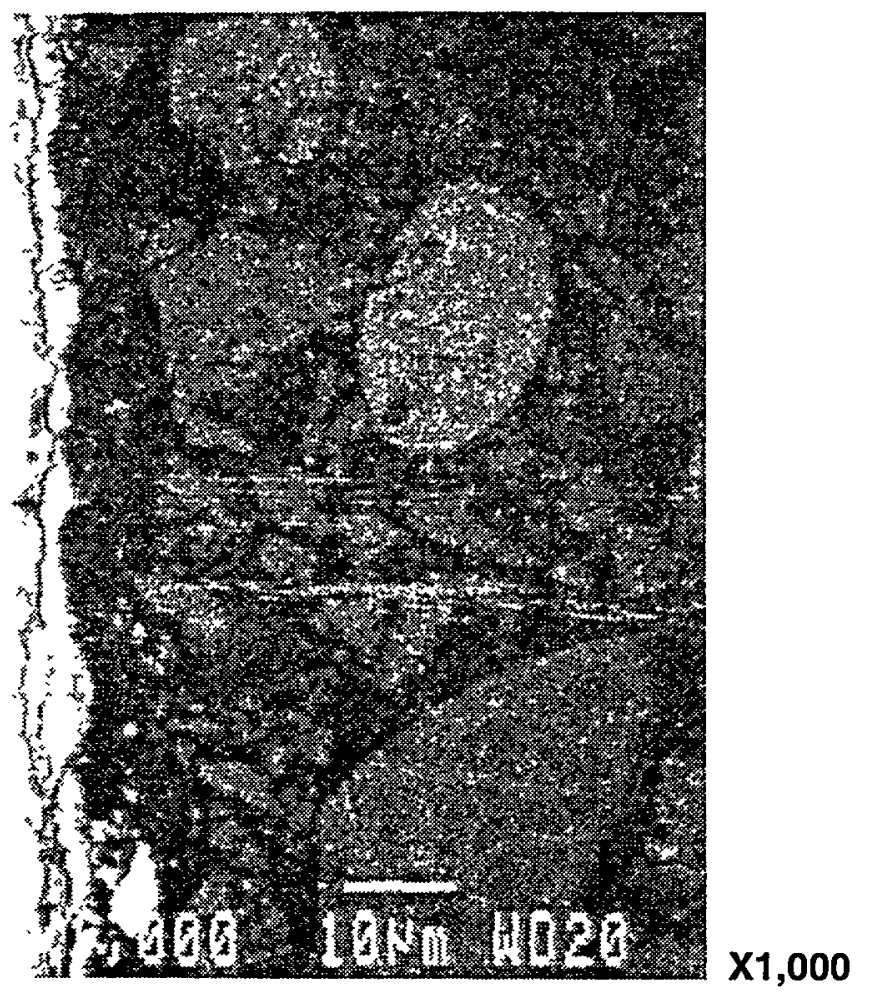

Figure 11. Electron micrographs of the surface and cross section of a Stellite 6 specimen after 14 days exposure to an anodic current density of $0.35 \mathrm{~mA} / \mathrm{cm}^{2}$. 
sample preparation, and the oxide film is the thick line separating the two. The thickness of the oxide film is determined by measuring the apparent film thickness on this magnified image of the cross section. (Film thickness is discussed in more detail later in the report.) We also observed that this oxide film was cracked in several locations both parallel and perpendicular to the alloy surface.

The surface morphology from the accelerated high-pH aging test is shown in Figure 12. The large crystals apparent here were identified as zirconium dioxide $\left(\mathrm{ZrO}_{2}\right)$. The apparent source of the $\mathrm{ZrO}_{2}$ was the specimen rack in the corrosion autoclave. We infer that the high $\mathrm{pH}(9.0)$ in this test either corroded the zirconium specimen rack or encouraged $\mathrm{ZrO}_{2}$ in the coating to dissolve in the water, and that the $\mathrm{ZrO}_{2}$ then precipitated on available surfaces when the water was cooled at the end of the test. These large crystals, which resided only at the surface of the film, were removed by cleaning the specimen with isopropyl alcohol. Smaller crystals remained. Figure 13 shows the specimen after cleaning, at two different magnifications. The appearance of the small crystals contrasts significantly with the morphology of a natural aging oxide film, where the surface is typified by a more uniform coating. Energy Dispersive Spectroscopy (EDS) analysis of the large particle in the center of the frame of the lower photograph indicates that the crystals appear to be iron-rich and are most likely oxides.

Overall, the evaluation of the oxide film morphology showed that oxide films produced by accelerated aging via anodic current were rougher in surface structure than films produced by natural aging. Films produced by accelerated aging via high $\mathrm{pH}$ included the presence of metal/oxide crystals that are not present in films produced by natural aging. These differences are significant, and they cast doubt on the validity of using these aging acceleration methods to produce an oxide film with friction characteristics representative of oxide films occurring on Stellite 6 surfaces in BWR systems.

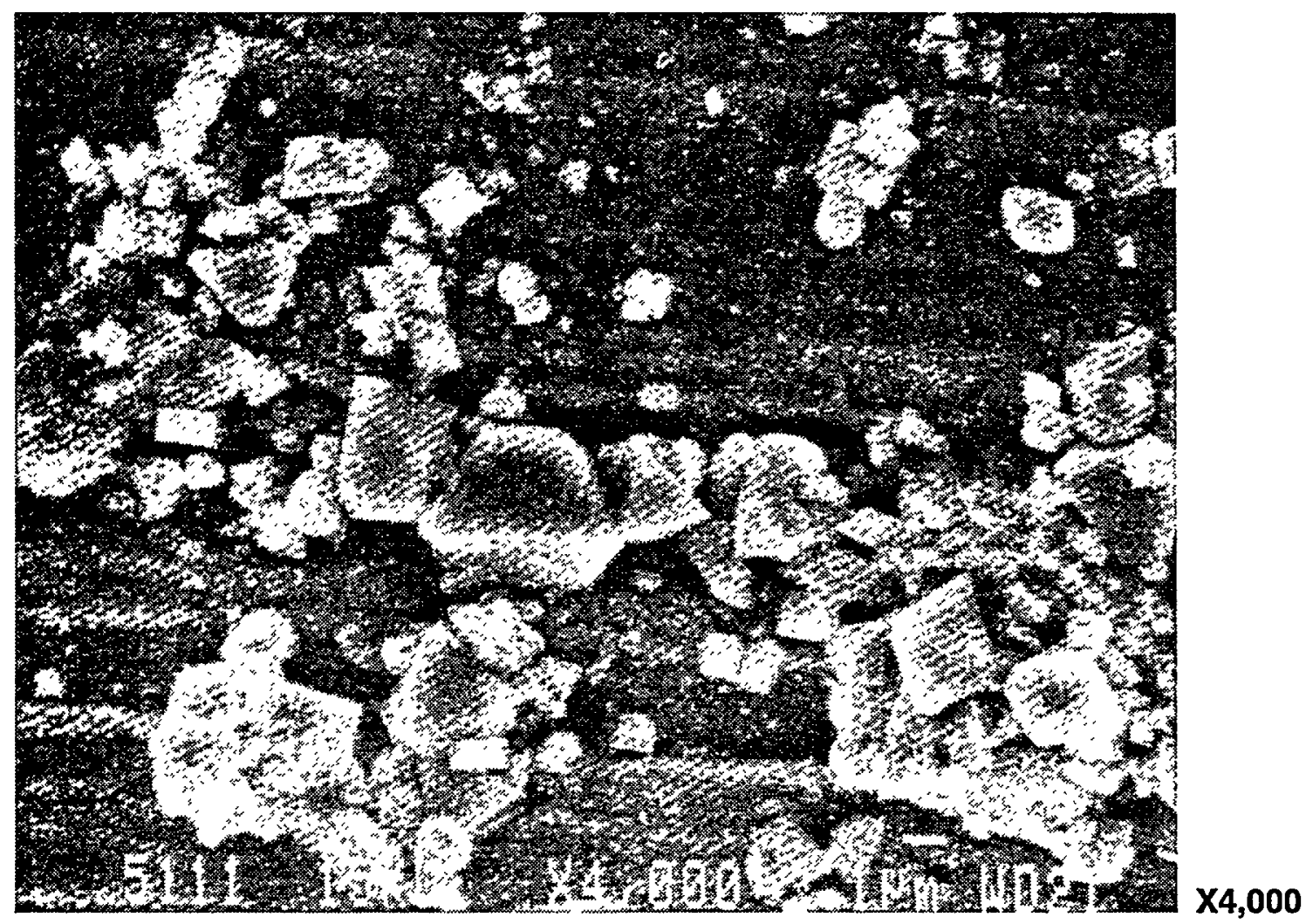

Figure 12. Electron micrograph of the surface of a Stellite 6 specimen after 19 days exposure to high-pH conditions; the large, zirconium-rich crystals are conspicuous. 


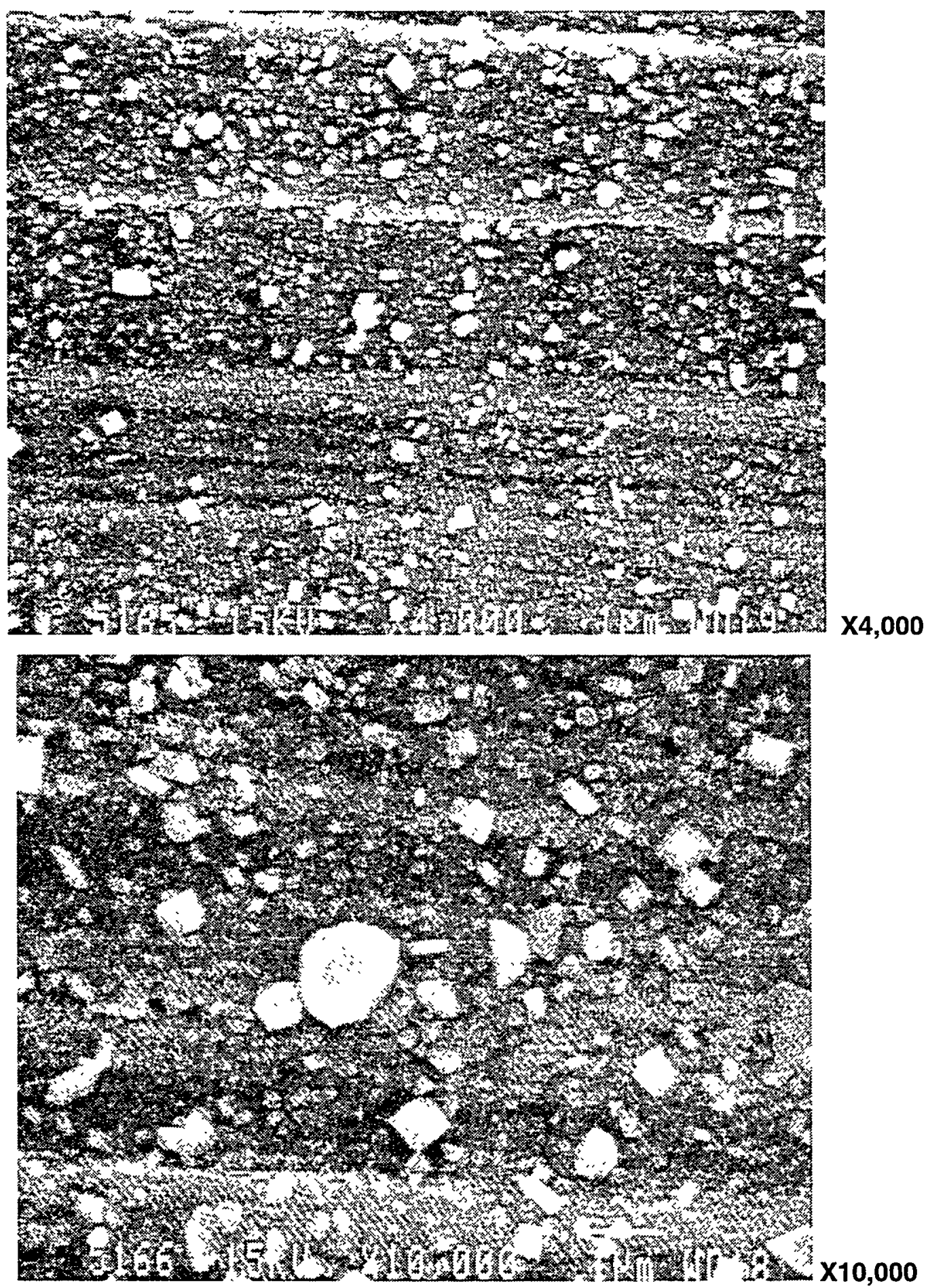

Figure 13. Electron micrographs of the surface of a Stellite 6 specimen after 19 days exposure to high$\mathrm{pH}$ conditions; the zirconium-rich crystals have been removed, but iron-rich crystals remain. 


\subsection{Composition}

Figure 14 shows an AES depth profile of the oxide film after 20 days exposure to natural aging conditions. As shown in the figure, the chromium concentration is almost constant, whereas the cobalt concentration rapidly rises between 1000 and $2000 \AA$. [One Angstrom $(\AA)$ equals one ten-millionth $\left(10^{-7}\right)$ of a millimeter.]

Specimens from the 2-, 10-, 20-, 25-, 40-, 50-, and 78-day natural aging tests were analyzed using XPS. Figures 15 through 19 show the elemental concentrations for selected species in atomic percent, plotted against sputtering time (which corresponds with depth, although the conversion between sputtering time and depth is not the same for each figure) for the 10-, 20-, 25-, 40-, and 78-day tests. (The 2-day specimen was also analyzed, but due to an equipment malfunction the plot is not available.)

Figures 20 through 24 show similar information, but organized differently. In these figures, the concentration of a given species for the 10-, 20-, 25-, 40-, and 78-day testing is shown on the same figure. The 10-, 20-, and 40-day specimens were from the testing identified earlier in this report as the third set of tests, and the 25- and 78-day specimens were from the fourth set of tests. The only species presented in these figures are cobalt, cobalt oxide, chromium, chromium oxide, and oxygen. Although other species are present in small quantities, only these five are discussed; as such, the totals for these five species at any given sputtering time add up to $100 \%$. These figures reveal several interesting trends. For instance, the concentration of cobalt at the surface of the oxide film, either as free cobalt or as a cobalt oxide, is very low. Deeper into the oxide film the concentration of cobalt increases until it reaches a relatively stable concentration of 35 to $45 \%$ at depths below the oxide film. This depletion of the cobalt at the surface of the Stellite 6 is an indication that the cobalt has leached out of the oxide film and into the coolant. The distribution of chromium is very different. The concentration of chromium throughout the oxide film is relatively constant at about $40 \%$. Below the oxide film, the chromium is free, whereas within the oxide film it primarily appears as a chromium oxide.

For all the natural aging specimens, the oxide film is low in cobalt and high in chromium. Although the concentration profiles of cobalt, cobalt oxide, and chromium are relatively consistent from specimen to specimen, the concentration profiles of chromium oxide and oxygen show subtle differences for two of the specimens, compared to the other three. The concentration of the chromium oxides at the surface of the oxide film from the fourth set of tests (the 25 -day and 78-day specimens) is $5 \%$ or less. However, the concentration of the chromium oxides at the surface of the oxide film from the third set of tests (the 10-day, 20-day, and 40-day specimens) is 20 to $30 \%$. The concentration of oxygen at the surface of the oxide film shows similar differences. For the fourth test series, the oxygen concentration is about $90 \%$ at the surface, whereas for the third test series the oxygen concentration is 70 to $80 \%$ at the surface. We wonder if these differences can be attributed to differences in the two corrosion autoclaves that produced the oxide films on the specimens.

The oxide films of two of these specimens (a 10-day and a 50-day specimen) were also analyzed at NIST using an Atomic Force Microscope and X-ray diffraction. The results indicate that the surface of the oxide film contains crystalline solids within an amorphous substrate. This type of surface can be likened to the surface of a piece of sandpaper in which the grains on the sandpaper are analogous to the crystalline solids. As the surface of the Stellite 6 ages, the crystals become larger, similar to a piece of sandpaper with larger grains on it. The composition of the crystalline solids was not determined, but we expect them to be chromium oxide, cobalt oxides, or carbides. Such crystalline solids are, in general, very abrasive. When two such surfaces are placed against each other and one moved relative to the other, the friction can be quite high, especially during the first stroke. With subsequent stroking, the crystalline solids will either plastically deform or fracture as the two surfaces pass each other. As such, the friction would be expected to decrease with continued stroking until the friction of the bulk Stellite 6 material is 


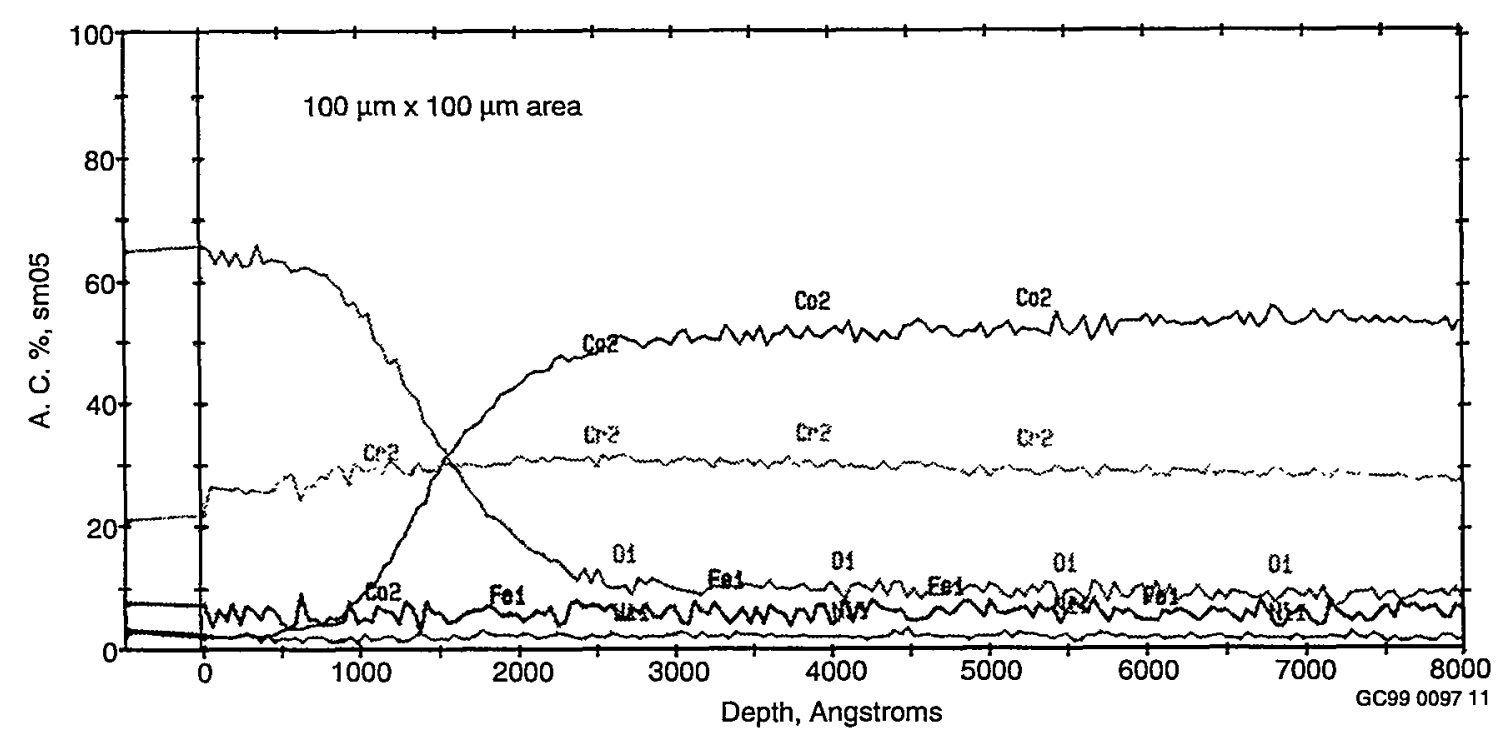

Figure 14. AES depth profile for Stellite 6 after 20 days exposure to natural aging conditions.

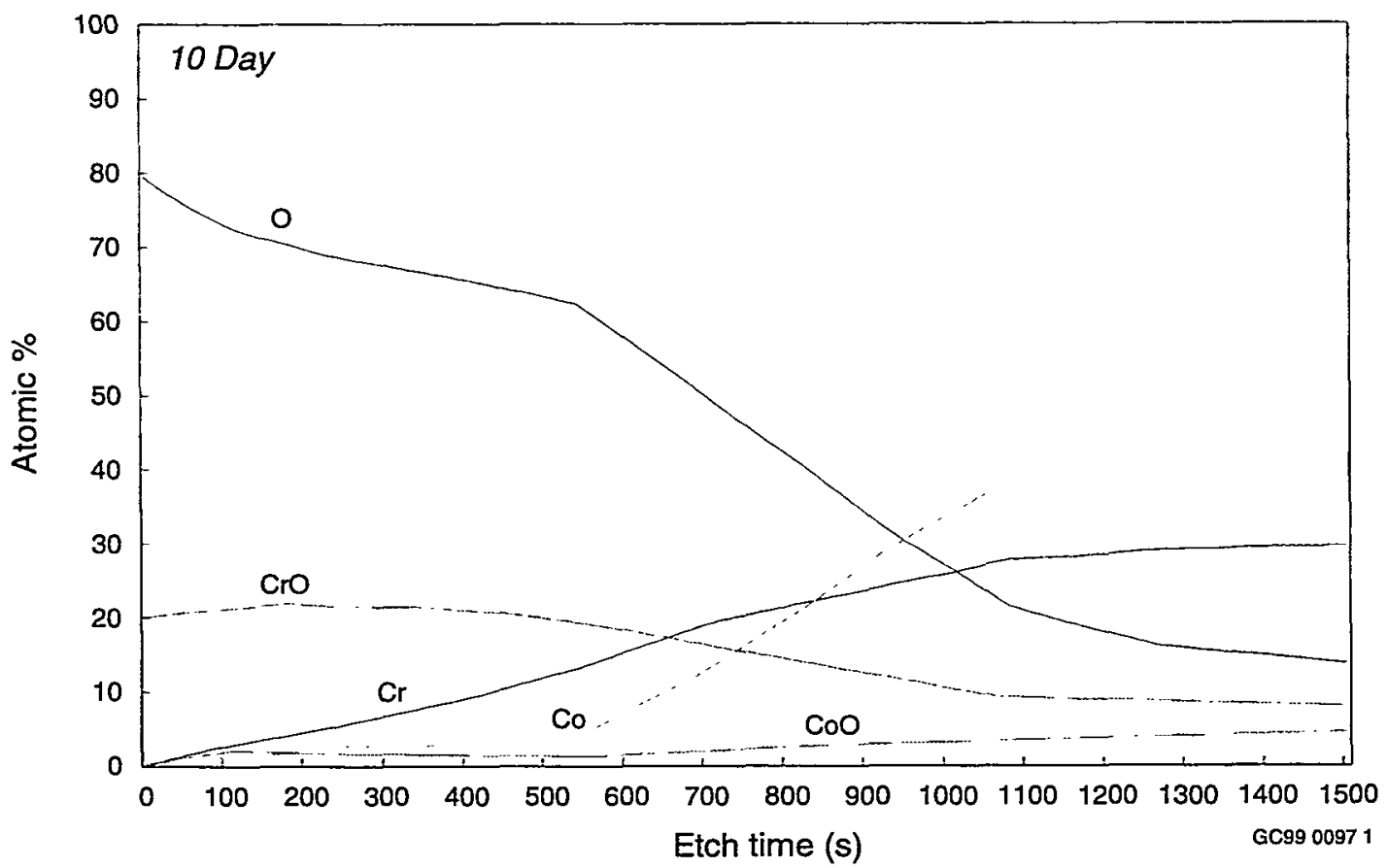

Figure 15. XPS depth profile for Stellite 6 after 10 days exposure to natural aging conditions.

reached. This would be comparable to two pieces of sandpaper rubbing against each other. During the first stroke, the surface grains are intact and offer the most resistance. As the surface grains are fractured, the resistance decreases until eventually just the two pieces of paper backing are rubbing against each other. The friction behavior of the oxide films is discussed in more detail later in the report. 


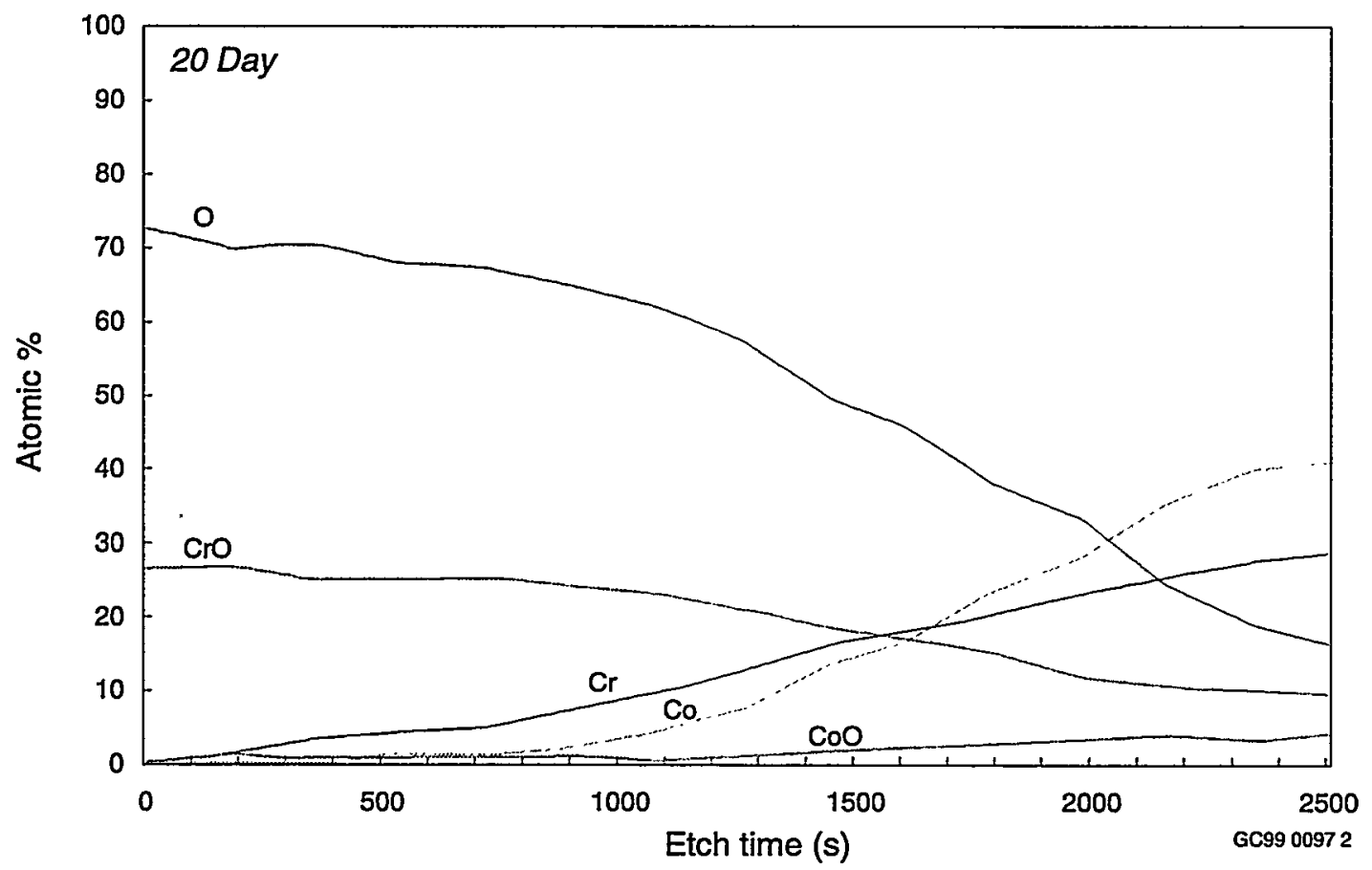

Figure 16. XPS depth profile for Stellite 6 after 20 days exposure to natural aging conditions.

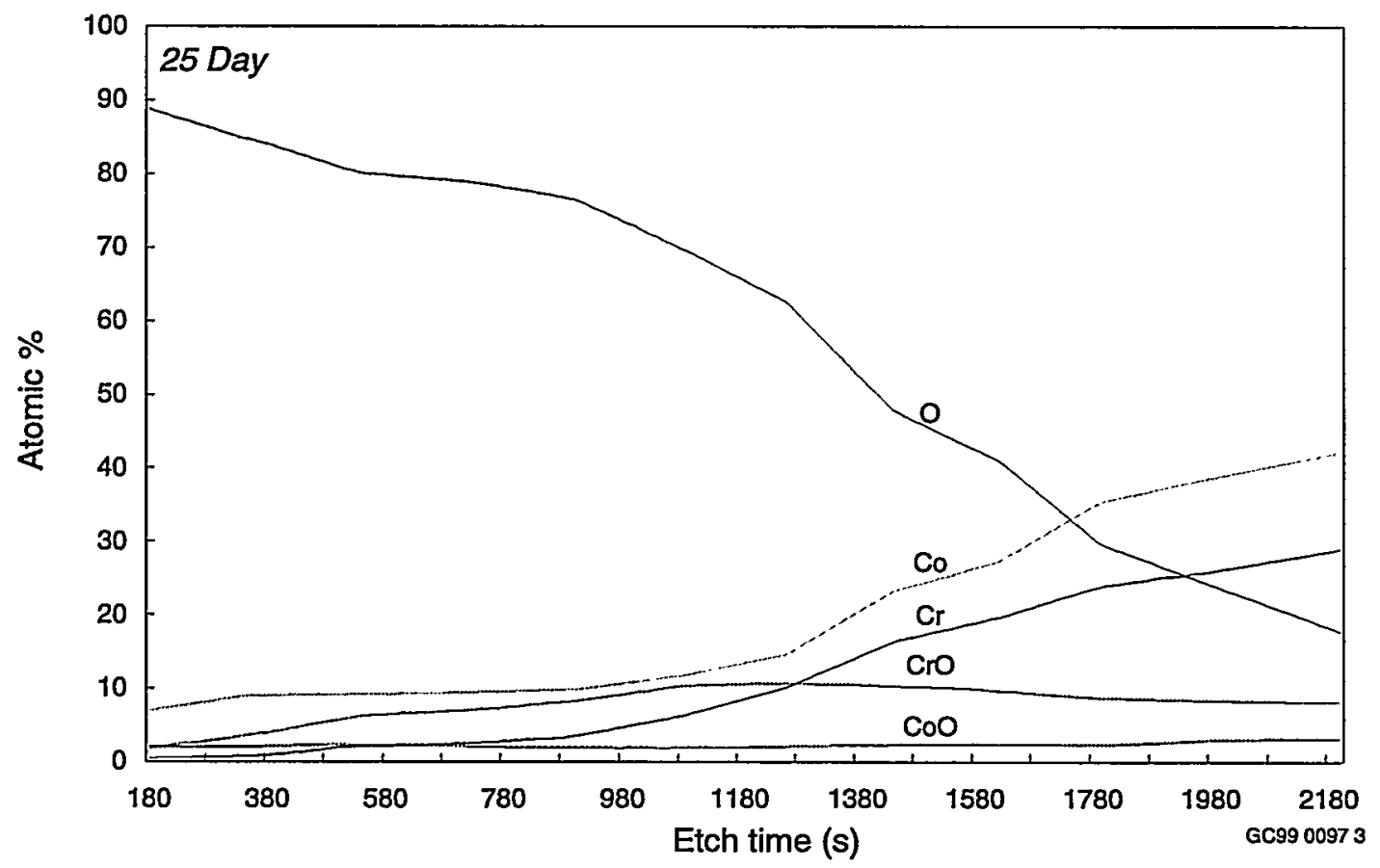

Figure 17. XPS depth profile for Stellite 6 after 25 days exposure to natural aging conditions. 


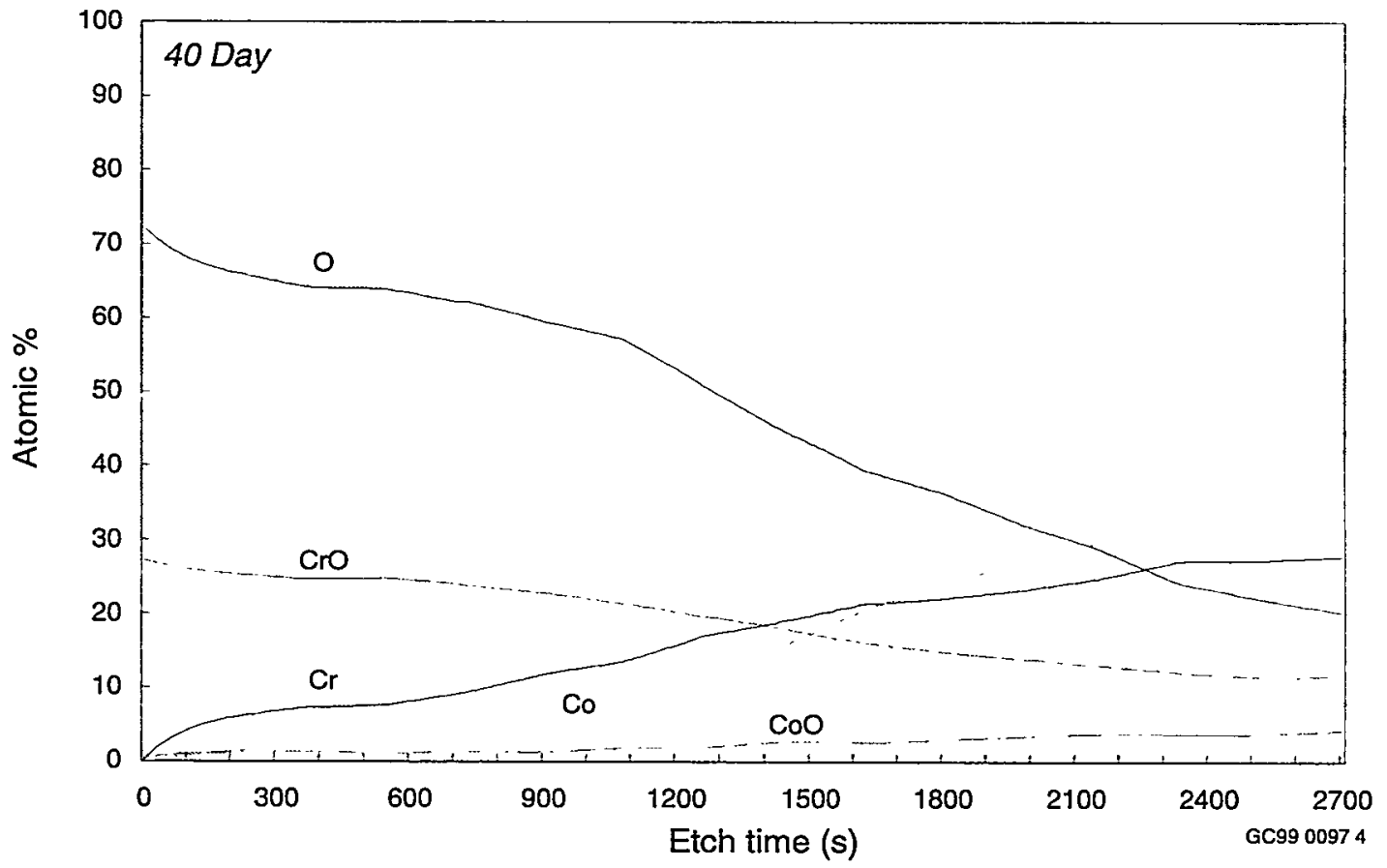

Figure 18. XPS depth profile for Stellite 6 after 40 days exposure to natural aging conditions.

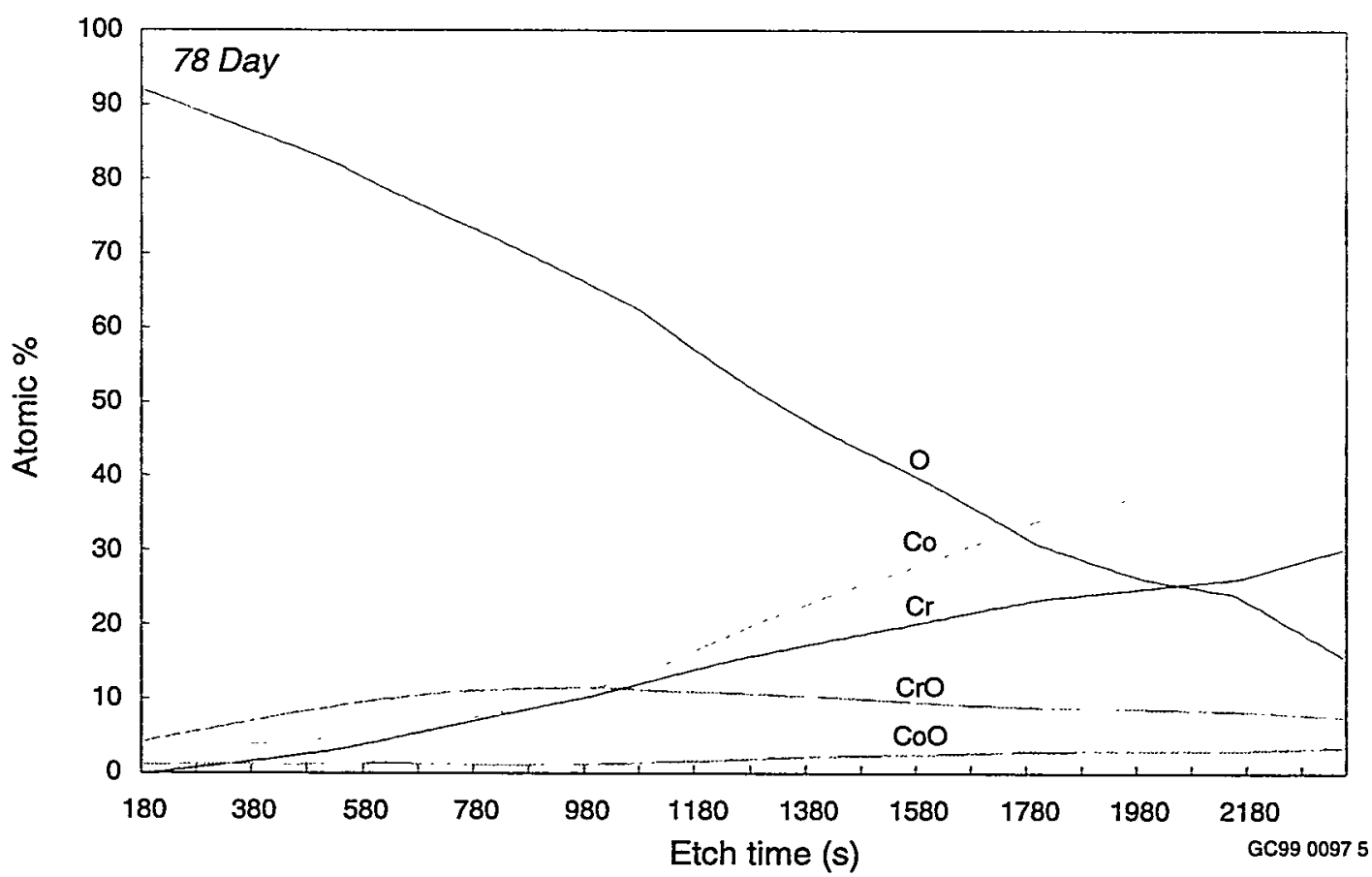

Figure 19. XPS depth profile for Stellite 6 after 78 days exposure to natural aging conditions. 


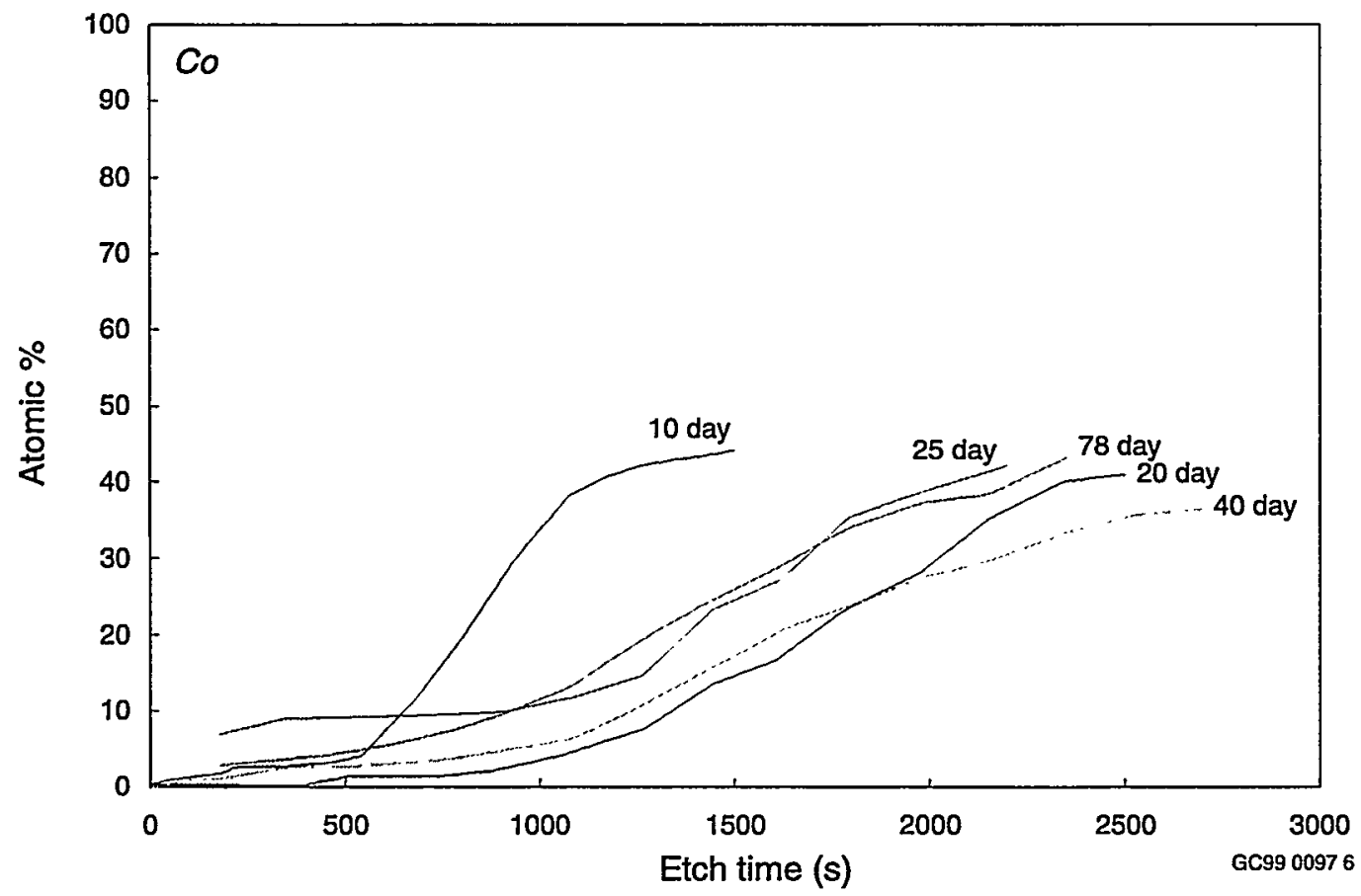

Figure 20. XPS depth profile of the cobalt in Stellite 6 specimens exposed to natural aging conditions.

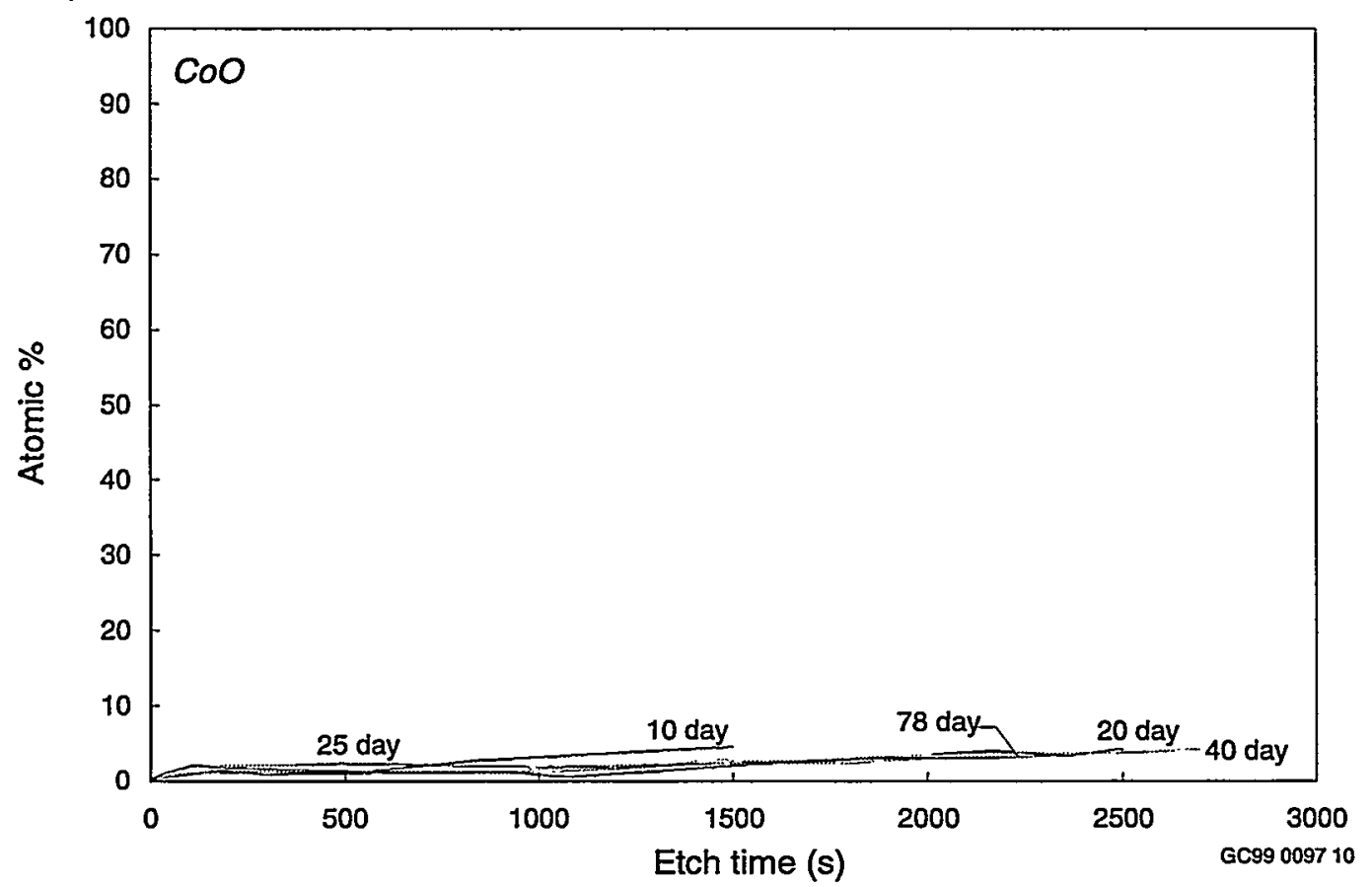

Figure 21. XPS depth profile of the cobalt oxide in Stellite 6 specimens exposed to natural aging conditions. 


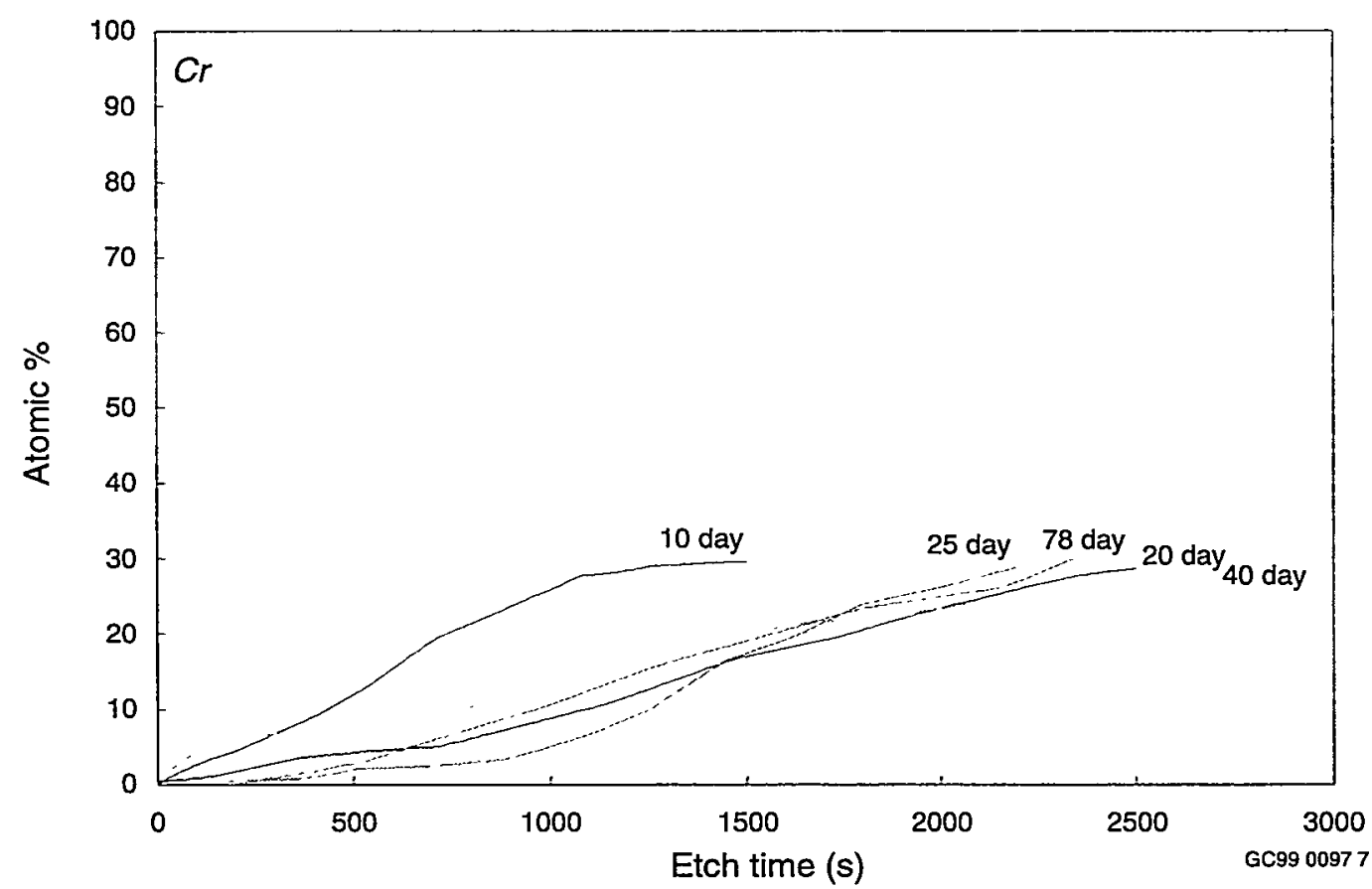

Figure 22. XPS depth profile of the chromium in Stellite 6 specimens exposed to natural aging conditions.

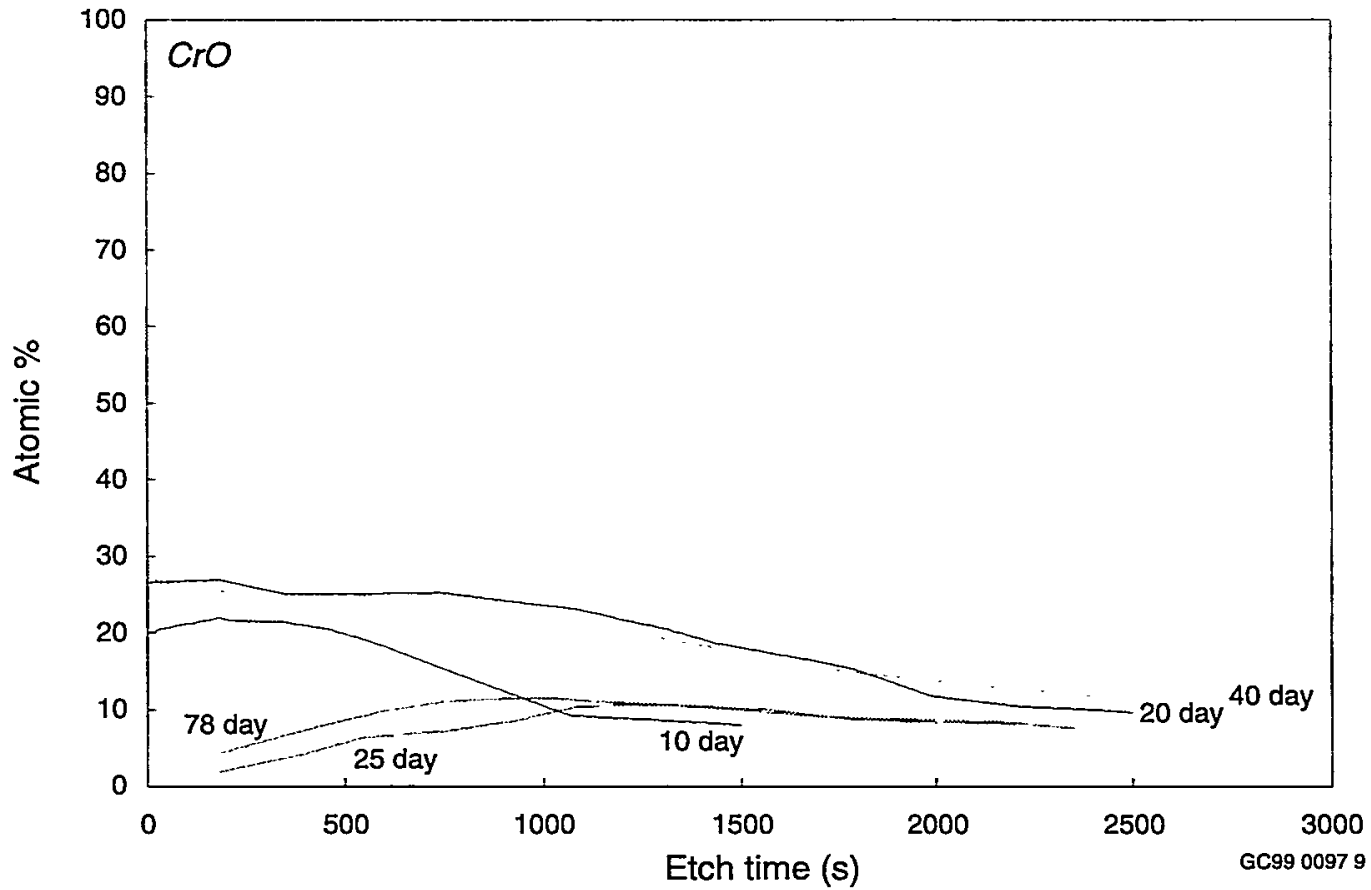

Figure 23. XPS depth profile of the chromium oxide in Stellite 6 specimens exposed to natural aging conditions. 


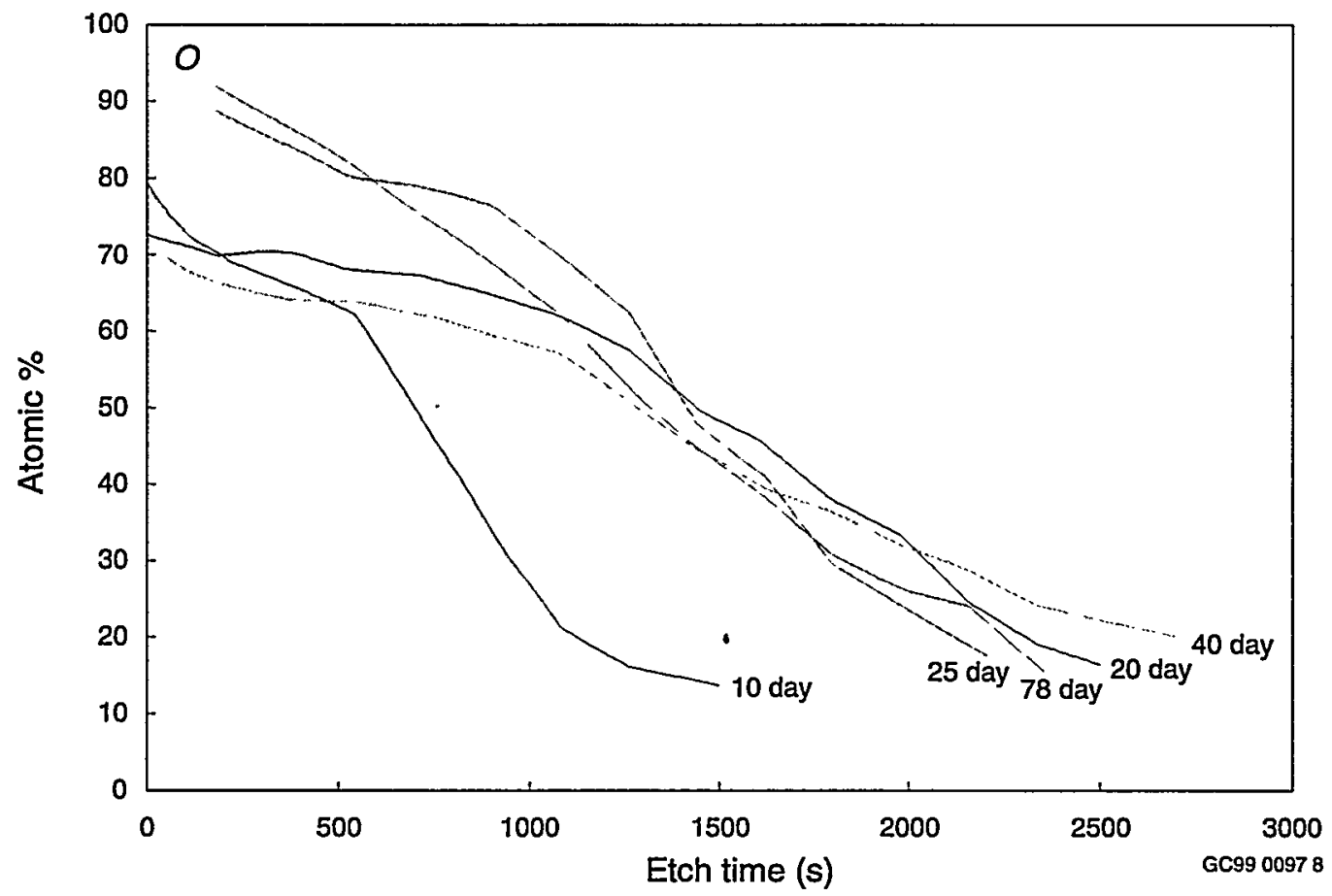

Figure 24. XPS depth profile of the oxygen in Stellite 6 specimens exposed to natural aging conditions.

Specimens from the natural aging tests that were subjected to simulated valve wedging cycles were also analyzed using XPS. Because the primary purpose of the XPS analysis was to determine the oxide film thickness, only the chromium and chromium oxide profiles were processed; detailed compositional profiles were not processed and plotted for all species.

Figure 25 shows the oxide film composition from a specimen subjected to accelerated aging using an anodic current. This is an AES depth profile for a Stellite 6 specimen exposed to a current density of $0.15 \mathrm{~mA} / \mathrm{cm}^{2}$ for 11 days. Compared to the oxide films from the natural aging, the oxide film for this specimen is lower in chromium, higher in iron, and much higher in cobalt. This result is typical of the films produced by aging accelerated using an anodic current.

Figure 26 shows the results of an XPS depth profile completed for a specimen subjected to accelerated aging with high $\mathrm{pH}$. This profile was obtained after cleaning the surface with isopropyl alcohol to remove the zirconium dioxide $\left(\mathrm{ZrO}_{2}\right)$ crystals. The presence of the $\mathrm{ZrO}_{2}$ crystals was confined to the surface, as no $\mathrm{ZrO}_{2}$ crystals were found in the XPS depth profile through the thickness of the film. The results show that the oxide film composition for the high-pH specimens is similar to the composition of the natural aging specimens. One difference in the results, a difference not shown in this figure, was the presence of iron and iron oxide in the film. The iron was fairly evenly distributed through the film thickness; the iron oxide content was higher near the surface of the film and lower at greater depth.

Overall, the XPS and AES results indicate that accelerating the aging using an anodic current produces an oxide film that is much higher in cobalt, somewhat higher in iron, and somewhat lower in chromium, as compared to oxide films developed using natural aging conditions. Accelerating the aging using a high fluid $\mathrm{pH}$ produces an oxide film that contains iron oxide and a small amount of iron, as compared to virtually no iron or iron oxide in the films developed using natural aging conditions. These differences in composition cast doubt on the validity of using accelerated aging techniques to produce a representative oxide film; the differences in composition are likely to contribute to differences in friction characteristics. 


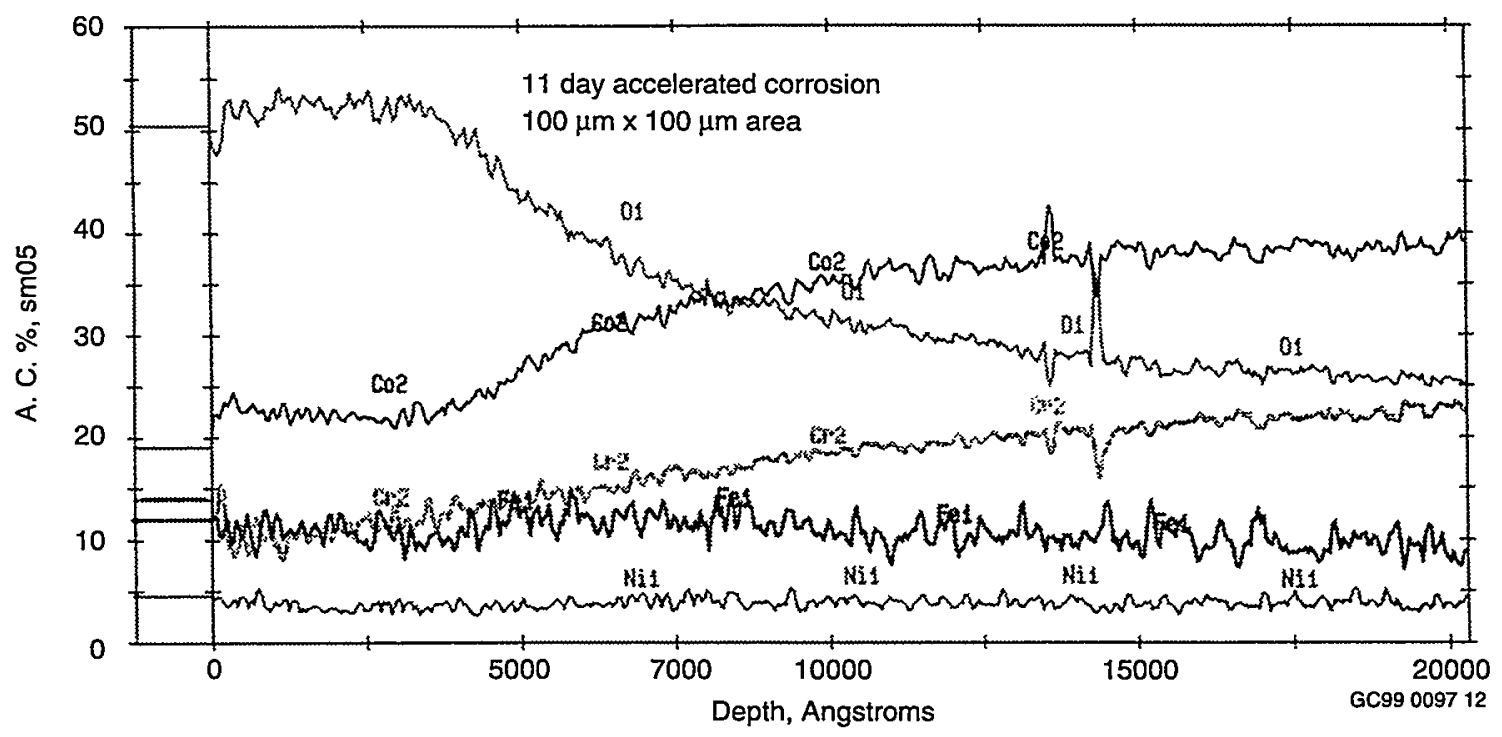

Figure 25. AES depth profile for Stellite 6 after 11 days exposure to an anodic current density of $0.15 \mathrm{~mA} / \mathrm{cm}^{2}$.

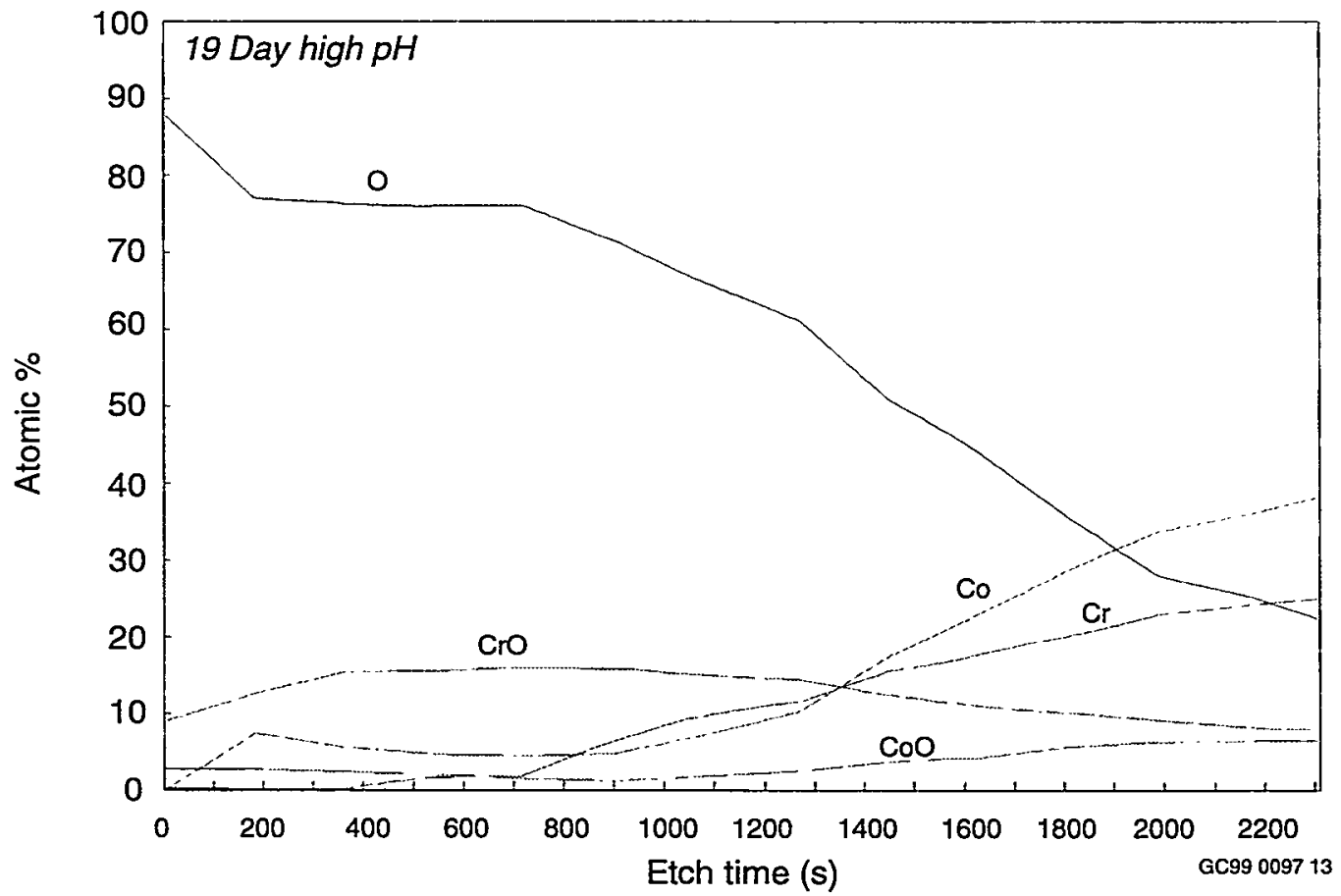

Figure 26. XPS depth profile for Stellite 6 after 19 days exposure to high-pH aging conditions.

\subsection{Film Thickness}

The thickness of the oxide film was determined two ways, by metallographic cross section and from XPS depth profiles. For consistency, only the XPS data are reported for the natural aging specimens and the high-pH specimens, because of the difficulty in resolving the film boundaries in the images from the scanning electron microscope (SEM). To remove as many uncertainties as possible, all the XPS data discussed here were taken from the same source. 
Tables 3 and 4 present a summary of the thickness of the oxide film for the naturally aged specimens. The data in Table 3 are from natural aging specimens that were not subjected to a surface load or deformation, whereas the data in Table 4 are from natural aging specimens that were subjected to simulated valve wedging cycles. For this research, the thickness was defined as the depth where the concentration of the chromium and the chromium oxide were equal in the XPS depth profiles. Other researchers have used this method to define the oxide film thickness, but it is not the only method being used. For instance, some researchers define the oxide film thickness as the point where the oxygen concentration within the oxide film is reduced to one half the oxygen concentration at the surface. For our needs, consistent use of a single method is more important than the selection of one method over another one. Each of these thicknesses is the result of examining the composition of the oxide film from a single specimen, so we have no way to estimate the statistical variation at each exposure time. We recognize, however, that the statistical variation might be large.

In addition, during the review performed at NIST, researchers there noticed differences in the concentration of the chromium oxide at the surface of the oxide film during the fourth test series compared with the third test series. These differences extend into the thickness of the oxide film, but are less significant with greater depth. Nonetheless, this variation in the chromium oxide concentration could influence the thickness estimates for the fourth test series, introducing uncertainties in addition to those discussed above. Because no statistically significant repeat testing was performed, it is difficult to assess the magnitude of the data uncertainty.

Table 3. Oxide film thickness on Stellite 6 exposed to natural aging; thicknesses are determined from XPS results.

\begin{tabular}{cc}
\hline $\begin{array}{c}\text { Time exposed to natural } \\
\text { aging conditions } \\
\text { (days) }\end{array}$ & $\begin{array}{c}\text { Oxide film } \\
\text { thickness } \\
(\AA)\end{array}$ \\
\hline 2 & $\mathrm{n} / \mathrm{a}$ \\
10 & 480 \\
20 & 1000 \\
25 & 1100 \\
40 & 1085 \\
50 & 1350 \\
78 & 1750 \\
\hline
\end{tabular}

Table 4. Oxide film thickness on Stellite 6 exposed to natural aging and simulated valve wedging loads; thicknesses are determined from XPS results.

\begin{tabular}{ll}
$\begin{array}{c}\text { Time exposed to natural } \\
\text { aging conditions } \\
\text { (days) }\end{array}$ & \multicolumn{1}{c}{$\begin{array}{c}\text { Oxide film } \\
\text { thickness } \\
(\AA)\end{array}$} \\
\hline 25 & 1100 \\
$25+\mathrm{IST}^{\mathrm{a}}$ & 750 \\
$25+\mathrm{IST}^{\mathrm{a}}+25$ & 1800 \\
$25+\mathrm{IST}^{\mathrm{a}}+25+\mathrm{IST}^{\mathrm{a}}$ & 1350 \\
\hline a. Simulated in-service test wedging cycles. & \\
\hline
\end{tabular}


Based on the oxide film thickness data obtained, the oxide film thickness versus time is plotted in Figure 27, along with a best fit of the data. These results indicate that the oxide film growth rate appears to be parabolic. By comparison, the work of Honda et al. (1987) investigated the oxide film growth characteristics of Type 304 Stainless Steel and of carbon steel. Figure 28 shows that the oxide film growth rate of Stellite 6 is slower than that of the Type 304 Stainless Steel and much slower than the growth rate of carbon steel. Although the thickness of the oxide film is continuing to increase, the ability to safely operate a valve is not necessarily based on the thickness or thinness of the oxide film. Rather, safe operation of a valve is dependent on the mechanical properties of the oxide film as it ages, specifically the coefficient of friction.

Work at Battelle Columbus included testing to determine whether the simulated valve wedging affected the oxide film thickness, and if so, how additional exposure to BWR conditions affects the subsequent growth of the oxide film. Figure 29 presents the results of this testing and shows the effect a simulated valve wedging cycle has on the long-term growth characteristics of the oxide film. The oxide film thickness before the in-service test wedging cycle (boxes) is compared to the oxide film thickness after an in-service test wedging cycle (inverted triangle); included for comparison is the data fit of the naturally aged, undisturbed oxide film thickness. The resulting film thicknesses after 25 days and after 50 days appear to follow the general thickness trend observed for specimens that were allowed to age without being disturbed.

The oxide film thicknesses for the accelerated anodic aging tests were determined from metallographic cross sections; an example is provided in Figure 11. The results are summarized in Table 5. The oxide films are much thicker than those formed under natural aging conditions.

Table 5. Oxide film thickness on Stellite 6 exposed to accelerated aging via an anodic current; the thicknesses are determined from an electron micrograph of the surface cross section.

\begin{tabular}{ll}
\hline \multicolumn{1}{c}{$\begin{array}{c}\text { Anodic polarization } \\
\text { conditions }\end{array}$} & $\begin{array}{c}\text { Oxide film } \\
\text { thickness } \\
(\AA)\end{array}$ \\
\hline $\begin{array}{l}11 \text { days @ } 0.15 \mathrm{~mA} / \mathrm{cm}^{2} \\
11 \text { days @ } 0.15 \mathrm{~mA} / \mathrm{cm}^{2} \text { followed } \\
\text { by } 2.5 \text { days @ } 0.19 \mathrm{~mA} / \mathrm{cm}^{2}\end{array}$ & 5000 to 10,000 \\
14 days @ $0.35 \mathrm{~mA} / \mathrm{cm}^{2}$ & 30,000 to 50,000 \\
\hline
\end{tabular}

The film thickness for an accelerated high-pH aging specimen was determined from the XPS plot in Figure 26 as the depth at which the chromium and chromium oxide concentrations were equal. The oxide film thickness as defined by this method is $1100 \AA$ for this 19 -day specimen, which is similar to that measured on the 20- to 40-day natural aging specimens. The similarities in the oxide film thicknesses indicate that increasing the $\mathrm{pH}$ of the water was not an effective method for accelerating the growth of the oxide film on the specimens.

Overall, the results show that accelerated aging using an anodic current was successful at producing a thicker oxide film in a shorter time, as compared with natural aging. Accelerated aging using high-pH water was not successful at accelerating the growth of the oxide film. The results also indicate that for natural aging conditions, the film thickness did not stabilize after 78 days of aging; rather, it continued to grow at a rate proportional to the square root of time. The review effort performed by NIST 


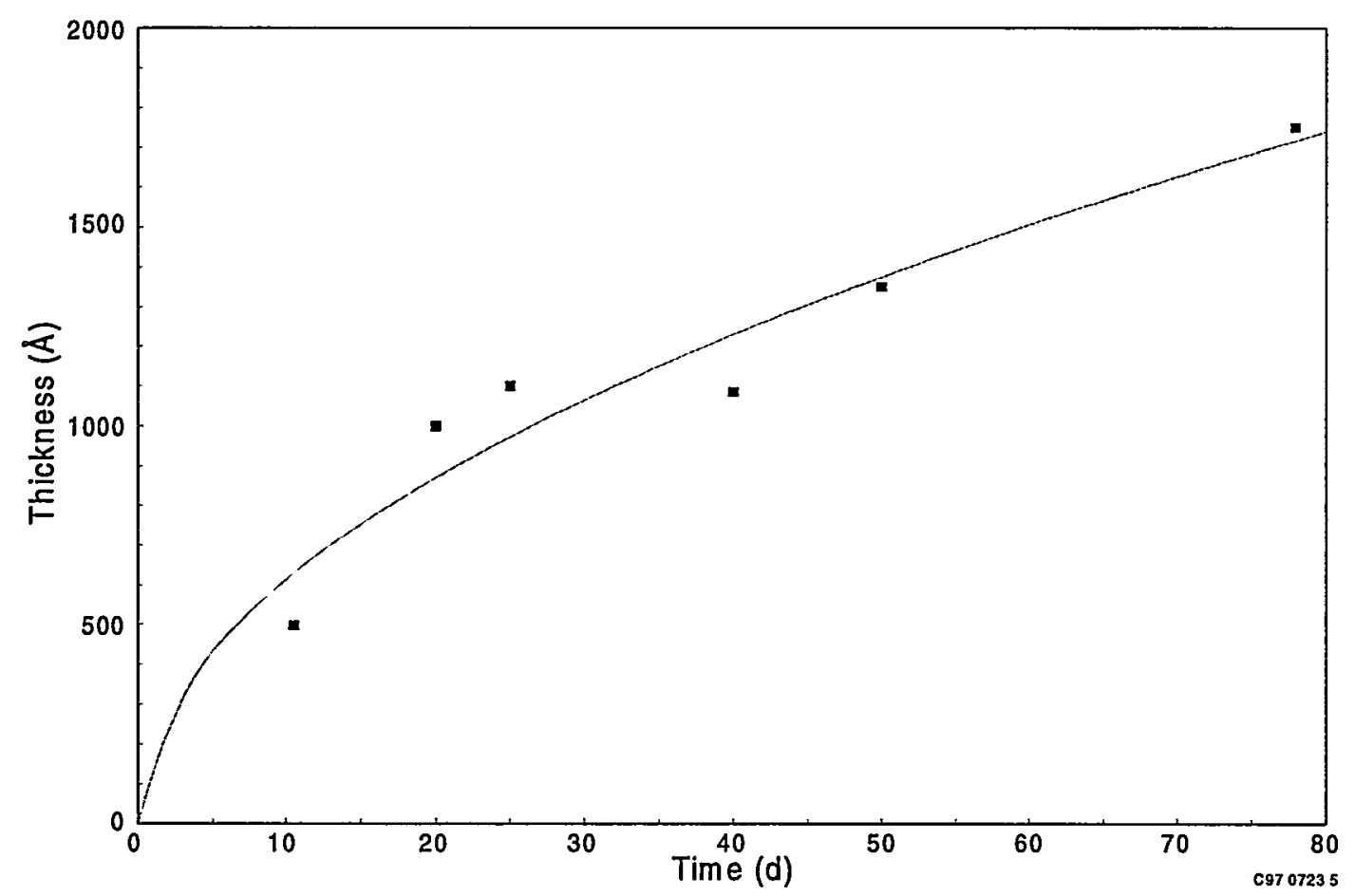

Figure 27. Oxide film thickness versus time for Stellite 6 , showing the data from the natural aging tests and the parabolic data fit.

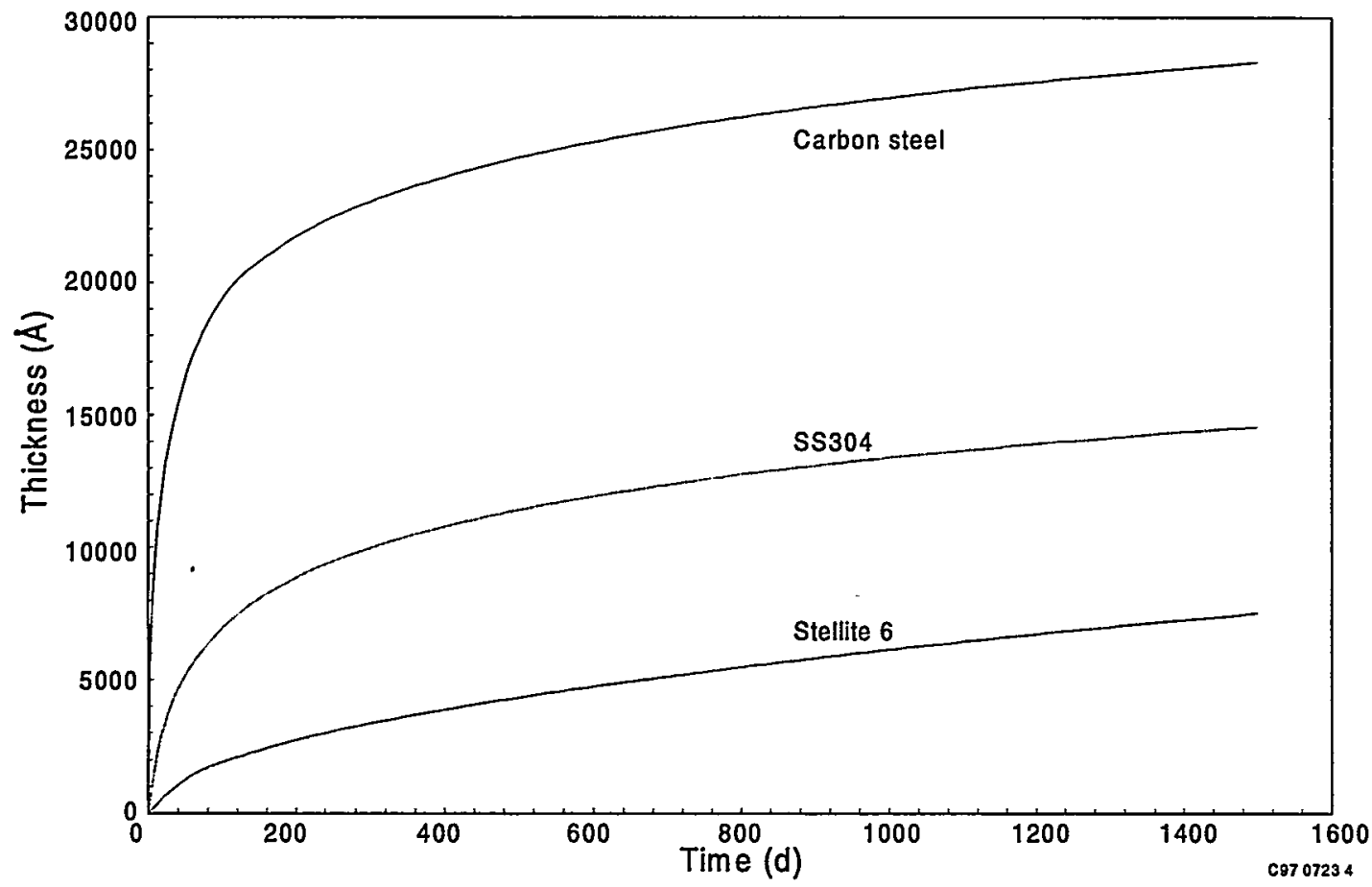

Figure 28. Oxide film thickness versus time for Stellite 6, Type 304 Stainless Steel, and a carbon steel. 


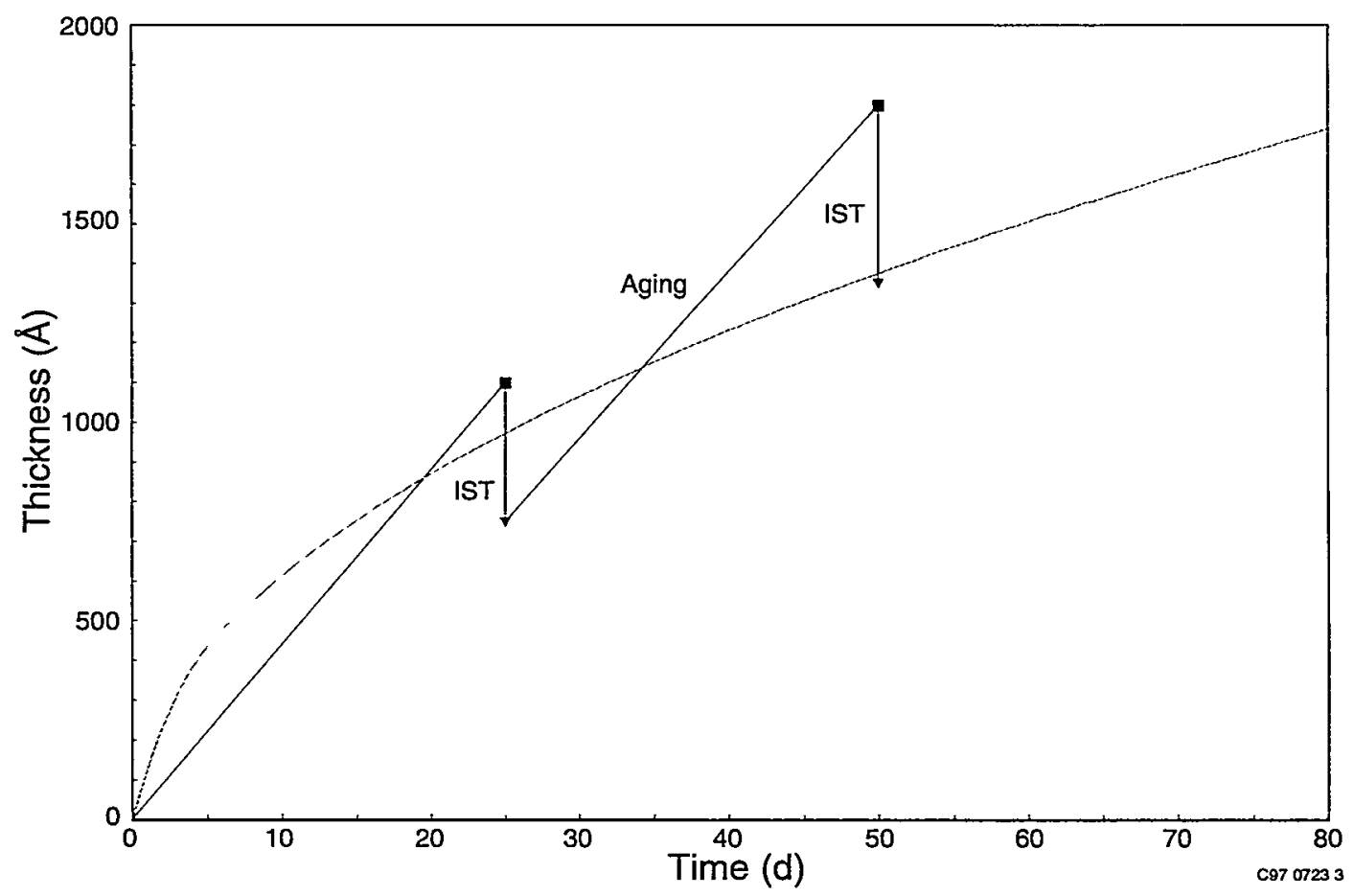

Figure 29. Oxide film thickness versus time for Stellite 6, showing the data from the simulated valve wedging tests and the parabolic data fit of the naturally aged tests.

supports the concept that the thickness of the oxide film will increase as a function of exposure time, although the growth rate may decrease over time. Even though the thickness of the oxide film continued to increase, the ability to safely operate a valve is not necessarily affected by the thickness or thinness of the oxide film, but rather on the mechanical properties of the oxide film as it ages. In particular, the friction of the oxide film as the material ages is of particular interest to assessing valve operability concerns.

\subsection{Accelerated Versus Natural Aging}

The results described here provide an indication of the difficulty that can be encountered in using accelerated aging techniques to grow oxide films typical of the composition and structure expected in a reactor environment. The accelerating techniques attempted in this test project suffer from either having no significant effect on the thickness of the oxide film, or from possible confounding effects on friction by altering the film composition or surface structure.

Specifically, the use of a small anodic current to accelerate the aging was successful in producing a thick film in a short time. However, the surface structure (the presence of nodules) and chemical composition (higher cobalt, lower chromium) of the film were significantly different than for films produced by natural aging. The use of high $\mathrm{pH}$ to accelerate the aging did not produce a thick film in a short time, and the surface structure (the presence of small iron-rich metal/oxide crystals) and chemical composition (presence of iron and iron oxide) were somewhat different than for films produced by natural aging. These differences, together with the corresponding differences in the friction results (reported in the next section of the report), indicated that these aging acceleration methods are not suitable for producing oxide films that are representative of films produced over longer periods of time under natural (normal BWR) conditions. 


\section{RESULTS OF FRICTION TESTS}

During the friction testing performed at Battelle Columbus, the force at the pull rod and the normal force applied by the bellows were continuously monitored so that a running trace representing the coefficient of friction was produced for the entire stroke. Examples of such traces are shown in Figure 30. In the following discussion, the results of the friction testing are presented in terms of the maximum and the nominal friction during each stroke. The maximum values are the highest value observed during the stroke and typically occur at the beginning of the stroke. The nominal values are the "eyeball" average during the sliding portion of the stroke.

Five sets of specimens subjected to natural aging conditions underwent friction testing. The aging times for these specimen sets were 2, 10, 20, 40, and 78 days. A photo of the 78-day specimens before and after friction testing is shown in Figure 31; other specimens were similar in appearance. A sixth specimen set was friction tested after being subjected to natural aging conditions combined with simulated valve wedging cycles representing typical in-service testing. These specimens were naturally aged for 78 days with a simulated valve wedging cycle at 25 days and again at 50 days. In addition, NIST also performed several friction tests as part of their review of the Stellite 6 testing. Specifically, 10-day and 50-day specimens (from the third set of tests) were subjected to friction testing at NIST. Unlike the friction testing performed in the high-temperature, high-pressure autoclave at Battelle Columbus, the testing at NIST was performed at ambient temperature and pressure. The purpose of this testing was to investigate whether the configuration of the specimens in the friction autoclave at Battelle Columbus was representative of the way the Stellite 6 surfaces in a valve interact, or whether the resulting friction values contained biases introduced by the friction test configuration.

Four sets of specimens subjected to accelerated anodic aging underwent friction testing. These specimens had been subjected to aging times of (a) 11 days at $0.15 \mathrm{~mA} / \mathrm{cm}^{2}$ (two sets of specimens), (b) 11 days at $0.15 \mathrm{~mA} / \mathrm{cm}^{2}$ followed by 2.5 days at $0.19 \mathrm{~mA} / \mathrm{cm}^{2}$, and (c) 14 days at $0.35 \mathrm{~mA} / \mathrm{cm}^{2}$. Two

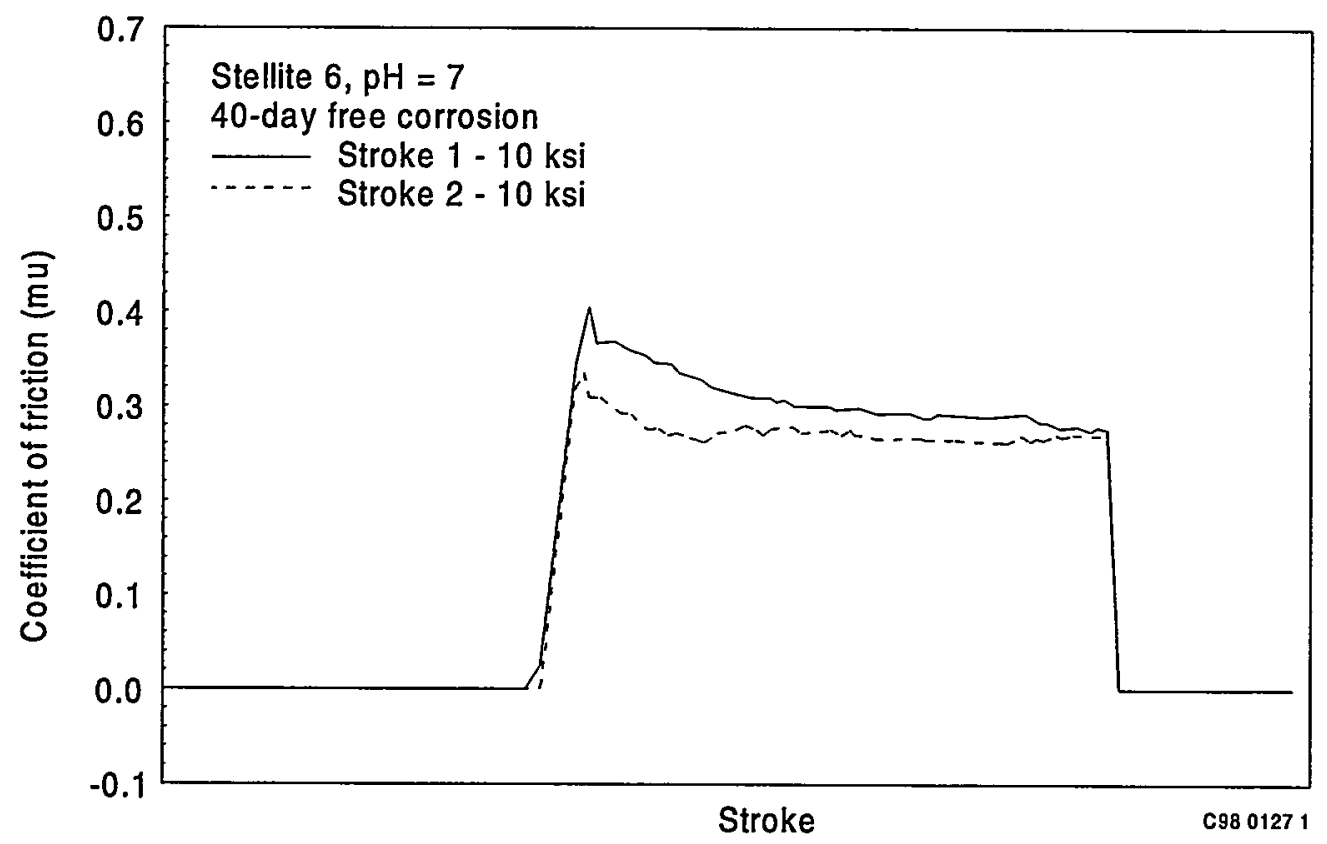

Figure 30. Typical friction traces from the friction testing of Stellite 6. 

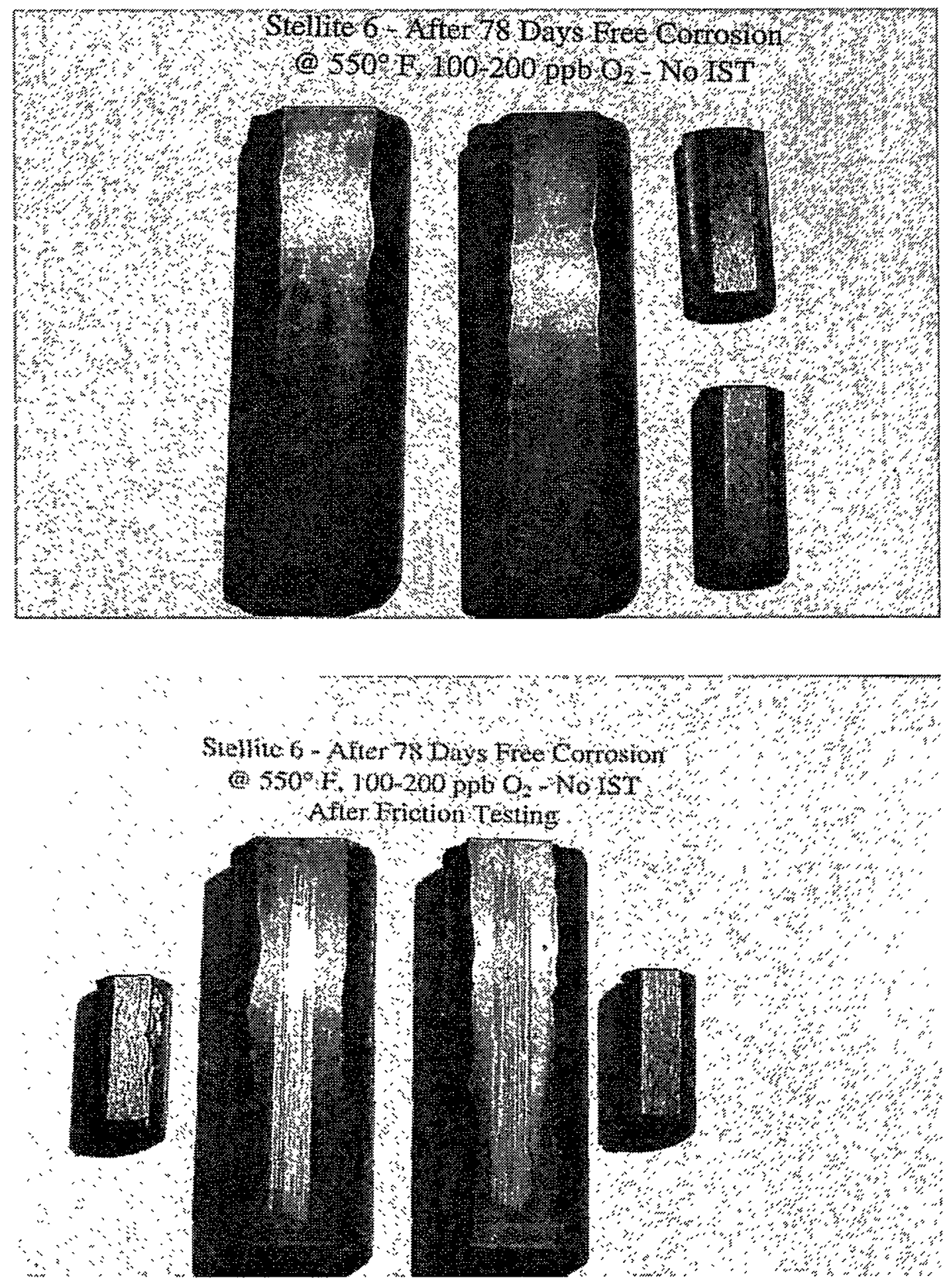

Figure 31. Photograph of 78-day natural aging Stellite 6 specimens before and after friction testing. 
sets of specimens subjected to accelerated high-pH aging (19 days) underwent friction testing. One set was tested with the zirconium-rich crystals present on the oxide film, and the other set was tested after the crystals had been removed (by cleaning with isopropyl alcohol). Iron-rich crystals remained in the oxide film after cleaning.

Testing of the 2-, 10-, 20-, and 40-day natural aging specimens showed that in general, both the nominal and the maximum coefficient of friction increased with aging time. The results also showed that the coefficient of friction during subsequent strokes was lower than in the first stroke, for a given specimen set and a given aging time (the friction coefficient typically stabilized after multiple strokes). This can be seen in Figure 32, in that the nominal coefficient of friction is much higher during the first two strokes than in the other strokes, and the maximum friction is much higher during the first six strokes than in the others.

Friction data for the specimens aged by the two acceleration methods are presented in Figure 33 . The results are discussed in more detail later in this section.

One set of specimens not subjected to any aging underwent friction testing. The data from this testing, combined with the data presented in Figures 32 and 33, are shown in Figure 34. This figure indicates the presence of friction coefficient "bands" that are characteristic of the three surface conditions: (a) unaged, (b) natural aging, and (c) accelerated aging (both anodic and high-pH). Compared with unaged specimens, the bands indicate an increase in friction coefficient of approximately 0.1 for the natural aging specimens, and an increase of 0.2 for the accelerated aging specimens. When moving from one surface condition to another, the bands can be thought of as being moved up or down. As such, the friction would change as an absolute value, not as a fixed percentage, which would distort the shape of the band. For example, the increase in the friction coefficient from 0.2 for condition (a) to 0.3 for condition (b) is simply an increase of 0.1 , and should not be regarded as an increase of $50 \%$. Likewise, the increase from 0.2 for condition (a) to 0.4 for condition (c) is simply an increase of 0.2 , and should not be regarded as a $100 \%$ increase in friction coefficient.

The highest maximum friction values (upper plot, Figure 34) for the first stroke on accelerated aging samples are from the high-pH specimens, not the anodic current specimens. The greatest overlap in the bands occurs with the maximum friction in the first stroke, where data from natural aging specimens with longer aging times overlap with data from anodic current specimens.

Overall, the results show that the chemical composition and morphology (presence of crystals or nodules) of the oxide film have a notable effect on the frictional behavior of the Stellite 6 specimens. Successive stroking also affects the frictional behavior. These variables are evaluated in the following discussion.

\subsection{Differences Due to Aging of the Surface}

Results from friction testing of the naturally aged specimens at Battelle Columbus are plotted versus aging time in Figure 35. This figure indicates an increasing trend in both the maximum and the nominal coefficient of friction during the first and second stroke as the specimens age. For the third and subsequent strokes, the maximum friction shows a continuing increase with longer aging time, whereas the nominal friction begins to stabilize after 40 days. The maximum aging time ( 78 days) for these tests is short compared with the many years a nuclear power plant is expected to operate. The short aging times used in these tests do not provide enough information to determine whether the friction coefficient increases indefinitely with longer aging times or whether the friction coefficient eventually reaches a stable plateau, at some as-yet unknown aging time or film thickness. 

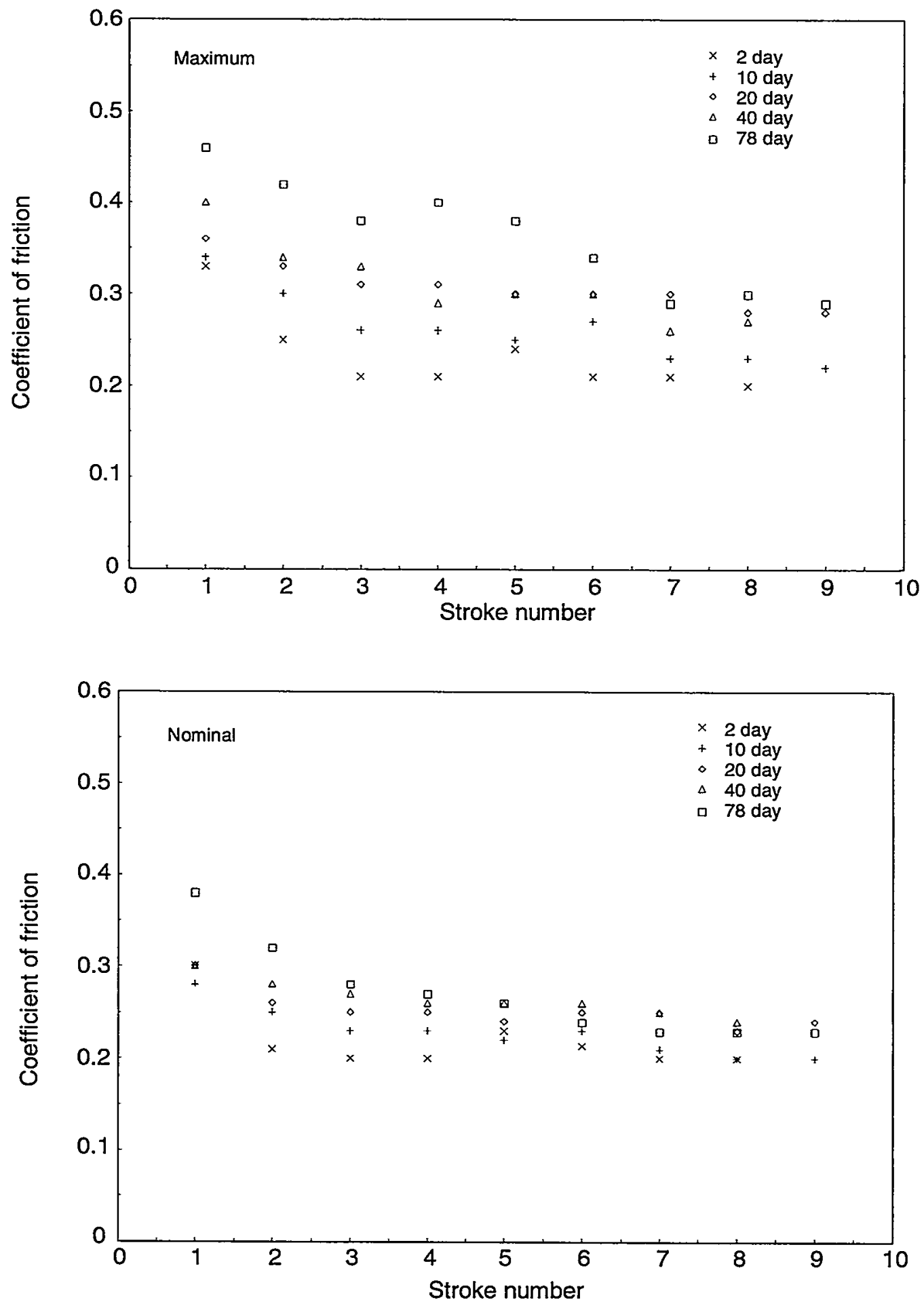

Figure 32. Coefficient of friction versus stroke for Stellite 6 specimens exposed to natural aging conditions; maximum values (top) and nominal values (bottom). 

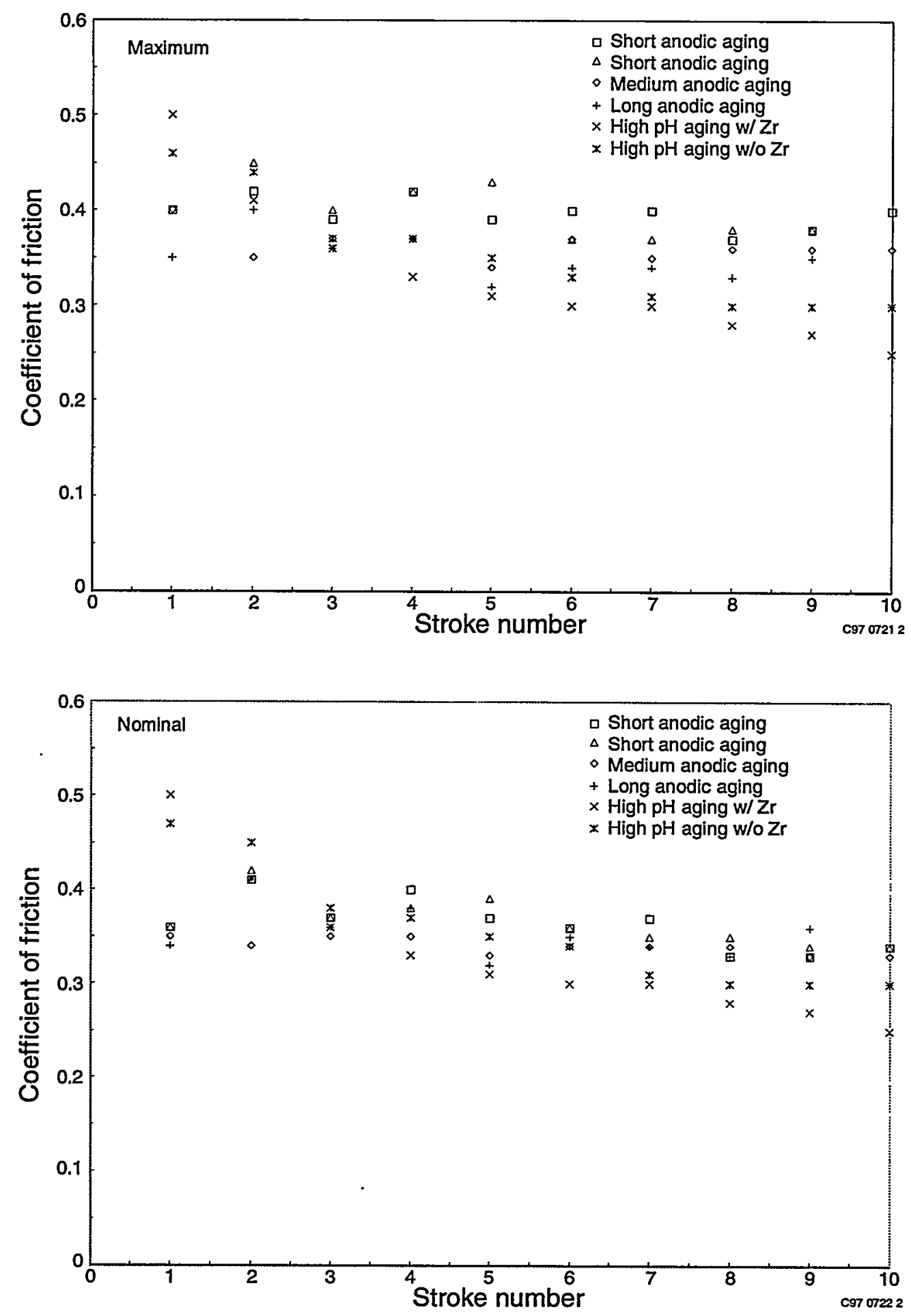

Figure 33. Coefficient of friction versus stroke for Stellite 6 specimens exposed to accelerated aging conditions; maximum values (top) and nominal values (bottom). 

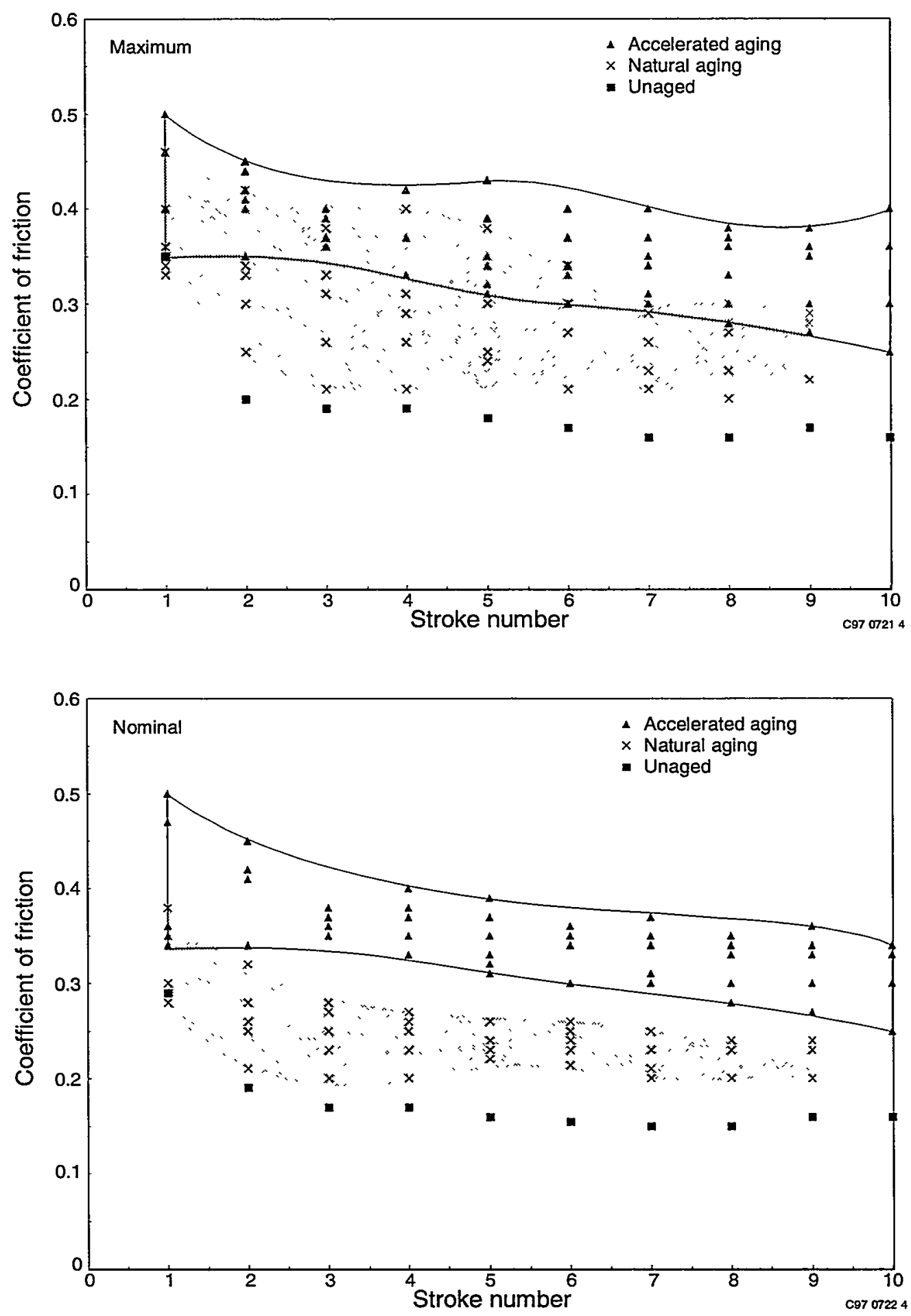

Figure 34. Coefficient of friction versus stroke for unaged and aged Stellite 6 specimens; maximum values (top) and nominal values (bottom). 

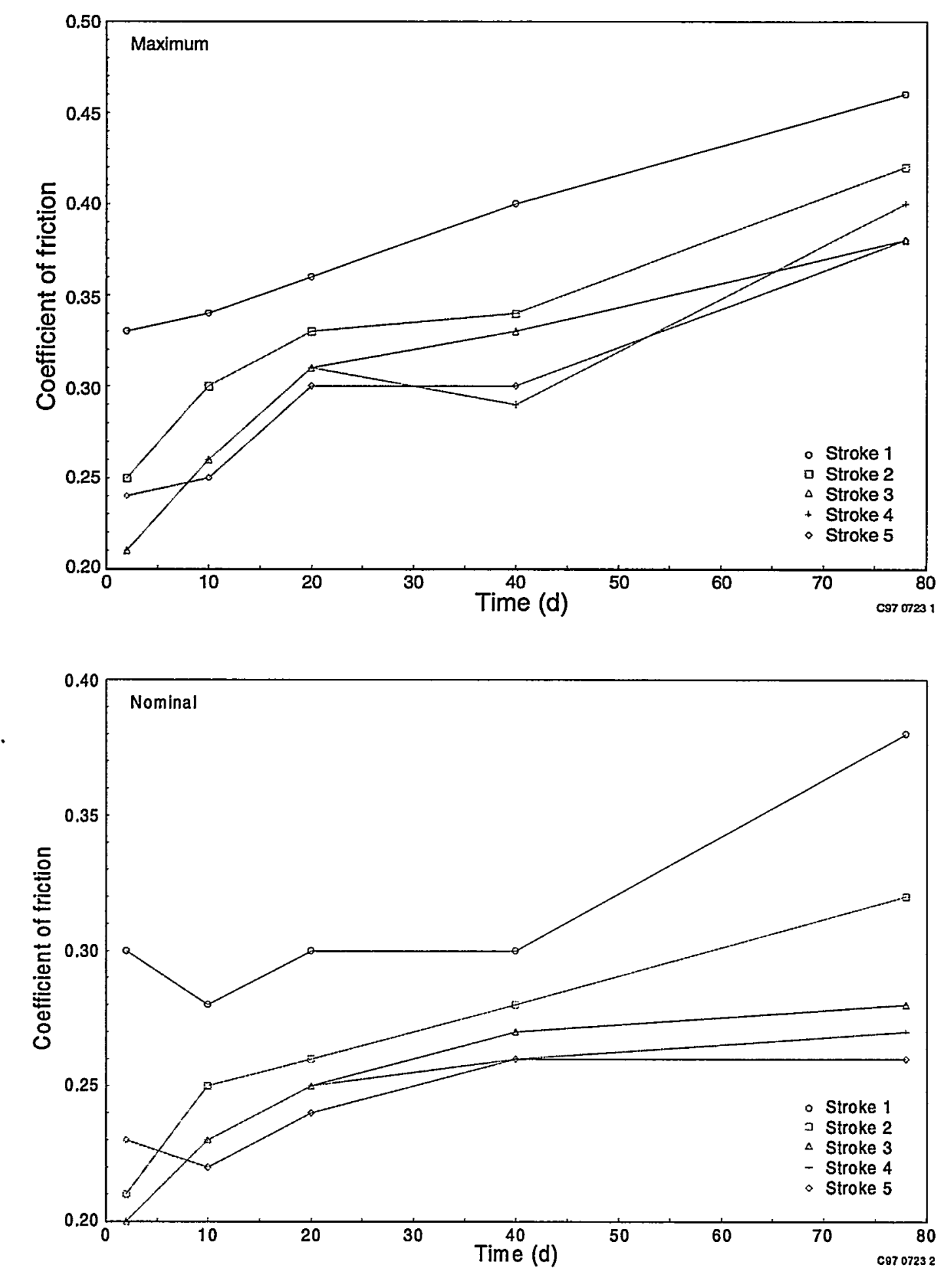

Figure 35. Coefficient of friction versus time for naturally aged Stellite 6 specimens; maximum values (top) and nominal values (bottom). 
Figure 36 shows the friction results from the accelerated aging (anodic current) specimens, plotted against film thickness, along with the data shown in Figure 35 for the naturally aged specimens. (Results from high-pH specimens are not included.) Because the structure and chemical composition of the oxide films produced by anodic acceleration are different from those produced by natural aging, these results are not specifically applicable to Stellite 6 surfaces aged under BWR conditions. However, the trend shown in these results is interesting, in that it shows an eventual plateau in the friction coefficient. Intuitively, we would expect the same kind of trend to eventually manifest with naturally aged Stellite 6, but again, available data are insufficient to confirm the existence of such a plateau or to identify the magnitude of the friction coefficient or the aging time at which it occurs. We have excluded numerical values from the vertical axis in Figure 36 as a reminder to the reader that numerical values of the friction coefficient in this comparison are not relevant to Stellite 6 surfaces in nuclear applications.

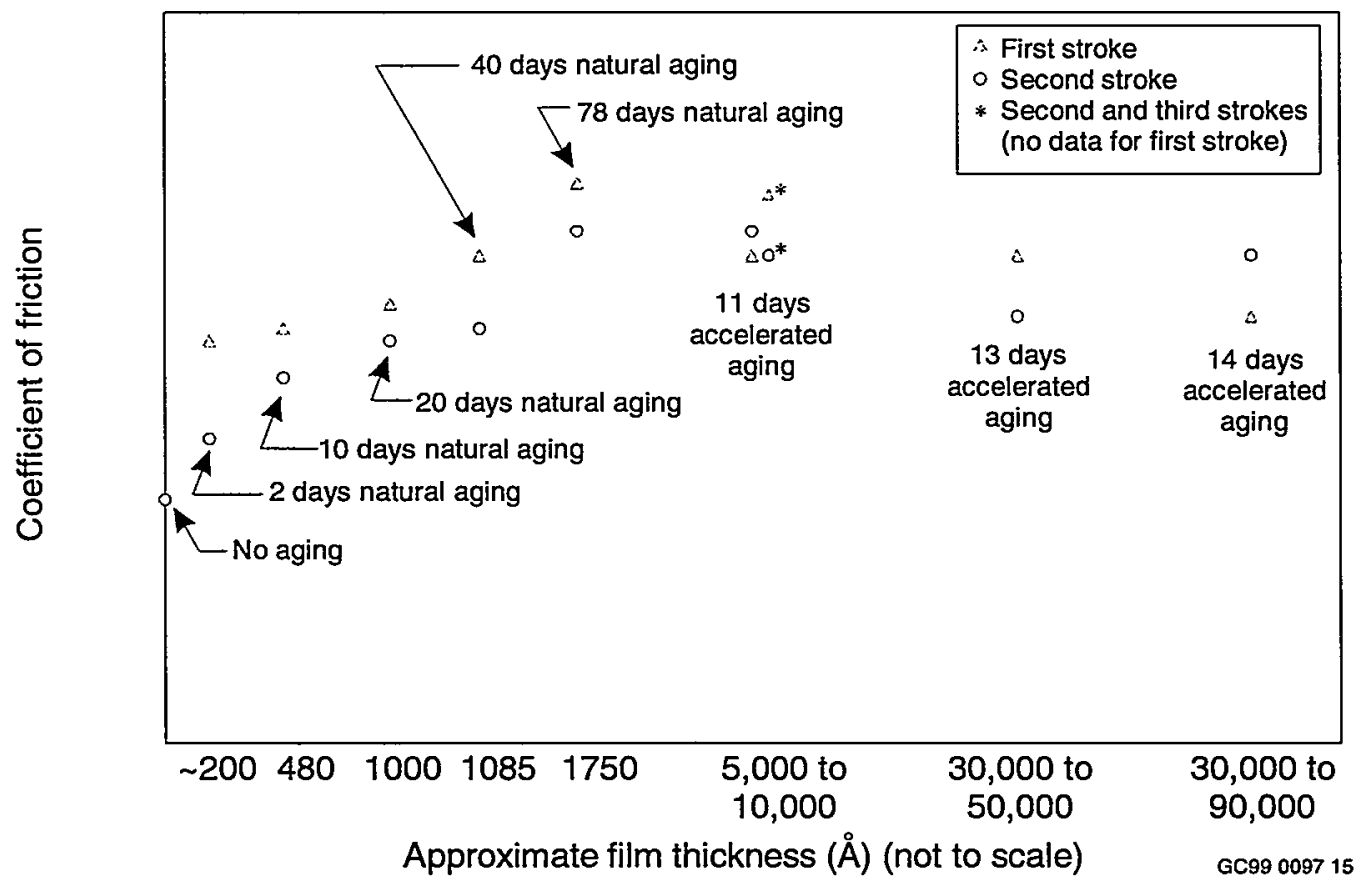

Figure 36. Coefficient of friction (maximum) versus approximate film thickness for naturally aged and accelerated aging (anodic current) Stellite 6 specimens.

\subsection{Differences Due to Chemical Composition and Surface Structure}

The increase in friction with greater aging of the specimens is the result of the growth characteristics of the oxide film. In particular, as the surface ages, the crystalline solids in the oxide film grow larger. Oxide films of different ages can be compared to pieces of sandpaper with different degrees of roughness. The grains on the sandpaper are analogous to the crystalline solids, and as the surface of the Stellite 6 ages, the crystals become larger, similar to rougher sandpaper, corresponding with coarser grit or larger grains. The composition of the crystalline solids was not determined, but we expect them to be chromium oxide, cobalt oxides, or carbides. Such crystalline solids are, in general, very abrasive. When two such surfaces are placed against each other, the friction can be quite high, especially during the first stroke. With subsequent stroking, the crystalline solids will either plastically deform or fracture as the two surfaces pass each other. As such, the friction should decrease with continued stroking until the friction of the bulk Stellite 6 material reached. This is similar to two pieces of sandpaper rubbing against each other. During the first stroke, the surface grains are intact and offer the most resistance to motion. As the surface grains are fractured, the resistance to motion decreases, approaching a friction value representing the two pieces of paper backing rubbing against each other. 
An additional concern is the possibility that the coefficient of friction could increase as the normal load on the surface increases. In effect, with crystals on both sliding surfaces, a higher load could cause the crystals to interlock more; in order for the two surfaces to move relative to each other, more of the crystals would have to be fractured. The result of such a scenario would be a coefficient of friction that exhibits a load sensitivity. If such a scenario exists, the phenomenon would need to be quantified through additional testing so as to ensure that safe operation limits of safety-related valves are well defined.

The larger crystals (from high-pH exposure) or nodules (from anodic polarization) found on the surface of the accelerated aging specimens appear to have a significant contribution to the high friction, especially during the first stroke. In these cases, it is probable that the larger crystal size and different chemical composition of the crystalline structure contribute to this higher friction. As with the naturally aged specimens, it appeared that harder particles on one surface plastically deformed or fractured areas on the other surface as they pass. We also note that the removal of the zirconium-containing crystals on the high-pH specimens lowered the corresponding coefficient of friction. However, the remaining iron-rich particles, and incorporation of iron and iron oxide through the oxide film, were sufficient to cause the friction coefficient to be higher than that measured on the specimens exposed to natural aging conditions. We speculate that the mechanical properties of this iron-rich film, and the large crystalline structure observe on the micrographs of the surface, were largely responsible for the difference.

While there may be an effect on the friction due to the film thickness, we infer that it is of significantly lower magnitude than the effect due to composition and morphology. In other words, beyond a minimum oxide film thickness, the mechanical properties of the oxide film have a far greater effect on whether a valve can operate safely. This effect is evident in Figure 37, which compares friction results from the high-pH specimens (Figure 33) with the results from the 20- and 40-day natural aging specimens (Figure 32). The film thickness was approximately the same (1100 $\AA$ ) for these specimens, yet the friction coefficient was at least 0.1 higher with the high-pH specimens than with the natural aging specimens.

\subsection{Effect of Friction Testing Versus Valve Operation}

Part of the work performed by NIST was to evaluate the testing process in comparison with the operation of an actual valve. As part of this evaluation, the NIST team identified a difference that might be important. Specimens prepared for friction testing were installed into the friction autoclave in full face to face contact without any relative motion. The friction autoclave was heated and pressurized to BWR conditions, and then the normal 10-ksi contact stress was applied for 10 to 20 seconds before the actual friction test began. Based on this operation of the friction autoclave, all of the oxide film would be trapped between the surfaces before the specimens began moving relative to each other.

In an actual valve, however, the surfaces are moving before they contact each other; the surfaces come into contact as the valve nears flow isolation. When the surfaces first touch each other, it is possible that the leading edges might shear the oxide film from the surface, whereas the trailing surfaces would tend to trap the oxide film in a manner similar to what occurs in the friction autoclave. Whether an actual valve shears most of the oxide film off or traps most of the oxide film would depend on how and when the valve disc contacts the valve body seats.

To investigate the effect the contact method has on the resulting friction between the valve disc and the valve body seat, NIST performed additional friction testing on 10-day and 50-day specimens. The testing used either a 0.5 -in. steel ball or a 0.125 -in. steel ball moving against the flat surface of a Stellite 6 specimen so that the oxide film would not be trapped between the surfaces, but rather could be pushed aside by the ball. This testing was performed at ambient temperature and pressure and yielded friction values in the range of 0.15 to 0.17 . When the contact geometry was changed to a small $1.8 \mathrm{~mm}^{2}$ flat surface against the flat surface of a Stellite 6 specimen, such that the oxide film would be trapped between 


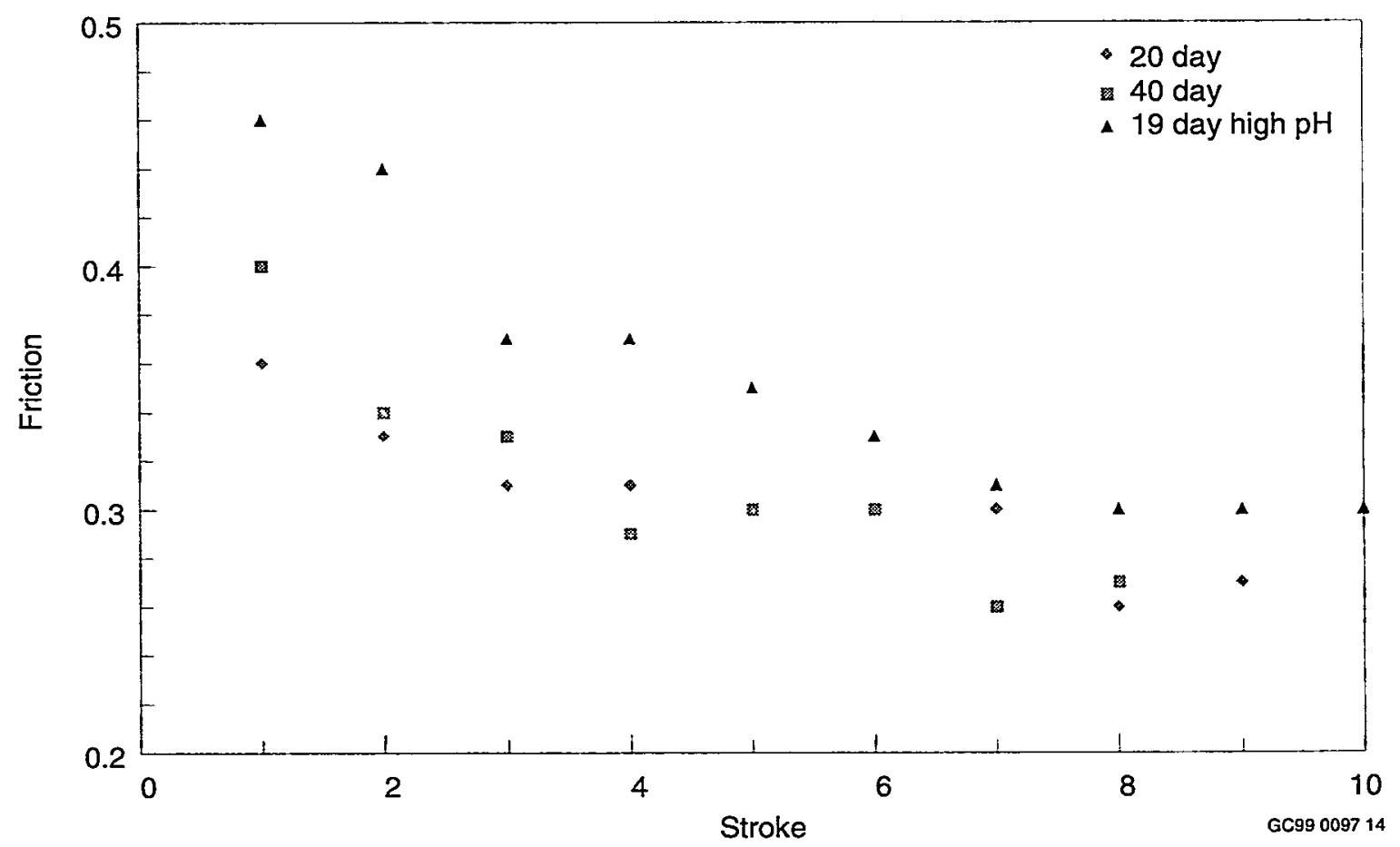

Figure 37. Coefficient of friction versus stroke for 20- and 40-day naturally aged and high-pH accelerated aging Stellite 6 specimens.

the surfaces, friction values in the range of 0.30 to 0.35 were observed. By comparison, the friction testing performed by Battelle at BWR coolant conditions produced maximum friction values in the range of 0.35 to 0.40 .

This additional testing implies that trapping the corrosion products between two moving surfaces can have a significant effect on the friction. Thus, the contact mode between the valve disc and the valve body seats can be very important. In the event the disc tips and contacts the valve body seats such that the oxide film is scrapped off and not trapped between the two surfaces, the resulting friction values are likely to be lower than the values produced by our friction tests at Battelle. However, the friction values will not be as low as the results from the testing with a steel ball on the flat Stellite 6 surface. In the event the disc drops flat onto the valve body seats near valve isolation and traps the oxide film between the surfaces, the friction values reported here for the naturally aged specimens are very reasonable (qualified, of course, for the short duration of the aging times.).

\subsection{Changes in Friction with Stroking}

In general, the first stroke shows higher friction than succeeding strokes. The difference is greater for some specimens than for others. The decrease in the friction coefficient with continued stroking is probably caused by a change in the surface condition of the specimens due to plastic deformation or fracturing of the crystals. The results indicate that the first stroke a valve experiences after it has been allowed to age and establish an oxide film will result in the highest coefficient of friction and therefore require the highest stem thrust to successfully operate the valve. This result has important implications for valves being subjected to in-plant testing: such in-plant tests need to collect data from the very first stroke a valve experiences following a period of inactivity, and data from subsequent strokes will be less relevant to valve operability and plant safety. 
The presence of any oxide film, combined with the crystalline structure of the film, caused a significant increase in the friction coefficient, as compared to unaged specimens. The appearance of lower friction in subsequent strokes (as compared to the first stroke) was a phenomenon that manifested even for the very thin films produced by 2 and 10 days of natural aging (Figure 32). Even for these specimens, the friction decreased significantly between the first and second strokes and again between the second and third strokes. Interestingly, the friction coefficient was high during the first stroke for the unaged specimens, too, about the same as for the 2-and 10-day aged specimens (Figure 34). During the next few strokes, the friction coefficients for the unaged specimens are only a little lower than for the 2- and 10day specimens. These results indicate the possible presence of an extremely thin oxide film (with small, hard granules) on the "unaged" specimen. This very thin film most likely would have formed during the several hours it took to heat up the friction autoclave. If such a film was present, it was worn or smeared away during the first stroke, just as the very thin film on the 2-day natural aging specimens was apparently worn away during the first two strokes, as indicated by the response of the friction coefficient.

This decreasing friction trend is a different outcome than we observed in earlier valve testing, specifically the gate valve blowdown testing performed by the INEEL in 1989 and early 1990 (DeWall and Steele, 1989; Steele et al., 1991). In those tests, fully equipped full-scale gate valves were subjected to blowdown flows and tested for their ability to close (or open) against the resulting high differential pressure loads. The first several differential pressure strokes were opening strokes against very little flow. Typically, the first few full differential pressure strokes were performed cold (ambient temperature), followed by several strokes at elevated temperature. The results from those tests showed very little change in the friction coefficient from stroke to stroke under elevated temperature conditions. In contrast, the friction tests that are the subject of this report showed a decreasing trend with subsequent strokes.

The difference in the outcome is due to basic differences in the test parameters. The 1989-90 flow tests were designed to test new and refurbished valves, absent any effect (oxide film) due to aging. Before the tests, the valves were verified to be leak tight, and if necessary, the sealing surfaces were machined to achieve a leak tight condition. In addition, between each of the tests, the valves were exposed to the atmosphere; they were not maintained in an environment that was conducive to the formation of an oxide film. As such, the testing represented design basis testing on new valves, not valves that had been allowed to age at BWR coolant conditions. The consistency of the friction coefficient indicates that no significant oxide film had developed on the sealing surface, and certainly not one that would be indicative of an aged valve. In contrast, the friction tests documented in this report were deliberately designed to produce an oxide film on the surfaces of the Stellite 6 specimens, and the decreasing friction trend is evidence of the effects of repeated stroking on the oxide film.

\subsection{Possible Precipitation of Magnetite}

Both types of accelerated aging methods produced oxide films with either distinct nodules or crystals on the surface. The crystals present in the high-pH case were identified as iron-rich, and although the crystals appear to be present discretely on the specimen (Figure 13), the presence of iron was detected through the film thickness. For this reason, we postulate a possible dissolution or precipitation mechanism. Based on the AES results shown in Figure 25, we expect that the oxide film developed on specimens aged using an anodic current would be iron-rich as well, probably in the form of magnetite $\left(\mathrm{Fe}_{3} \mathrm{O}_{4}\right)$. The presence of iron in the oxide films of these accelerated aging specimens corresponds with higher friction coefficients, as compared with the natural aging specimens. The cause/effect relationship suggested here is likely, though not certain.

If it is possible for magnetite to form in the corrosion autoclave at accelerated aging conditions, and then to precipitate on the Stellite 6 surfaces as the oxide film grows, then it is also possible that in a BWR plant, where there is a measurable amount of magnetite flowing in the system (there are filters to remove 
it), magnetite could precipitate on the valve seats and become embedded in the oxide film. The presence of magnetite precipitant would cause some increase in the valve operating requirements as a result of the increased friction coefficient. Indeed, this effect may explain some of the reported discrepancies between valve tests in the plant and laboratory data generated in very clean environments.

There is some information in the literature regarding the solubility of magnetite as a function of $\mathrm{pH}$ and temperature (Takamatsu et al., 1990; Sweeton and Baes, 1970). This information indicates that if there are local differences in fluid temperature or chemistry $(\mathrm{pH})$, magnetite can dissolve at some locations and precipitate at other locations.

From the results to date, we conclude that the maximum friction obtained during the first stroke of the naturally aged specimens should be considered most applicable to RWCU valves in BWRs. The applicability of the friction coefficients for the oxide films grown under accelerated aging conditions depends on the extent to which iron-rich particles or other stray particles are present on in-plant valves. We know of no currently available data on the composition of the oxide film for in-plant Stellite 6 surfaces. However, the presence of magnetite in the oxide film is a possibility that deserves consideration.

\subsection{Static Versus Dynamic Friction}

The friction results presented in this report refer to both the maximum and nominal friction coefficients observed during testing. To identify which is the most appropriate friction coefficient to use, we examined the characteristic shape of all the friction traces from this program. These traces typically exhibit a high friction at the beginning of the stroke, with decreasing friction over the course of the stroke to a value as much as 25 percent lower than that initially measured. For examples, see Figure 30 . This shape, with a peak friction coefficient at the beginning of the stroke, might be the result of a static or "breakaway" friction versus a dynamic or "sliding" friction; or it might be an effect due to changes in the surface of the specimen during the course of the stroke.

A static or "breakaway" friction coefficient, which is distinctly different from a dynamic or "sliding" friction coefficient, would have a friction force versus sliding distance (or time) curve that exhibits a sharp spike at the point of breakaway. Such spikes are common for materials where friction is controlled by adhesion as opposed to abrasion. Examining the shape of the friction traces from the naturally aged Stellite 6 , we observe a continuous decay from an initially higher value, as opposed to a sharp spike. Because of this shape, and because Stellite 6 is well known for its anti-galling characteristics, the friction is most likely not exhibiting a static versus dynamic friction effect.

We infer that the steadily decaying shape on these friction traces is the result of a surface that is changing over the course of the stroke, with the change leading to a lower friction at the surface. This interpretation is consistent with the sandpaper analogy presented earlier in this report, where the surface structure of the oxide film is characterized by the presence of granular or crystalline particles, and the friction behavior is similar to the effect of rubbing two pieces of sandpaper together. This interpretation concurs with the findings of the friction experts at NIST, who noted that the shape of these friction traces is consistent with their experience with this type of friction.

\subsection{Effect of Simulated Valve Wedging}

Figure 38 presents the maximum and nominal friction coefficients for specimens subjected to simulated valve wedging, compared to specimens not subjected to simulated valve wedging, both sets having undergone 78 days of natural aging. A slightly lower value in both the maximum and nominal friction was observed during the first stroke for specimens that had undergone the simulated valve wedging, with nominal friction coefficients of 0.36 versus 0.38 and maximums of 0.43 versus 0.46 . 

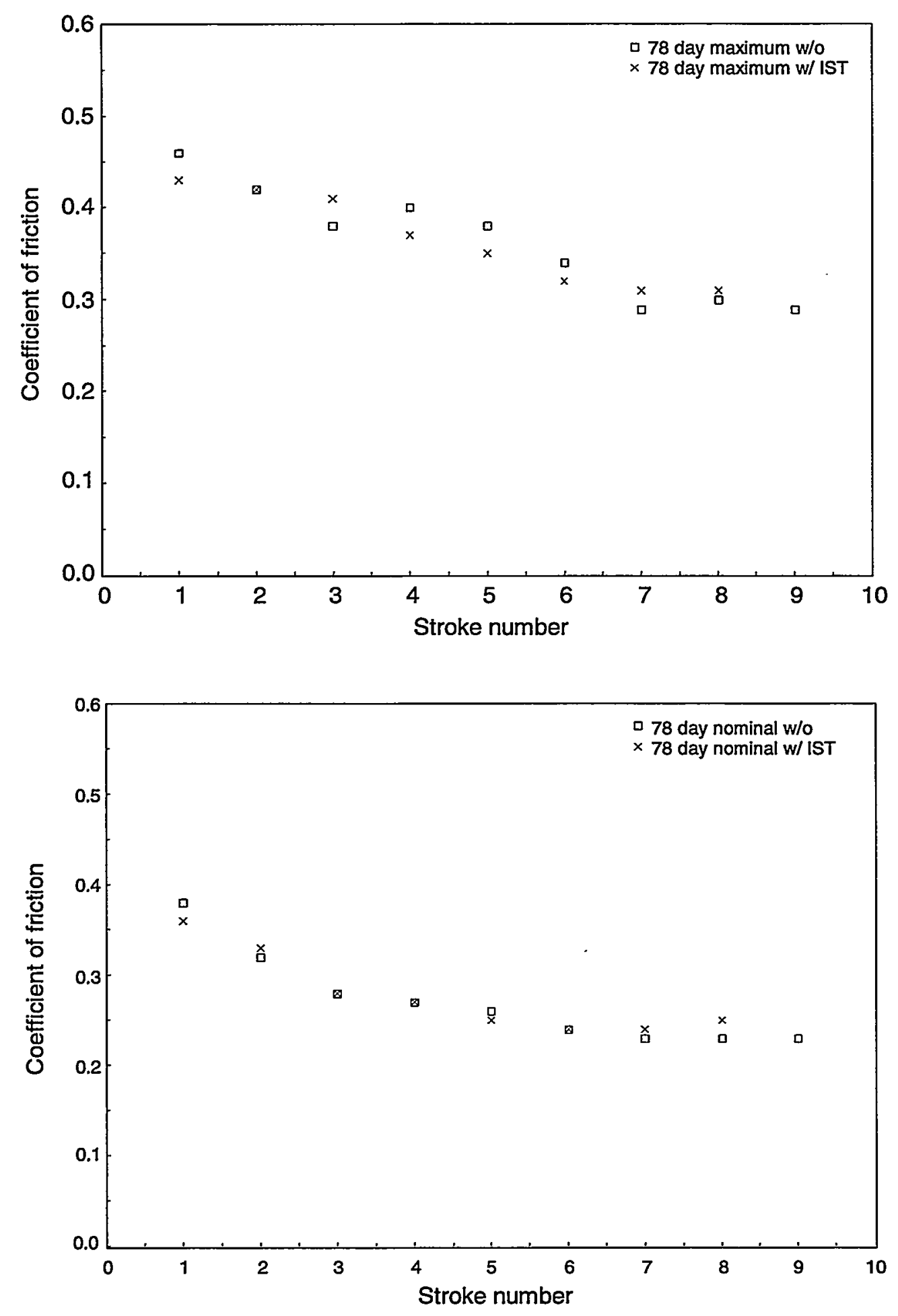

Figure 38. Coefficient of friction versus stroke for naturally aged Stellite 6 specimens and specimens subject to in-service testing; maximum values (top) and nominal values (bottom). 
During subsequent strokes, the effect of the simulated valve wedging on the resulting friction coefficient was either negligible or varied from stroke to stroke.

The friction behavior of each successive stroke appears to be influenced by changes in the condition of the surface due to previous strokes. As such, only the first stroke would be strongly influenced by the simulated valve wedging. Although the single data point obtained in this study suggests that valve wedging cycles will decrease the expected friction, the difference is small. Before a definitive claim can be made as to either a small decrease in the coefficient of friction, or no effect due to the simulated valve wedging, it would be prudent to perform further testing to obtain additional data that would verify the direction and magnitude of the effect. 


\section{SUMMARY AND CONCLUSIONS}

The results of the aging tests show the presence of a very thin oxide film after very short exposure times of only a few days. The results of the friction tests show that even a very thin oxide film causes an increase in friction. Although the thickness of the oxide film continues to increase with greater aging time, the key to being able to safely operate a valve is not necessarily based on the thickness or thinness of the oxide film, but rather on the mechanical properties of the oxide film as the Stellite 6 surface ages.

The results of the AFM and X-ray diffraction analyses at NIST indicate that the surface of the oxide film contains crystalline solids within an amorphous substrate. The composition of the solids was not determined, but is expected to be chromium oxides, cobalt oxides, or carbides. Crystalline solids in general are very abrasive and can result in high friction between the moving surfaces, analogous to rubbing two pieces of sandpaper together. Longer aging times correspond with larger crystalline grains and higher friction.

The friction testing produce an important result with significant implications for in-plant testing. For all of the naturally aged specimens, the highest friction occurred on the first stroke. For example, the peak friction for the 40-day naturally aged sample was 0.40 on the first stroke, 0.34 on the second stroke, and a little lower on subsequent strokes. It appears that the first stroke smears the oxide film and dislodges some of the granules, so that subsequent strokes see lower friction values and less variation in the friction. This result underscores the importance of planning in-plant tests so that data are collected from the first stroke following a period of inactivity.

Because of the crystalline structure, it is possible that the friction coefficient might increase as the load on the surface increases. Further testing might identify any such load sensitivity in the friction between the moving surfaces, so as to define safe operating limits for safety-related gate valves.

Although the single data point obtained in this study suggests that the simulated valve wedging would slightly decrease the expected friction, the difference is small. Before a definitive claim can be made as to either a small decrease in the friction, or no effect due to the simulated valve wedging, it would be prudent to obtain additional data to verify the direction and magnitude of the effect.

In the limited data provided by naturally aged specimens ( 78 days maximum exposure, very thin oxide films), the maximum friction shows no evidence of stabilizing as the specimen ages. We expect that natural aging with longer exposure times would provide evidence of a plateau in the coefficient of friction beyond a certain aging time. With the limited data available, we cannot form hypotheses about the friction value or the aging time at which such a plateau would appear. Data from specimens subjected to accelerated aging via anodic current showed evidence of such a plateau, but the relevance of this result is questionable because of differences in the composition and structure of oxide films produced by accelerated versus natural aging.

The composition and surface structure of the oxide films grown using acceleration techniques (anodic current and higher $\mathrm{pH}$ ) differ from those formed during natural aging. Large granular structures, iron enrichment, cobalt in the film, and additional oxide particles were observed in the accelerated tests. Considering these differences, oxide films produced by the acceleration methods are not representative of those produced by natural aging in the laboratory.

However, the oxide films grown using acceleration techniques may be considered relevant to plant operations if highly oxidizing potentials can occur in the plant, if $\mathrm{pH}$ excursions can occur, or if magnetite or other stray particles are deposited on and incorporated into the oxide films on the Stellite 6 sealing surfaces in the valves. The results from the high-pH test indicate that precipitation of aging products on 
valve sealing surfaces from aging elsewhere can increase the friction, a phenomenon that might occur in a plant environment. We know of no currently available data on film composition or thickness for in-plant Stellite 6 surfaces, but the presence of magnetite on the oxide film on valve hardfacing is a possibility that deserves consideration. 


\section{REFERENCES}

DeWall, K.G. and R. Steele, Jr., 1989, BWR Reactor Water Cleanup System Flexible Wedge Gate Isolation Valve Qualification and High Energy Flow Interruption Test, NUREG/CR-5406, EGG2569.

Honda, T., E. Kashimura, K. Ohashi, and Y. Furutani, 1987, "Corrosion of Ferrous Materials and Deposition of Trace Metal Ions in High Purity Water at High Temperature," Corrosion Engineering 36, No. 5, pp. 257-266.

Steele, R. Jr., K.G. DeWall, J.C.Watkins, 1991, Generic Issue 87: Flexible Wedge Gate Valve Test Program, NUREG/CR-5558, EGG-2600.

Sweeton and Baes, 1970, "Solubility of Magnetite and Hydrolysis of Ferrous Ion in Aqueous Solutions at Elevated Temperatures," Journal of Chemical Thermodynamics 2, p. 479.

Takamatsu, H., K. Matsueda, K. Onimura, K. Arioka, S. Tokunaga, and K. Katsura, 1990, "IGA/IGSCC Propagation Behaviors of Alloy 600," Proceedings of the 4th International Degradation of Materials in Nuclear Power Systems - Water Reactors. 